\title{
AVALIAÇÃO DA POSIÇÃO DO DISCO ARTICULAR EM PACIENTES USUÁRIOS DE DENTADURAS DUPLAS E PORTADORES DE SONS ARTICULARES, POR MEIO DE IMAGEM DE RESSONÂNCIA
}

MAGNÉTICA DA ATM

Tese apresentada à Faculdade de Odontologia de Bauru, da Universidade de São Paulo, como parte dos requisitos para a obtenção do título de Doutor em Odontologia, área de Reabilitação Oral. 


\title{
AVALIAÇÃO DA POSIÇÃO DO DISCO ARTICULAR EM PACIENTES USUÁRIOS DE DENTADURAS DUPLAS E PORTADORES DE SONS ARTICULARES, POR MEIO DE IMAGEM DE RESSONÂNCIA MAGNÉTICA DA ATM
}

\section{VINÍCIUS CARVALHO PORTO}

\author{
Tese apresentada à Faculdade \\ de Odontologia de Bauru, da \\ Universidade de São Paulo, como \\ parte dos requisitos para a obtenção \\ do título de Doutor em Odontologia, \\ área de Reabilitação Oral.
}

\section{BAURU}


22 de Março de 1972

Salvador - BA

$1990-1994$

$1995-1996$

$1996-1997$

$1998-2000$

$2000-2002$

Associações
Nascimento

Curso de Odontologia, Faculdade de Odontologia da Universidade Federal da Bahia.

Professor Substituto do Departamento de Odontologia Restauradora da Faculdade de Odontologia da Universidade federal da Bahia.

Especialização em Prótese Dentária, pela Faculdade de Odontologia de Bauru, USP.

Curso de Pós-Graduação em Reabilitação Oral - Prótese, ao nível de Mestrado, na Faculdade de Odontologia de Bauru, USP.

Curso de Pós-Graduação em Reabilitação Oral - Prótese, ao nível de Doutorado, na Faculdade de Odontologia de Bauru, USP

ABO - Associação Brasileira de Odontologia - Secção Bahia.

APG - Associação dos Pós-

ii Graduandos da Faculdade de Odontologia de Bauru. 
Aos meus pais, João e Lídia, pelo incentivo, apoio e compreensão nesta etapa de minha vida. Por valorizarem a educação dos filhos e por terem me proporcionado a realização de um sonho. Um dia hei de unir as profissões que vocês exerceram. Vocês foram capazes de ter o melhor para dar o melhor aos seus filhos. Vocês são a razão do meu sucesso

A minha irmã, Viviane, companheira e exemplo de como a dedicação e a responsabilidade contribuem na formação de um indivíduo. Estarei sempre do seu lado.

A minha madrinha, Marlinda, que com as palavras $e$ atitudes transmitem a tranqüilidade nos momentos mais tensos. Pela simplicidade com que se pronuncia e pela paz que irradia.

A Deus, que em todos os momentos da vida sempre se faz presente. 
A Vanessa, pela companhia, compreensão, alegria, carinho e sabedoria. Por ter se constituído na outra metade dos meus pensamentos. Por querer desfrutar comigo o mais belo dos sentimentos que é o amor 
Ao Prof. Dr. Milton Carlos Gonçalves Salvador, um amigo, uma pessoa que se mostrou ao meu lado, procurando solucionar os meus problemas. Pela atenção, gratidão e colaboração em todos os passos do meu trabalho. Pela confiança que depositou em mim,

Meu profundo respeito e minha amizade. 
A minha nova Família residente em Bauru, o Senhor Elzo Lara e Esposa Valdicéia, avós Valdemar e Conceição pelo acolhimento e carinho.

Aos meus cunhados e irmãos de coração, Luís Guilherme Lara, Andréia Figueiredo Souza, Renato e Roberta Cassani e filhos Lucas e Gabriel que também são constituintes de passos importantes deste trabalho.

Aos Professores do Departamento de Prótese da Faculdade de Odontologia de Bauru- USP, pelos conhecimentos transmitidos, atenção, respeito e exemplo.

Ao Prof. Dr. Paulo César Rodrigues Conti, pela contribuição na idealização desta pesquisa.

A Doutora Rejane Ribeiro Rotta, pelo fundamental auxílio na análise de resultados deste trabalho

Ao Professor Antônio Barcelar de Rezende, pelo incentivo e brilhantismo com que conduz a Prótese.

Aos pacientes, pela confiança e amizade conquistadas.

À Faculdade de Odontologia de Bauru e à Comissão de Pós-Graduação, por tornar acessível todas as atividades desenvolvidas durante o curso. 
À FAPESP, pelo respaldo fornecido por meio das Bolsas de estudo no período de execução deste trabalho.

Aos Profs. Drs. Luiz Fernando Pegoraro, Gerson Bonfante, Acácio L. do Vale, José Valdes Conti e Lucimar Vieira Falavinha pela prestatividade e orientação profissional e pessoal, sendo exemplos a serem seguidos.

Aos colegas de Mestrado, Luís Gustavo, Rafael, Renato, Jeferson, Mauro, Osvaldo, Mariana, Luciana, Lheyla, Tatiana, Paulo e Stela, pela integração e amizades cultivadas durante o curso

Aos funcionários do Departamento de Prótese, Edna, Débora, Claúdia, Reivanildo, Marcelo, Luzia, Didi, Geraldo, pela atenção e prestação de serviços em todos os instantes de necessidade.

A Enfermeira do Centro de Diagnóstico de Imagem, Lucila, pela importante cooperação na fase experimental desta pesquisa. Aos demais funcionários do CDI, Ari, Luciana. Tatiana, Solange, Liege, Ellen, Gisele, Beatriz, Norival e Dona Maria, meus agradecimentos pelo longo período de convivência. Aos Médicos responsáveis do CDI, Antônio Carlos Castro, Eron Barros, Adriano Fernandes, Régis Coelho e César Camarinha, pela realização deste projeto e facilitação do meu acesso ao local de trabalho de vocês.

Aos funcionários da Pós-graduação e Biblioteca, por estarem sempre solícitos aos pedidos e pelo profissionalismo com que desempenham suas funções. 
Ao funcionário Kazuo do setor de informática da FOB-USP, pela melhor resolução das imagens de Ressonância Magnética desta pesquisa.

Ao Marcus Thami e Ana pela qualidade e precisão da impressão deste trabalho.

Ao Prof. José Roberto Lauris, pela aplicação e competência desferidas na análise dos dados estatísticos.

A Aline Carvalho Batista, por Ter me auxiliado na feitura dos gráficos deste trabalho. Pela sua predisposição de ajudar sem impor qualquer restrição. Por essa atenção é que se entendi o seu carisma.

Aos colegas e amigos do curso de Mestrado Vágner Ortega e Daniela Castilio pela amizade adquirida.

Aos colegas de turma Anuar, Carlinhos, Juliano, Nelsinho, Stefânia, Rudys, William e Gildo pelo respeito, convivência e amizade.

A Luciano Castellucci e Paulo Rocha, pelo fortalecimento da amizade e pelo respeito mútuo.

Aos meus amigos, Vágner, Marcelo, Luciano Lemos, Paulinho, Rivail, Alexandre, que apesar do tempo que ficávamos distantes, sempre nos momentos de reuniões e encontros esporádicos, faziam fortalecer nossa amizade. 
A Henrique e Letícia, pela compreensão e atenção desprendidas, desde a seleção para o curso.

A Paloma Dias Telles, pela luta, conquista de um djetivo e vitória alcançada.

A todos aqueles que de alguma forma contribuíram para o sucesso deste trabalho,

Meus sinceros agradecimentos. 


\section{SUMÁRIO}

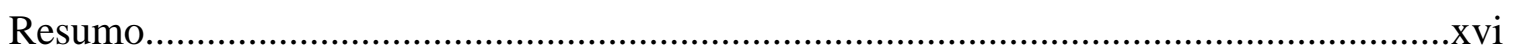

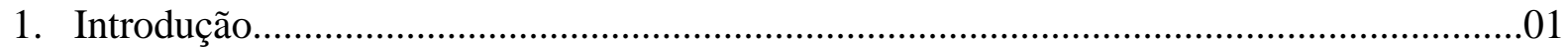

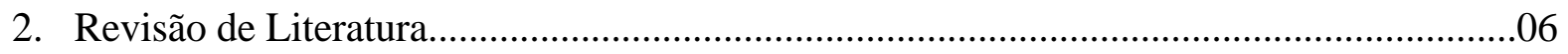

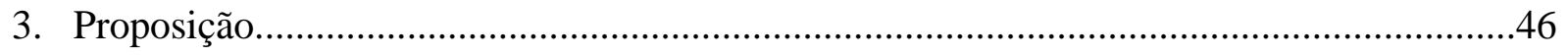

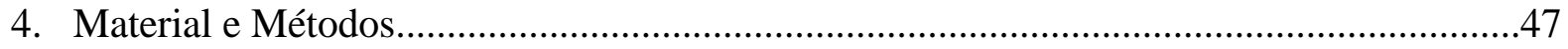

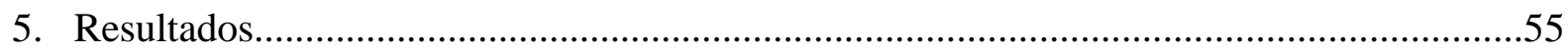

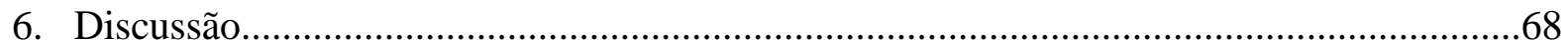

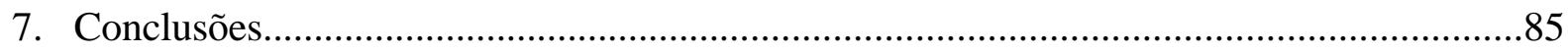

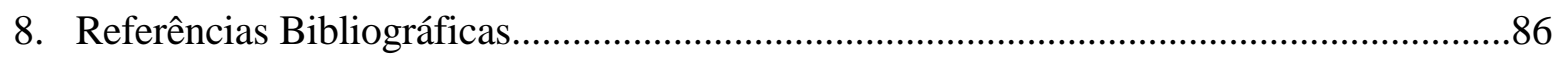

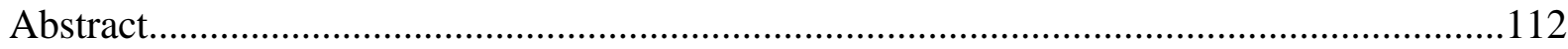




\section{LISTA DE FIGURAS}

FIGURA 1- Posições do disco articular em boca aberta e fechada.........................................02

FIGURA 2- Classificação de ORSINI et al........................................................................

FIGURA 3- Classificação de HELMS et al...........................................................................

FIGURA 4- Classificação de RAMMELSBERG et al..........................................................08

FIGURA 5- Classificação de MUKARAMI et al WO - anterior e SR - posterior...............09

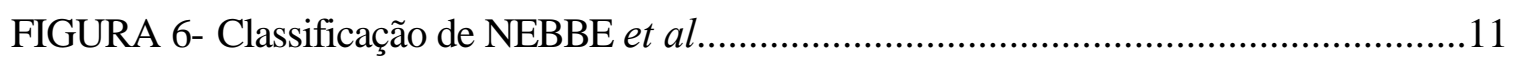

FIGURA 7- Classificação de SILVERSTEIN et al..........................................................12

FIGURA 8- Classificação de DAVANT et al................................................................13

FIGURA 9- Classificação de KURITA et al......................................................................14

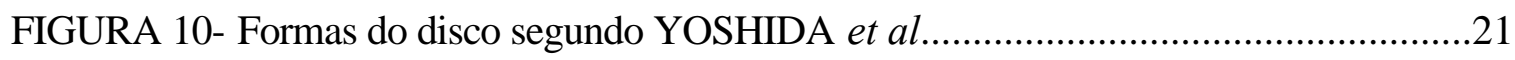

FIGURA 11- Paciente submetido a exame por RM. Cópia do artigo do LANGLAIS et

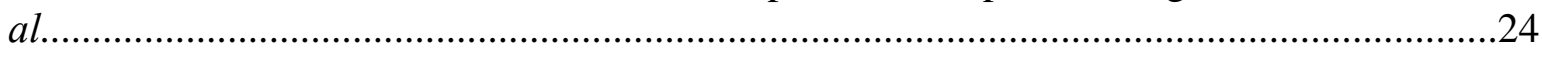

FIGURA 12- Emissão de pulsos de radiofreqüência (LANGLAIS et al) ............................25

FIGURA 13- Relaxamento e volta a posição original. (LANGLAIS et al) ...........................26

FIGURA 14- Posições do disco articular segundo TASAKI et al: 1- Posição superior; $2-$ DD anterior; 3- DD parcial anterior na parte lateral da ATM; 4- DD parcial anterior na parte medial da ATM; 5- DD ântero-lateral; 6- DD ântero-medial; 7- DD lateral; 8- DD medial; 9- DD posterior.

FIGURA 15- Corte sagital (A) e coronal (B) da ATM (KAPLAN; ASSAEL e PERTES;

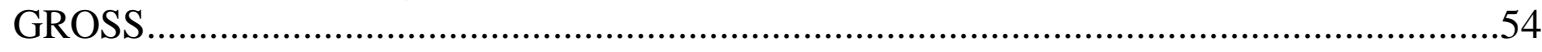

FIGURA 16- Número de articulações apresentando diferentes morfologias do disco nos grupos controle e sintomático. .58

FIGURA 17- Número de pacientes com diferentes posições do disco, nos grupos controle e sintomático. .60

FIGURA 18- Prevalência de deslocamento nos grupos sintomáticos e controle. .62

FIGURA 19- Número de articulações dos grupos controle e sintomático com diferentes posições anatômicas dos disco articular onde, S- Superior; DTA- Deslocamento total 
anterior do disco; DPAL- Deslocamento parcial no 1/3 lateral; DPAM- Deslocamento parcial no 1/3 medial; DL- Deslocamento lateral; DM- Deslocamento Medial; DP-

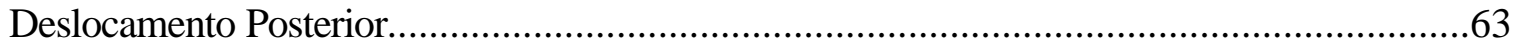

FIGURA 20- Posição superior do disco em cortes parassagital de boca fechada (A) e parassagital de boca aberta (B). Morfologia do disco bicôncava.......................................64

FIGURA 21- DDSR. DD total anterior em corte parassagital de boca fechada (A) e permanência do disco deslocado em corte parassagital de boca aberta (B) .64

FIGURA 22- DDR. DD total anterior em corte parassagital de boca fechada (A) e redução do disco deslocado em corte parassagital de boca aberta (B) .65

FIGURA 23- Deslocamento medial (A) e lateral (B) do disco em corte coronal de boca

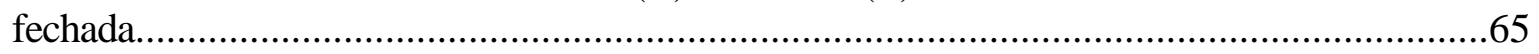

FIGURA 24- DDR rotacional. Deslocamento ântero-lateral do disco com redução. (A) parassagital em boca fechada, (B) coronal em boca fechada, (C) parassagital em boca aberta....... 


\section{LISTA DE TABELAS}

TABELA 1- Número de articulações com DD em relação ao gênero e a idade. .55

TABELA 2- Número de articulações, com posição superior do disco ou com deslocamentos do disco, que apresentavam intensificação de sinais. .56

TABELA 3- - Número de articulações que apresentavam intensidade e redução de sinais nas diferentes estruturas anatômicas, nos grupos sintomático e controle .56

TABELA 4- Número de articulações, com posição superior do disco ou com deslocamentos do disco, que apresentavam ou não diferentes translações condilares....57

TABELA 5- Número de articulações, com posição superior do disco ou com deslocamentos do disco, que apresentavam as diferentes morfologias do disco. .58

TABELA 6- Número de articulações normais, remodeladas e com degenerações ósseo-articulares presentes em diferentes estruturas anatômicas, nos grupos controle e sintomático. 
TABELA 7- Número de articulações com achados clínicos positivos e negativos em relação ao deslocamento do disco... 61 


\section{LISTA DE ABREVIATURAS}

1. $\quad \chi^{2}$-Qui-quadrado

2. ATM - Articulação Temporomandibular

3. DD - Deslocamento do disco

4. DDR - Deslocamento do disco com redução

5. DDSR - Deslocamento do disco sem redução

6. DI- Desarranjo interno

7. DOD - Doença ósseo degenerativa

8. DTMs - Desordens Temporomandibulares

9. DVO - Dimensão Vertical de Oclusão

10. FOV - Profundidade de campo

11. GRASS - Gradient-recalled acquisition in the steady state (técnica de aquisição de imagem por RM)

12. MIH - Máxima Intercuspidação Habitual

13. PTs - Próteses Totais

14. RM-Ressonância Magnética

15. RTrs - Radiografias Transcranianas

16. SE - Sequiência de pulso "spin echo"

17. TC - Tomografia Computadorizada

18. $\mathrm{T} 1-\mathrm{Tempo}$ de relaxamento longitudinal (spin-lattice)

19. T2 - Tempo de relaxamento transverso (spin-spin)

20. $\mathrm{T} 2 *$ - Gradient echo 
21. TE-Tempo de eco

22. TR - Tempo de repetição 


\section{AVALIAÇÃO DA POSIÇÃO DO DISCO ARTICULAR EM PACIENTES}

USUÁRIOS DE DENTADURAS DUPLAS E PORTADORES DE SONS

\section{ARTICULARES, POR MEIO DE IMAGEM DE RESSONÂNCIA MAGNÉTICA DA}

ATM

\section{RESUMO}

A Articulação Temporomandibular (ATM) é um complexo sinovial constituído por estruturas anatômicas que se relacionam de diversas maneiras. As alterações do padrão de normalidade, muitas vezes denominadas de Disfunção Temporomandibulares (DTMs), são encontradas tanto em pacientes experimentais, quanto assintomáticos . O objetivo do presente trabalho foi avaliar a posição do disco articular por meio de Ressonância Magnética (RM) da ATM e a sua relação com a presença ou ausência, detectada clinicamente, de sons articulares e de sintomas de DTMs, em pacientes utilizando Próteses Totais duplas. A amostra constituiu de 15 pacientes com sons articulares e 10 pacientes sem sons articulares (grupo controle) e as imagens foram realizadas em Máxima Intercuspidação Habitual e em Máxima Abertura Bucal. As ressonâncias foram avaliadas ao negatoscópio, por um único examinador, sem conhecimento prévio da história clínica dos pacientes. A análise dos resultados demonstrou que, das 18 ATMs que apresentavam estalidos articulares, 4 possuíam o disco em uma posição normal. Por outro lado, em 9 ATMs assintomáticas, foi detectada a presença de sinais de deslocamento do disco (DD). De um total de 6 pacientes diagnosticados clinicamente com hipermobilidade, 3 apresentavam deslocamento do disco com redução (DDR), enquanto o restante possuía o disco em uma posição normal. De um total de 30 ATMs estudadas no grupo experimental, 19 apresentavam DDR após a 
abertura bucal. Diferentemente, em 2 ATMs, o disco permaneceu deslocado para anterior na máxima abertura bucal. $\mathrm{O}$ disco permaneceu estável, tanto em fechamento quanto em abertura bucal, em 9 ATMs. No grupo controle, em 11 ATMs havia um relacionamento superior do disco, 6 apresentaram DDR e em 3 houve deslocamento do disco sem redução (DDSR). Houve uma ligeira tendência de DD nas mulheres, apesar dos valores não terem sido estatisticamente significantes tanto para o gênero quanto para idade. Este estudo mostrou que os DD são comuns tanto em pacientes experimentais, quanto no grupo controle. 
1- INTRODUÇÃO 


\section{INTRODUÇÃO}

O disco ou menisco articular é uma estrutura da Articulação Temporomandibular (ATM) que permite o relacionamento das superfícies ósseas articulares. O disco consiste de tecido fibroso denso, constituído de proteoglicanas similares às encontradas na espinha dorsal ${ }^{114}$. Estas estruturas tem um grau de hidratação que é facilmente visto em imagens por RM e que decresce com a sua degeneração ou dissecação ${ }^{37}$. Geralmente, o disco possui uma forma bicôncava, delimitada pela eminência articular e fossa glenóide, apoiando sua porção inferior côncava à cabeça do côndilo. Em articulações normais, os espaços articulares superior e inferior não se comunicam e o disco é ligado medial e lateralmente ao pescoço do côndilo. Posteriormente, o disco está conectado a um tecido elástico e vascularizado denominado de tecido retrodiscal, que permite a distensão e relaxamento do disco durante os movimentos de abertura e fechamento da boca ${ }^{50}$. O disco articular relaciona-se ainda, nos seus limites posterior, medial e lateral, com inserções musculares e tecido conjuntivo, perceptíveis na medida que a mandíbula desempenha os seus movimentos funcionais.

No início dos anos 80, KATZBERG; KEITH; GURALNICK. (1983) ${ }^{53}$ definiram o DI (desarranjo interno) da ATM como um relacionamento anormal do disco em relação ao côndilo, fossa e eminência articular. O termo DI implica em um impedimento mecânico que interfere com a movimentação de uma articulação ${ }^{107,}{ }^{142}$. Um sinal muitas vezes presente é o estalido articular, cuja etiologia ainda é bastante controversa. Essencialmente, os estalidos têm sido atribuídos à ação do côndilo sob a banda posterior do disco, enquanto que a crepitação é considerado um estágio mais avançado das Disfunção Temporomandibulares (DTMs), tais como as doenças degenerativas da ATM. A limitação 
e o desvio na abertura da boca são fatores clínicos que caracterizam os vários estágios de

DIs. Em outras palavras, o DI tem sido dividido em deslocamento do disco (DD) com ou sem redução; no deslocamento do disco com redução (DDR), o mesmo está numa relação anterior ao côndilo na posição de boca fechada, retornando à posição original durante a abertura bucal. Este fenômeno é caracterizado por estalidos articulares. Quando o disco falha no seu retorno à posição normal durante a abertura, a condição é descrita como deslocamento do disco para anterior sem redução (DDSR), não ocorrendo estalidos articulares ${ }^{17}$. (Figura 1)

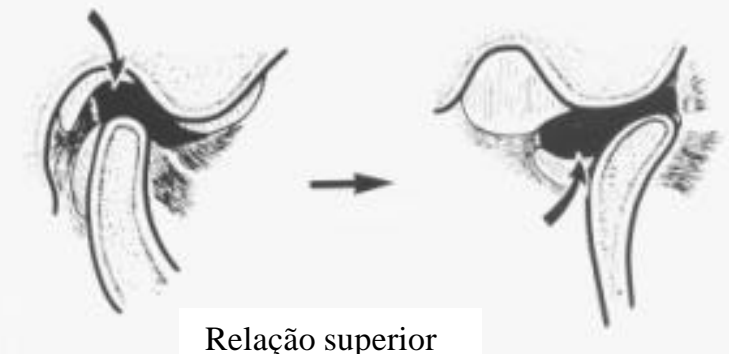

Relação superior côndilo-disco

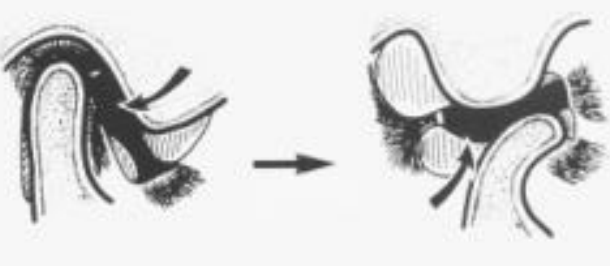

DDR

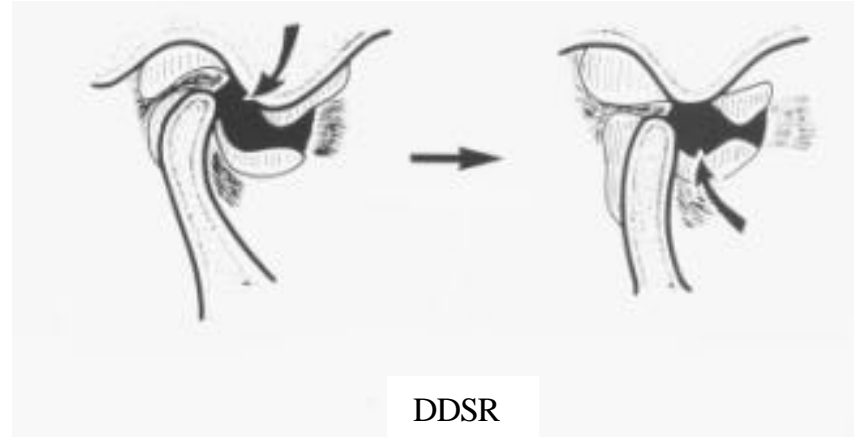

FIGURA 1 - Posições do disco em boca aberta e fechada

A morfologia do disco tem sido considerada como um importante fator na ocorrência de DIs da ATM, sendo portanto sugerida como determinante na limitação dos movimentos mandibulares e podendo ser alterada em detrimento de um deslocamento condilar. Quando este se apresenta para posterior, associado com um deslocamento anterior do disco, pode provocar compressão da zona retrodiscal e induzir sintomatologia dolorosa, tendo em vista que este tecido não foi desenvolvido primariamente para receber 
impactos de forma contínua. A tolerância ou não a estas cargas resultará em adaptação ou lesão do tecido retrodiscal, respectivamente ${ }^{19}$.

Infelizmente, a posição do disco não pode ser confiavelmente detectada somente pelo exame clínico. Os meios de diagnóstico de maior respaldo na visualização das posições normais do disco e DTMs são a artrografia, a tomografia computadorizada (TC) e a ressonância magnética $(\mathrm{RM})$. Embora estas técnicas possam produzir prejuízos biológicos ao paciente ou algum tipo de artefato de imagem, é freqüentemente difícil determinar se um tratamento para reposição do disco, ou mesmo uma discectomia, obteve sucesso somente se baseando na história ou exame clínico do paciente ${ }^{127,128}$. A conduta ideal para o tratamento de pacientes com DTMs é obter um maior número de informações clínicas suplementado com imagens adquiridas da ATM ${ }^{21}$. Muitos trabalhos abordam a artrografia como um meio fiel de reprodução da posição do disco $77,142,148$. Entretanto, o fato de constituir um método invasivo e desconfortável para obtenção diagnóstica, aliado ao surgimento da RM e TCs, a artrografia tornou-se uma avaliação menos utilizada para diagnóstico de DTMs. A evolução das imagens obtidas da ATM levou a crescente desinteresse pelas radiografias convencionais e artrografias e, por outro lado, a uma maior utilização de tomografias e RMs ${ }^{79}$. As TCs, embora possam ser utilizadas na disposição dos discos, são mais indicadas para a análise das variações das estruturas ósseas articulares. O deslocamento do côndilo para posterior torna-se um sinal sugestivo de alteração da posição do disco nas imagens tomográficas. Em estudos comparativos, a RM mostrou-se superior à TC quanto à visualização da configuração do disco, enquanto a TC não permitiu a análise dos limites entre o disco e seus ligamentos ${ }^{116,146}$. 
MUHL ${ }^{84}$ (1987) enfatizou a dificuldade de interpretação dos resultados quando desprovida da visualização precisa da relação côndilo-disco. Segundo as recomendações da Academia Americana de Odontologia (ADA), o uso de recursos invasivos na ATM deve ser restrito aos casos de DTMs que exigem uma mudança na estratégia de ratamento de acordo com a imagem produzida. Por outro lado, a RM permite a visão segura do complexo côndilo-disco, sem gerar desconforto ao indivíduo examinado, além de não emitir radiações ionizantes. A RM, no entanto, possui como desvantagens o alto custo do aparato, a ausência de detecção de perfurações nos discos, o fato de não ser disponível largamente nas instituições de ensino e a contra-indicação para pacientes claustrofóbicos.

Em uma análise de imagens de RM, pode ser ainda percebida a emissão de sinais provenientes dos espaços articulares superior e inferior e dos tecido retrodiscais. Caso haja sintomatologia dolorosa, avaliações por RM têm demonstrado uma intensidade maior de sinais $\mathrm{T}_{2}$ em comparação a articulações assintomáticas. A justificativa para isso pode ser o aumento da vascularização em tecidos de articulações sintomáticas ${ }^{109}$.

A imagem pelas RMs oferece a possibilidade de visualização dos componentes da ATM de uma forma que capacita o profissional a distinguir os aspectos normais daqueles patológicos. Lesões, tais como a osteoartrose, que representam as doenças degenerativas mais freqüentes da ATM, são o resultado de DIs ou doenças inflamatórias sistêmicas ${ }^{81}$.

Dor e disfunção da ATM têm afetado aproximadamente $28 \%$ da população em algum estágio da vida ${ }^{49}$. Os tecidos retrodiscais, compostos essencialmente por células e matriz extracelular, são altamente inervados e conseqüentemente passíveis de provocar sintomatologia dolorosa. Entretanto, estes tecidos podem sofrer um processo de adaptação 
ou reparo e tornar-se menos sensíveis. O sucesso do reparo dependerá do grau de DD, da extensão do dano tecidual, da quantidade de carga sobre a articulação e da capacidade de reparo de cada tecido ${ }^{92}$. Deslocamentos de discos, artralgias, artrites e artroses são considerados possíveis alterações da $\mathrm{ATM}^{48,100}$.

Inúmeros trabalhos discutem a posição do disco articular em pacientes dentados ${ }^{32,}$ 35, 38, 78, 97, 115, 118, 131,134, 140,141,143, 145, 146. Os DIs da ATM têm sido achados comuns mostrando uma prevalência crescente paralelamente ao aumento da idade ${ }^{43}$. Estudos em ATMs de espécimes necropsiadas revelaram uma prevalência de $12 \%$ de discos deslocados das articulações em 96 adultos com média de idade de 26 anos e, em contrapartida, indivíduos idosos com uma média de idade de 75 anos demonstraram prevalência de 34 a $40 \%$ de $\mathrm{DD}^{3,150}$. Todavia, estudos mais aprofundados da posição do disco em pacientes edentados são necessários, já que a lassidão dos ligamentos articulares que se inserem ao disco e também a morfologia e a anatomia das estruturas ósseas modificam-se com o decorrer da idade, podendo influenciar com a funcionabilidade do complexo côndilo-disco.

Baseado nos vários questionamentos sobre o disco articular, torna-se de extrema importância o estudo das possíveis posições que o disco pode ocupar em pacientes portadores de próteses totais duplas, bem como das outras estruturas da ATM. 
2- REVISÃO DA LITERATURA 


\section{REVISÃO DE LITERATURA}

\section{1- Classificação da posição do disco}

O disco articular é um componente da ATM que tem sido bastante discutido quanto à posição que ocupa no interior da fossa glenóide, tendo em vista que a imagem obtida pode complementar uma suspeita de um diagnóstico clínico. Para isso é preciso uma forma de tentar classificar melhor a sua posição.

Ainda não se chegou a uma opinião consensual sobre qual método de avaliação desempenha precisamente o relacionamento côndilo-disco. A definição clássica da posição normal do disco é defendida por KATZBERG et al. $(1985){ }^{54}$; KIRCOS et al. $(1986 ; 1987)$ 61, 62; WESTESSON (1993) ${ }^{141}$, KAMELCHUK et al. (1997) ${ }^{47}$; KATZBERG et al. (1996) 56, a qual diz que em Máxima Intercuspidação Habitual (MIH) o disco está localizado na posição de 12 horas, estando a zona intermediária interposta entre a cabeça do côndilo e a inclinação posterior da eminência articular. Uma vez que há a flexibilidade de se aceitar como normais as posições de 10 e 11 horas do disco, ORSINI et al. ${ }^{94}$ (1998) discutiram a validade do diagnóstico a partir de 4 critérios de interpretação da posição normal do disco (10, 11, 12 horas e côndilo situado na zona intermediária do disco) utilizando-se de RMs (Figura 2). Segundo os autores, o critério da zona intermediária do disco é o mais rigoroso e oferece menor número de falsos positivos quando o disco está sendo julgado numa vista sagital de boca fechada, sendo então o método mais preciso para identificação da posição do disco. Entretanto, resultados subseqüentes de sensibilidade e especificidade de possíveis fatores predisponentes a DTMs correlacionados com o DDSR não foram diferentes estatisticamente quando se utilizava qualquer um dos 4 critérios de diagnóstico. $\mathrm{Na}$ análise 
de DDR, a posição da zona intermediária do disco teve altos valores de sensibilidade e especificidade $^{99}$.

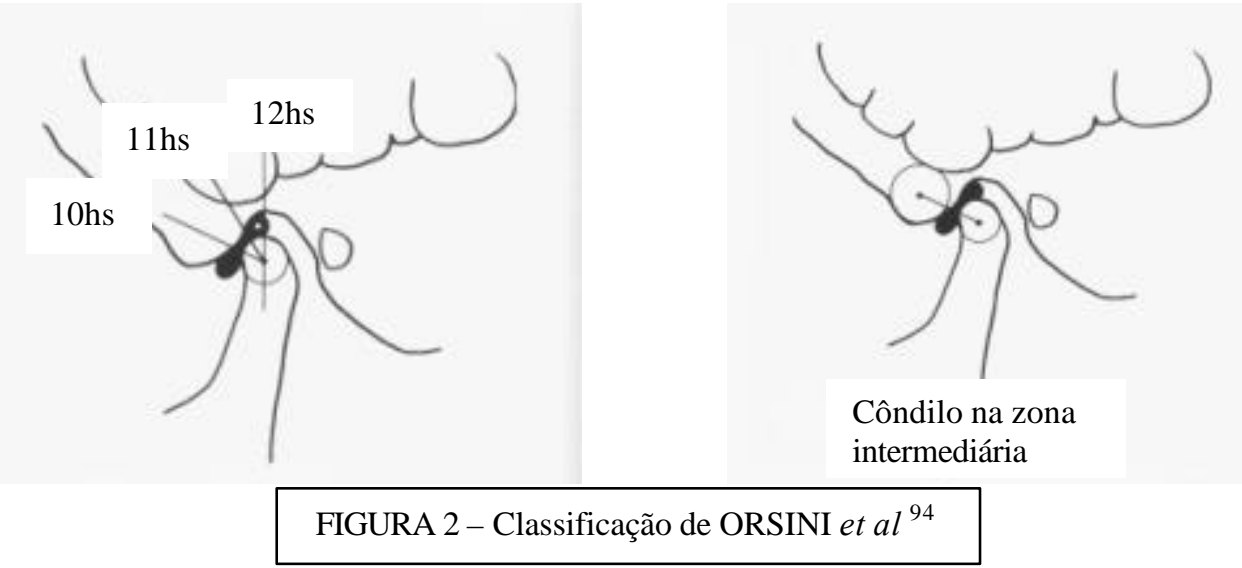

WESTESSON et al. (1987) ${ }^{146}$ e CHOLITGUL et al. (1997) ${ }^{10}$ descreveram que, num plano sagital, o disco estaria deslocado para anterior quando sua porção anterior estivesse anterior à proeminência anterior do côndilo na posição de $\mathrm{MIH}$. A diferença entre deslocamento do disco com redução e sem redução é percebida quando se observa uma reposição do disco na porção superior em abertura e, por outro, se não for reduzido, o disco aparecerá deslocado para anterior tanto em abertura quanto em MIH. Acrescentaram ainda que, numa vista coronal, os discos podem ser classificados em deslocados para medial, quando se movimenta medialmente ao pólo medial do côndilo, e deslocados para lateral, quando movimentados lateralmente ao pólo lateral do côndilo. Quando há um deslocamento, tanto no plano sagital quanto coronal, diz-se que houve um deslocamento combinado.

Similar a essa definição, WESTESSON; ERIKSSON; KURITA (1989) 145 descreveram que a posição do disco pode ser classificada em superior e anterior. A posição superior seria encontrada quando a banda posterior do disco estivesse localizada acima do 
ápice do côndilo e, a posição anterior do disco, quando a banda posterior do disco estivesse anterior ao côndilo. Utilizando-se da classificação da posição anterior acima descrita, HELMS et al. (1989) ${ }^{37}$ graduaram a posição anterior do disco em 1, caso a morfologia do disco se apresentasse normal e 2, caso a morfologia do disco estivesse anormal. $\mathrm{O}$ valor 0 era atribuído ao disco que estivesse com suas posições e morfologias normais (Figura 3).
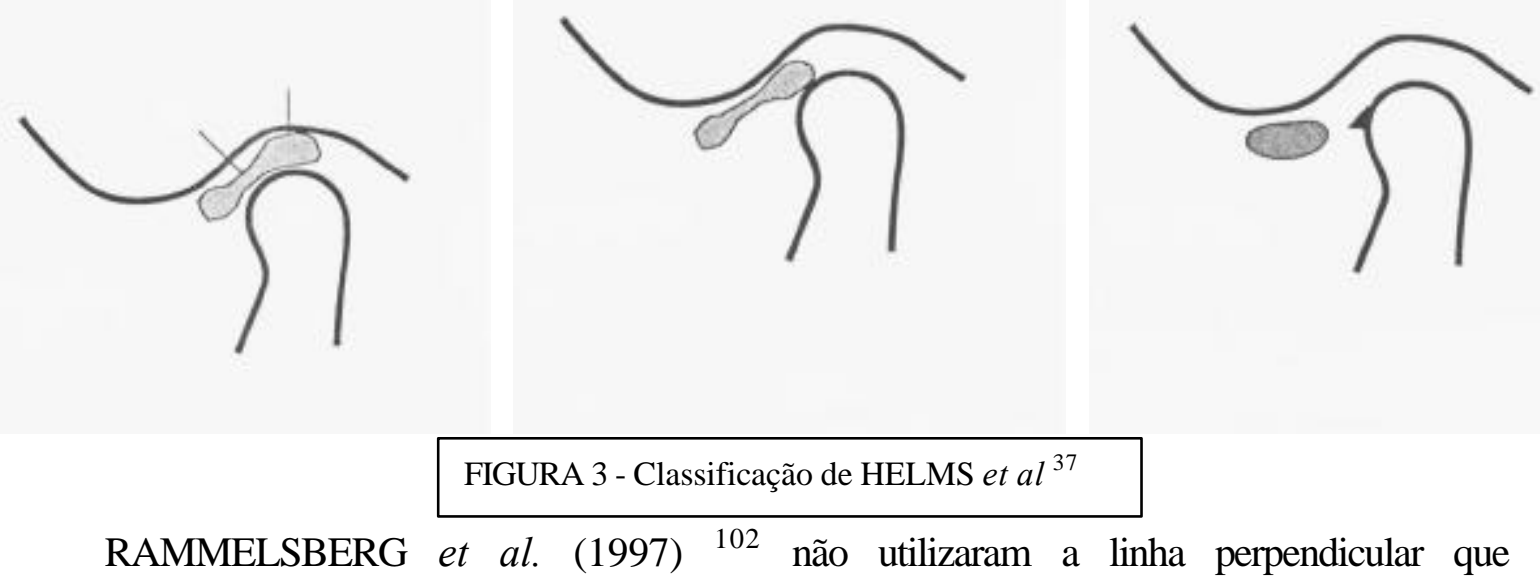
atravessa o meio do côndilo para definir a posição de 12 horas, mas sim uma linha perpendicular ao plano de Frankfort e que também atravessa o centro do côndilo. Uma posição anterior da junção entre a banda posterior do disco articular e a zona bilaminar seria medida em graus positivos, enquanto valores negativos indicariam uma posição do disco para posterior (Figura 4).

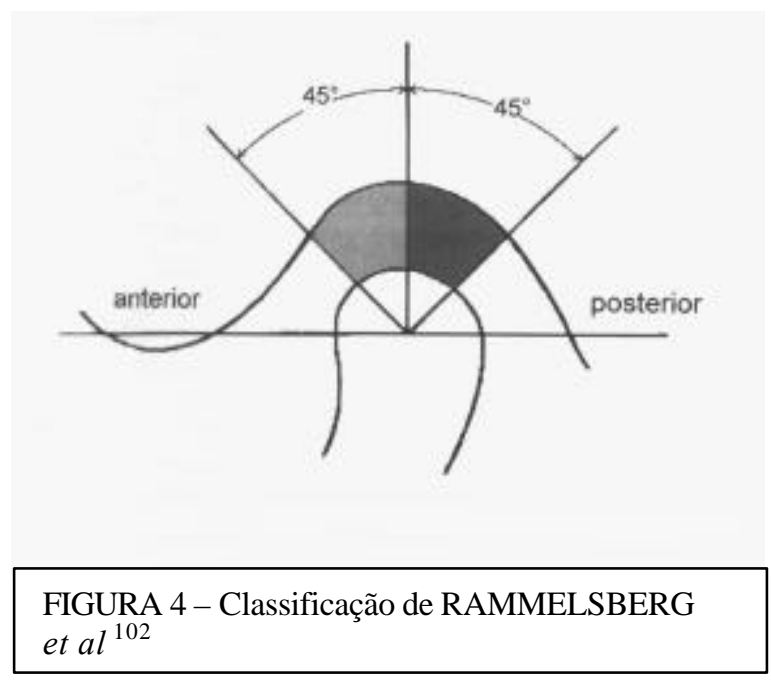


Para se avaliar a posição do disco, MURAKAMI et al. (1993) ${ }^{85}$ dividiram-na em 4 posições para boca fechada - A, B, C, D - e 2 posições para boca aberta - anterior e posterior, de acordo com a posição da porção da banda posterior do disco em relação à superfície funcional do côndilo. Para determinação destas referências, foram traçadas as linhas H0 - tangente do processo glenóide à eminência articular; linha H1 - paralela à linha H0, passando pela crista anterior da superfície funcional do côndilo; linha L1 perpendicular à linha $\mathrm{H} 0$, passando através da crista posterior da superfície funcional; linha L2 - perpendicular a H0, passando através da crista anterior da superfície funcional do côndilo e linha $\mathrm{P}$ - linha na qual o côndilo se situa mais próximo da eminência articular (Figura 5):

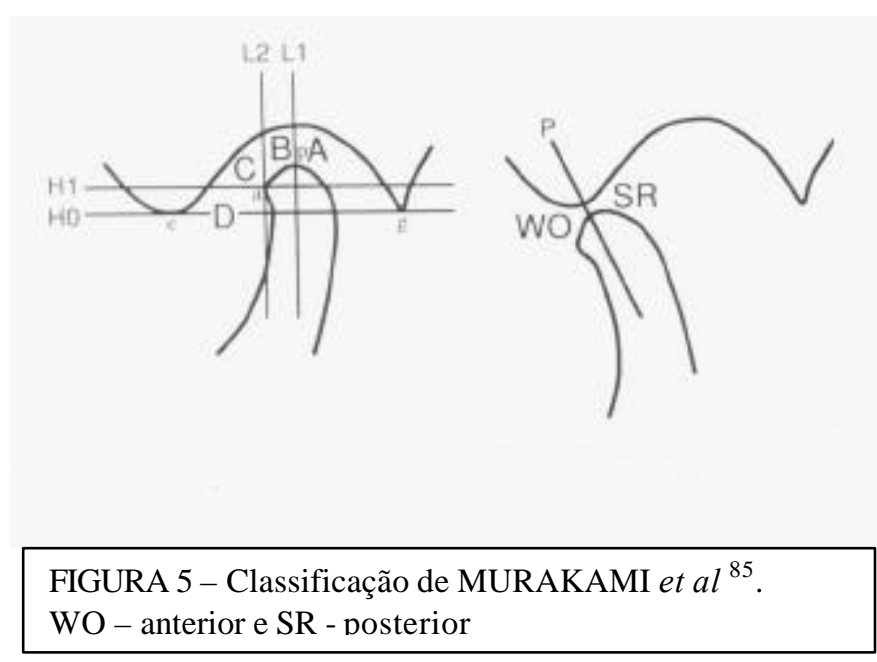

Por outro lado, alegando subjetividade de análise em relação às variáveis anatômicas, outros estudos defendem alternativas de avaliação da posição associado com a forma do disco. A classificação do disco foi inicialmente sumarizada por AKERMAN $(1986)^{3}$, em posição anterior ou normal e em 3 formas distintas: côncava, convexa ou de espessura uniforme. A morfologia do disco tem sido vista como um fator importante na origem dos DIs da ATM e na limitação dos movimentos funcionais mandibulares. 
Para tanto, uma classificação complementar à vista por AKERMAN (1986) ${ }^{3}$ foi desenvolvida por HEFFEZ e JORDAN $(1988,1989){ }^{35,36}$, a qual se baseou em 5 grupos de formas do disco. A forma do grupo 1 era considerada como normal, ou seja, a banda anterior do disco era igual ou menor à posterior e a forma do grupo 5 representava o grau máximo de severidade. Os procedimentos para a visualização do disco eram executados mediante tomadas por meio de artrotomogramas cefalométricos laterais e cortes sagitais histopatológicos. Estes mesmos autores ainda descreveram, por meio destas tomadas, cinco formas básicas da morfologia do disco: (1) gravata borboleta (normal), (2) em linha reta, (3) em funil, (4) bojudos e (5) em "Y". De uma apreciação de 100 exames, os relacionamentos côndilo-disco normais e os deslocamentos de disco de leve a moderado ocorreram geralmente com a forma em gravata borboleta, enquanto deslocamentos mais severos do disco sem redução ocorreram predominantemente com a morfologia número 4 ou mais bojuda. As variações degenerativas do disco são influenciadas pelo grau e tipo de DD e quanto mais avançado for o DI, mais alterada estará a configuração do disco ${ }^{154}$.

A forma da eminência articular tem sido considerada como fator predisponente para o DD. A eminência foi classificada em 4 formas: a) caixa; b) sigmóide; c) rasa e e) deformada ou irregular. Houve uma menor tendência de ocorrer DD em articulações com eminência mais rasa ${ }^{70}$.

NEBBE et al (1998) ${ }^{89}$, através de RM, discriminaram 6 categorias subjetivas de avaliação da posição do disco (posição normal; deslocamento levemente para anterior; deslocamento moderado; deslocamento completo; deslocamento completo sem redução; e sem classificação devido a má qualidade de imagem), transferindo para as RMs os planos 
de referência padronizados em radiografias cefalométricas laterais (Figura 6). Segundo os autores, estas referências poderiam não coincidir perfeitamente com a inclinação posterior da eminência articular, mas no entanto seriam uma aproximação adequada deste aspecto anatômico, permitindo que os componentes articulares funcionais fossem relacionados entre si.

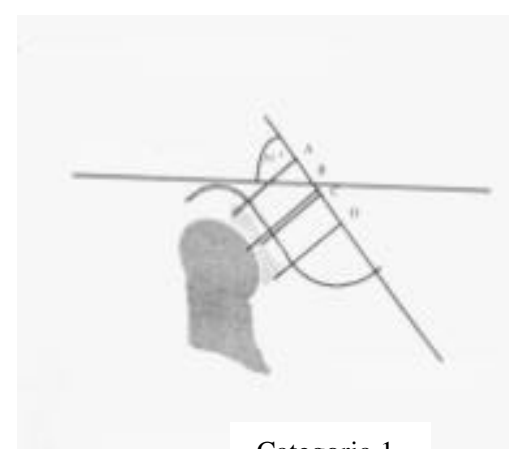

Categoria 1

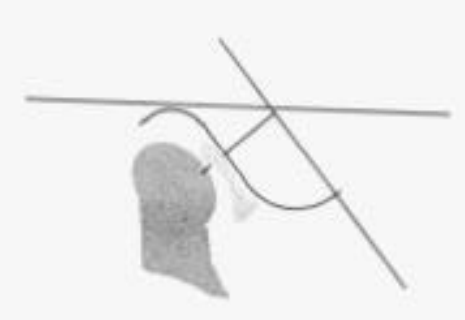

Categoria 2

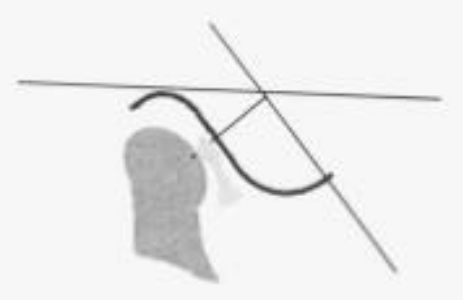

Categoria 3

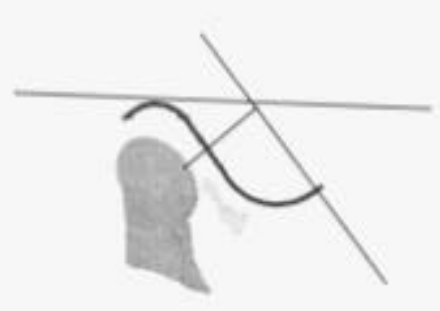

Categoria 4

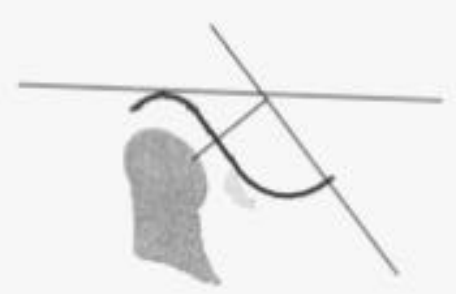

Categoria 5

FIGURA 6 - Classificação de NEBBE et al ${ }^{89}$ 
Ampliando as opções de diagnóstico da posição do disco articular, TASAKI et al. (1996) ${ }^{135}$ distribuíram em 10 categorias possíveis de classificar o disco: 1. Superior; 2. Deslocado para anterior; 3. Parcialmente deslocado para anterior na porção lateral da ATM; 4. Parcialmente deslocado para anterior na porção medial da ATM; 5. DD ânterolateral; 6. DD ântero-medial; 7. DD lateral; 8. DD medial; 9. DD posterior; 10. Indeterminado. Este sistema de classificação foi proposto para ser uma referência precisa e consistente de comunicação entre clínicos e pesquisadores.

A posição do disco ainda foi analisada através de geometria plana, baseando-se em pontos específicos da ATM e em uma figura geométrica cuja área foi calculada mediante equações matemáticas. Neste caso, as referências utilizadas foram (1) o ápice da eminência articular, (2) o ápice da fossa glenóide, (3) a porção mais superior da cabeça do côndilo, (4) a porção mais anterior da cabeça do côndilo e (5) o limite da banda posterior com o tecido retrodiscal (Figura 7). As operações eram desenvolvidas automaticamente pelo computador, após as referências terem sido digitadas, e os resultados mostraram-se mais precisos do que os métodos qualitativos ${ }^{118}$.

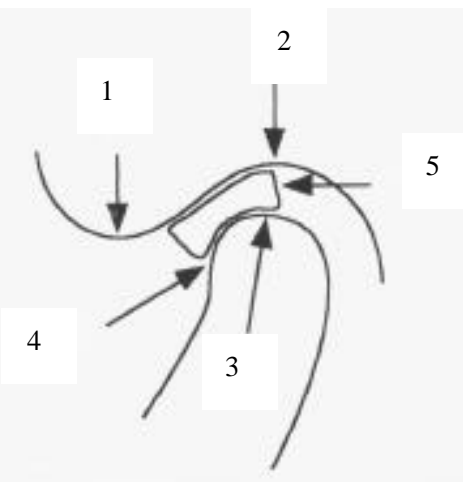

FIGURA 7 - Classificação de SILVERSTEIN et al ${ }^{118}$ 
Ainda na linha de métodos matemáticos na identificação da posição do disco, DAVANT et al. (1993) ${ }^{17}$ mostraram um método geométrico determinado pela análise quantitativa da posição do disco. Foram traçados dois pontos: o mais anterior (A) e o mais superior do côndilo (S). Tangentes foram desenhadas a partir destes pontos. A partir de perpendiculares a estes pontos, delimitou-se o centro do côndilo (C). Desenhou-se uma linha (C-E) a partir do ponto $\mathrm{C}$ até o ponto mais próximo ao aspecto posterior da eminência (E). A porção mais fina da zona intermediária do disco foi delimitada e uma linha paralela à linha C-E foi traçada. A distância desta linha à linha C-E representou o DD em medidas lineares. Uma outra linha $\mathrm{C}$-c foi traçada saindo do centro do côndilo à porção mais fina do disco. O ângulo formado entre esta linha e a linha perpendicular ao ponto A determinou o ângulo de DD. Uma relação normal do disco seria quando a linha C-E interceptasse a zona intermediária do disco articular (Valor zero). Caso esta porção intermediária estivesse para anterior ou posterior à linha $\mathrm{C}-\mathrm{E}$, valores positivos $\mathrm{e}$ negativos seriam assumidos respectivamente (Figura 8). Aproveitando essas medidas, os autores utilizaram um programa específico de análise da posição do disco no computador, seguindo os seguintes parâmetros:

1) área total do disco e o seu perímetro;

2) coordenadas $\mathrm{X}$ e $\mathrm{Y}$, a partir do centro do côndilo;

3) ângulo de DD e

4) Distância C-c.
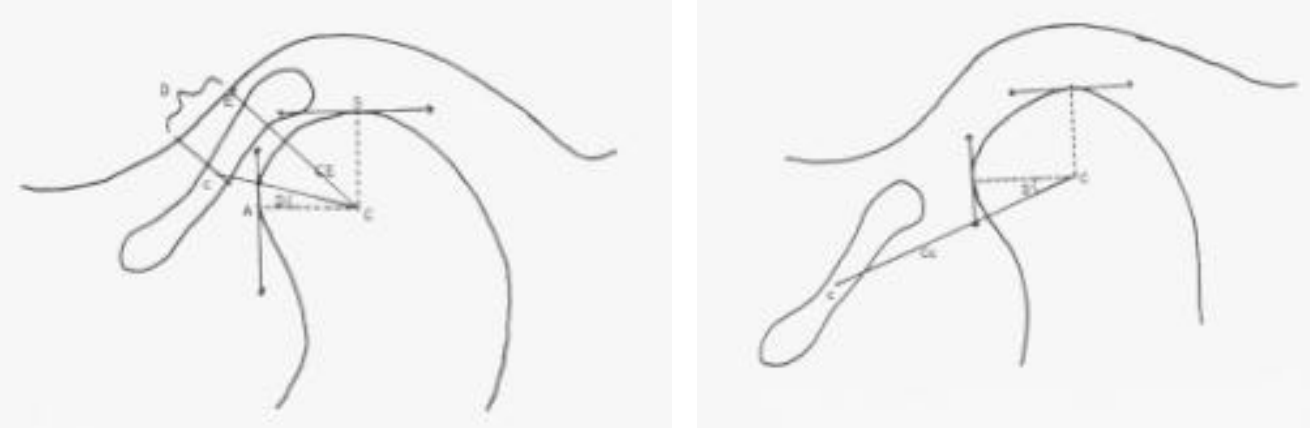
Um outro método de avaliação da posição do disco articular foi descrito por KURITA et al. (1998) ${ }^{68}$. A partir de 4 pontos de referência, traçavam-se linhas; uma linha tangente (T-P) foi traçada da crista inferior da eminência articular (T) até a crista superior do meato acústico externo (P). Linhas perpendiculares foram levantadas a partir do limite posterior da banda posterior do disco articular (D) e do côndilo (C), interceptando a linha T-P. As distâncias T-P, T-C e T-D, registradas em milímetros, permitem analisar os deslocamentos condilares e do disco por meio de imagens de diagnóstico (Figura 9).
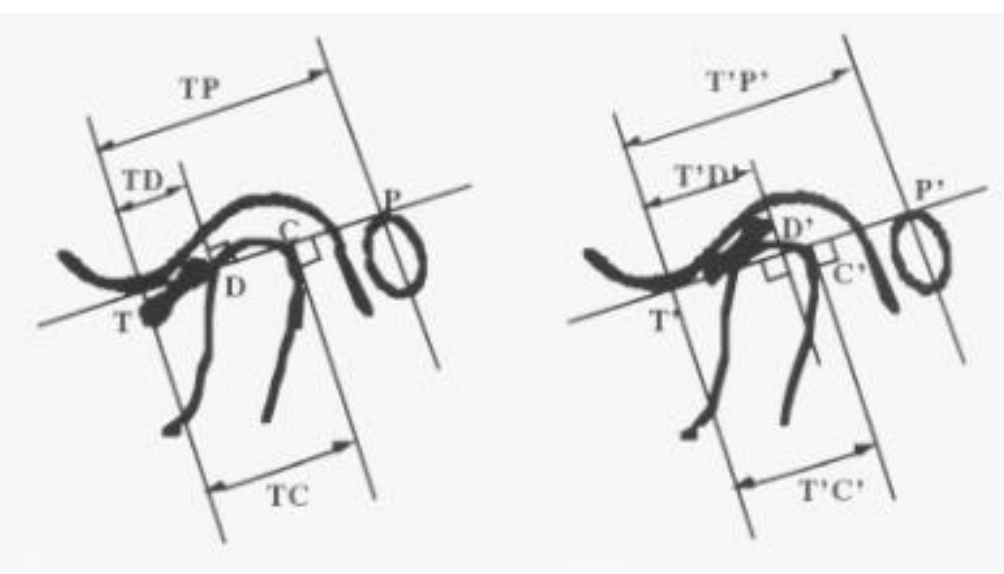

FIGURA 9 - Classificação de KURITA et al $^{68}$

\section{2- Exames complementares das patologias da ATM}

Os meios mais adequados de visualização das estruturas intrarticulares consistem na obtenção de imagens da ATM. Na avaliação sobre a confiabilidade e validade dos diagnósticos por imagem da ATM, observa-se que as tomografias e radiografias transcranianas são usadas para avaliação de alterações ósseas e proservação das mesmas, com pouca resolução de imagem dos tecidos moles. Até o final dos anos 70 e meados de 80, as artrografias apresentavam-se como técnicas prediletas para a visualização do disco através da injeção de material de contraste radiopaco ${ }^{78,106,140}$, e ainda hoje são largamente 
empregadas na revelação de perfurações ${ }^{24}$. Outras finalidades das artrografias são a captação do dinamismo, posição, morfologia e integridade do disco articular e outros tecidos moles da ATM. WESTESSON; ERIKSSON; KURITA (1989) ${ }^{145}$ descreveram a posição de normalidade do disco em 34 de 40 articulações assintomáticas, nas 6 restantes o diagnóstico radiográfico foi de deslocamento do disco (DD). Portanto, em $15 \%$ dos indivíduos clinicamente sugestivos de ausência de DD, houve na realidade resultados falsos negativos.

WESTESSON; ERIKSSON (1991) ${ }^{144}$, comparando achados clínicos e radiográficos (artrotomografias) em 51 pacientes com estalido ou história de estalido seguido de limitação da abertura bucal, constataram que houve o reposicionamento do disco quando havia apenas a presença do estalido na posição de boca aberta, enquanto os pacientes com limitação de abertura, os discos permaneciam deslocados para anterior. Em outro trabalho realizado com artrotomografias, ISBERG; STENSTRÖM; ISACSSON (1991) 45 selecionaram 50 pacientes com sinais e sintomas de sons articulares em pelo menos uma das ATMs. Após o exame inicial, todos os pacientes receberam tratamento por meio de placas oclusais, na tentativa de recaptura do disco, realizado por diferentes profissionais. Ao final do período de 5 anos, 17 pacientes que inicialmente eram assintomáticos para DD desenvolveram dores na articulação. Devido as dores terem permanecido severas durante o período de acompanhamento, a remoção do disco foi realizada em 10 pacientes, sendo que os 7 restantes receberam tratamento não cirúrgico. A articulação assintomática do lado contra-lateral sintomático demonstrou uma tendência a tornar sintomática, tendo em vista ser um elo fraco do sistema estomatognático. 
WESTESSON; BRONSTEIN; LIEDBERG (1985) ${ }^{142}$ avaliaram 58 espécimes necropsiadas, através de artrografias da ATM, verificando que quando o disco estava na posição superior (normal), poucas alterações morfológicas eram observadas; além disso, a sua extensão ântero-posterior era maior do que quando os discos se apresentavam deslocados. Quanto aos deslocamentos parciais para anterior do disco, a deformação era mais freqüente e localizada na porção do disco que estava posicionada para anterior. Articulações com disco completamente deslocados mostravam deformações em $77 \%$ das ocasiões, o que permitiu afirmar que o DD para anterior precede à sua deformação.

Utilizando-se de imagens de diagnóstico em 248 pacientes (225 artrografias e 23 RMs), ISBERG; HÄGGLUND; PAESANI (1998) ${ }^{43}$ observaram que houve diferenças estatisticamente significantes na incidência de DD nas mulheres, durante o período da adolescência. Esta diferença entretanto não foi significante quando os grupos foram divididos por faixa etária, embora tenha havido uma tendência de aumento dos deslocamentos de disco na terceira e quarta décadas de vida das mulheres. Por fim, não houve diferenças quanto aos relatos dos níveis de dor entre ambos os gêneros.

A avaliação da reposição do disco através de coberturas oclusais (“onlays”) e placa oclusal lisa, por meio de artrografia, mostrou que os pacientes tratados com "onlays" desenvolveram uma melhor relação articular e diminuição de sintomatologia muscular e articular ${ }^{77}$. Ainda no mesmo ano, WESTESSON; LUNDH, (1988) ${ }^{148}$, utilizando metodologia semelhante, compararam as imagens de artrografias e tomografias antes e após 6 meses de tratamento para DD com coberturas oclusais do tipo "onlays", verificando que o retorno de sintomas durante tratamento com "onlays" está freqüentemente associado com a recorrência de DD e que o deslocamento lateral do disco não é visto em pacientes 
com sucesso no tratamento. Os autores sugeriram que esta posição do disco é mais difícil de se tratar. Placas oclusais, com acompanhamentos artrográficos, têm sido utilizados para a verificação durante o período de tratamento de restabelecimento da posição côndilodisco, uma vez que a eliminação de sons articulares não necessariamente promoverá uma recaptura do disco ${ }^{129,130}$.

Entretanto, as artrografias não detectam se as variações patológicas estão localizadas no disco ou nos ligamentos posteriores, tendo em vista que estas estruturas não podem ser distintamente separadas ${ }^{139}$. O procedimento é invasivo, tecnicamente difícil e o paciente fica exposto a altas doses de radiação, dor e desconforto ${ }^{115}$. Há ainda complicações inerentes a artrografias como a perda da ponta da cânula no ato da injeção, formação de hematomas e infecções, e episódios agudos de hipertensão seguidos da administração de epinefrina adicionada ao material de contraste para prolongar a opacificação ${ }^{115}$. O espaço articular inferior que é dividido em regiões ou sulcos anterior e posterior apresenta-se como uma concavidade nos exames artrográficos. Classicamente, esta concavidade é considerada um reflexo de um DI da ATM, devido ao deslocamento anterior do disco articular, embora trabalhos procurem mostrar que a formação desses espaços articulares podem ocorrer em indivíduos assintomáticos ${ }^{51}$. Portanto, a dificuldade da técnica, a sensibilidade dos pacientes sintomáticos ao procedimento e o surgimento de métodos não invasivos causaram a diminuição da popularidade das artrografias.

Primariamente, para suprir as desvantagens das artrografias, surgiram as TCs que, em estudos correlacionando achados em TCs com morfologias encontradas em espécimes necropsiadas, obtiveram uma alta fidelidade ${ }^{131}$. As TCs representam um exame não invasivo, indolor e preciso. As doses de radiação são menores do que as artrografias, o que 
é importante quando atinge órgãos como olhos e glândula tireóide. HELMS et al.(1984) ${ }^{39}$, a partir da utilização da classificação do DD em leve, moderada e severa, obtiveram uma alta correlação (97\%) entre TCs e artrografias ou ATMs submetidas a cirurgias. CHRISTIANSEN et al. (1987) ${ }^{11}$ encontraram uma correlação positiva entre a posição dos discos baseada nas diversas posições condilares e espaços articulares. KINNIBURGH et al. (2000) ${ }^{60}$ mostraram que, utilizando-se de RMs como gold standard, as TC's foram capazes de determinar medidas do espaço articular e morfologia da eminência e, dessa forma, oferecer informações significativas para a avaliação de alterações intra-articulares. A precisão da TC na avaliação da posição do disco tem sido relatada ser de 40 a $67 \%$ 38, 131, ${ }^{146}$, o que é inferior à de $87 \%$ encontrada na determinação das variações ósseas. COHEN; ROSS; GORDON (1985) 13 afirmaram ainda que as TCs são úteis tanto no diagnóstico, identificando alterações tais como artroses, cistos, tumores, fraturas, anquiloses, neoplasias e outras anormalidades, quanto em modalidades terapêuticas ou ainda na avaliação do sucesso do relacionamento côndilo/disco. Tal avaliação será melhor diagnosticada pelo radiologista, caso haja um adequado conteúdo de informações clínicas. Portanto, as TCs têm se mostrado inadequadas para a visualização do disco articular.

A injeção de contraste combinada às TCs resulta em melhor visualização de determinadas estruturas articulares. Este exame, denominado de artrotomografia, tem sido utilizado para mostrar deslocamentos de disco com ou sem redução, doenças articulares degenerativas e possíveis perfurações do disco ${ }^{82}$.

RAMMELSBERG et al. (1997) ${ }^{102}$ utilizaram as RMs como parâmetro anatômico para análise de tomografias sagitais da posição do disco articular. Valores negativos eram representativos de deslocamento posterior do disco, enquanto os valores positivos de 
deslocamentos anteriores. A média da posição do disco nos grupos assintomáticos, com restrição da mobilidade e com estalido recíproco respectivamente variaram entre $-5^{\circ}$ a $10^{\circ}$, $70^{\circ}$ a $90^{\circ}$ e $20^{\circ}$ a $55^{\circ}$. Os resultados sugeriram que posições dos discos até $15^{\circ}$ nas tomografias mediais e $30^{\circ}$ nas tomografias laterais deveriam ser interpretadas como variações de uma ATM normal.

Com a introdução das imagens por RM no início da década de 80, para avaliação da ATM, a utilização de TC e artrografias tem diminuído significativamente para o diagnóstico das DTMs ${ }^{38,49,54,61}$. KAPLAN e HELMS (1989) ${ }^{49}$; WESTESSON $(1993)^{145}$ listaram como vantagens das RMs o fato de serem menos dependentes da habilidade do operador, mais precisas nos deslocamentos medial e lateral dos discos, de oferecerem mais detalhes de imagens dos tecidos moles por meio de método não invasivo e de não emitirem radiação ionizante. Como desvantagens salientaram o alto custo, a incapacidade de uso em pacientes claustrofóbicos, a diferença na qualidade de imagens produzidas por diferentes aparelhos e a não verificação da presença de perfurações no disco. A energia do campo magnético pode causar um descompasso do marcapasso ou desalojar objetos metálicos, provocando sangramentos indesejáveis. Grandes quantidades de amálgama e ouro não produzem artefatos de imagem, embora o aço inoxidável contido em alguns trabalhos protéticos e fios ortodônticos tendem a obliterar detalhes de imagens encontradas em áreas faciais, mas não necessariamente em áreas relacionadas à ATM 73, 115 . Embora um complexo aparato tecnológico seja utilizado para a produção de RMs, a operação das imagens não é complicada, sendo menos estressante e mais fácil tecnicamente do que outros meios de diagnóstico. Embora o magnetismo para a produção das imagens não seja considerado um risco para o feto, um estudo cauteloso da utilização das RMs durante o período de gestação é recomendado. A RM é indicada para uso em mulher grávida se 
outras formas de diagnóstico por imagem com radiação não ionizante são inadequadas ou se o exame de RM oferece informações imprescindíveis que não poderiam ser obtidas com a exposição a radiações ionizantes ${ }^{73}$.

O paciente que é bem informado a respeito de aspectos específicos do exame de uma RM, tais como o nível de barulho ao qual será submetido, dimensões internas do tubo de scanner e a duração do exame, freqüentemente tolera ser submetido ao processamento sem grandes dificuldades.

O contraste entre os tecidos produzidos por uma imagem por RM não é dependente da densidade tecidual, mas sim reflete variações da estrutura molecular $\mathrm{e}$ das características teciduais, permitindo dessa forma uma boa distinção entre os tecidos musculares, ósseos, fibrosos, gordurosos e vasculares ${ }^{16}$.

Uma das recentes vantagens das RMs é a capacidade de realizar movimentação dinâmica das imagens ${ }^{22}$, o que até bem pouco tempo atrás era considerada uma desvantagem ${ }^{24}$. Imagens do mesmo local, mas em diferentes aberturas bucais, descrevem com detalhes o disco, o côndilo, a eminência articular e a fossa glenóide. O paciente pode observar o movimento da articulação, resultando numa melhor compreensão das variações patológicas ${ }^{22}$. O dinamismo com as imagens das ressonâncias também foi avaliado por CONWAY et al. (1989) ${ }^{15}$ que, a partir de exames em 49 ATMs, obtiveram informações referentes a: (a) determinação do exato momento da recaptura do disco, (b) distinção das variantes normais de um disco patologicamente deslocado e (c) elucidação das dúvidas encontradas entre os exames clínicos e respectivas imagens. 
Em um estudo recente realizado sobre a capacidade de imagens dinâmicas em 62 indivíduos com um ou mais sinais de DTMs, utilizando um dispositivo de mordida (TMJ 200, Medrad, Inc, Pittsburg, Pa) para obtenção das RMs, avaliou-se a deformação flexural do disco articular na posição de boca aberta. A deformação origina-se da zona intermediária até a banda posterior numa articulação cujo disco esteja deslocado para anterior, durante a abertura bucal. Observou-se, durante a abertura, que a deformação do disco tanto poderia ser voltada para cima quanto para baixo e, das 80 ATMs examinadas, 30 tinham deformações para baixo, enquanto 50 tinham deformação para cima (Figura 10). O resultado sugeriu que uma deformação para cima pode representar um estágio mais avançado de um DI ${ }^{156}$.

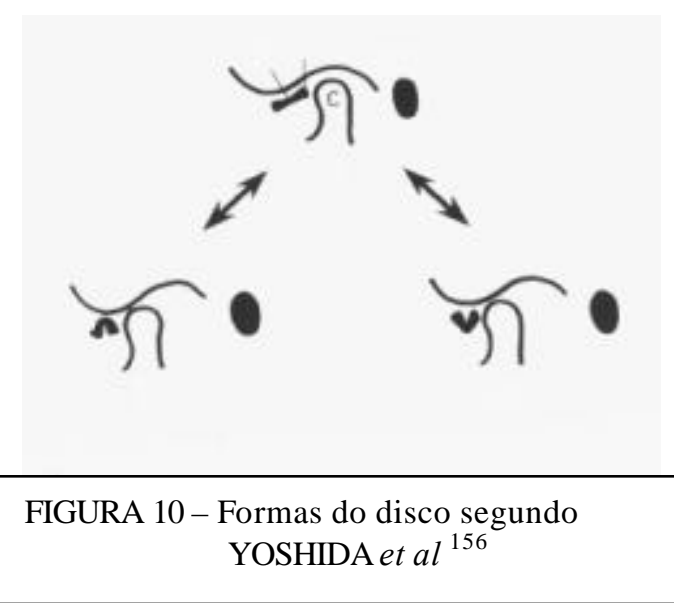

A tentativa de dinamizar as imagens das RMs torna-se cada vez mais constante. $\mathrm{O}$ Echo planar imaging (EPI) é uma técnica rápida de obtenção de imagens em menos de 1 segundo (média de 0,5 a $7 \mathrm{seg}$ ). O paciente é instruído por um microfone a abrir e fechar a boca espontaneamente, de forma contínua e vagarosa, evitando a necessidade de se interpor qualquer dispositivo para que se mantenha a boca aberta. Isto diferencia esta técnica das imagens pseudodinâmicas que obtém os resultados em graus de abertura determinados e das "MRI MOVIE" na qual todos os ciclos registrados são iguais, variando apenas no progressivo aumento do intervalo de tempo ${ }^{8}$. Pela rapidez de captação de 
imagens, esta técnica não produz uma qualidade tão boa quanto às imagens estáticas, além da possibilidade dos artefatos serem processados.

MUSGRAVE et al. (1991) ${ }^{87}$ compararam RMs obtidas em planos oblíquos, de acordo com o côndilo, com as imagens ortogonais (planos sagital e coronal). Pares de imagens obtidas por ambos os métodos foram julgadas quanto à qualidade das imagens. Analisando 21 pacientes - 14 com sinais e sintomas de DTMs e 7 assintomáticos - em mais da metade das RMs, as imagens em planos oblíquos demonstraram uma melhor visualização da anatomia do disco articular em comparação aos planos convencionais (notadamente em relação às imagens coronais).

Em contraposição a este estudo, HOLLENDER et al. (1998) ${ }^{40}$ descreveram um novo plano para imagens coronais para visualização do disco e côndilo. Se o disco é deslocado para anterior, a superfície articular do côndilo é coberta pelos ligamentos posteriores ou zona bilaminar, não sendo possível descrever o relacionamento entre as duas porções anatômicas. Ao invés dos localizadores axiais utilizados para obter imagens coronais, foram utilizados localizadores previamente empregados para imagens sagitais e coronais de boca fechada. O plano da imagem foi orientado perpendicular à inclinação posterior da eminência articular e do disco.

TASAKI et al. (1993) ${ }^{136}$, avaliando espécimes necropsiadas com oclusão estável, por meio de RM, observaram que o plano axial, além dos planos sagital e coronal, em relação ao longo eixo dos côndilos, não trouxe vantagens para a avaliação do DD ou das alterações ósseas. 
A utilização de RMs como gold standard mostraram que as ultra-sonografias da ATM são insuficientes para o estabelecimento de um diagnóstico preciso de DD, apesar de valores expressivos de especificidade mostrados pela ultra-sonografias dinâmica ${ }^{25}$.

No ano de 2000, TOYAMA et al. ${ }^{139}$ avaliaram a utilidade da RM combinada com artrografia em 13 ATMs de 11 pacientes com dor crônica, através de imagens T1 e T2 obtidas após injeção intra-articular de dimeglumine gadopentetate. As imagens mostraram

perfurações em 9 das articulações, sendo todas confirmadas após remoção do disco. A precisão na localização das perfurações foi de $67 \%$, enquanto para as adesões no espaço articular superior e inferior foi de $77 \%$ e $85 \%$, respectivamente. Todas as estruturas anatômicas e patológicas foram detectadas, sugerindo que esta modalidade de imagem pode ser indicada nos casos de intervenção cirúrgica.

Mais recentemente, CHU et al. (2001) ${ }^{12}$, mostraram que imagens de RMs em 3D ofereceram mais informações do que as imagens convencionais. $\mathrm{O}$ uso de programas avançados de computação permitem que dados de imagens de RM em 2D sejam reconstruídas em 3D. A vantagem das resoluções em 3D é que há a possibilidade de se inspecionar as diferentes estruturas da ATM por meio de vários planos em três dimensões.

\section{- Processamento da imagem da Ressonância por Magnética}

A energia liberada pelos aparelhos de raios- $\mathrm{x}$ transfere a um corpo a ser analisado uma radiação do tipo ionizante. Altos níveis desta radiação podem provocar efeitos deletérios a um indivíduo. 
Por outro lado, nas RMs, não há radiação ionizante, mas sim uma energia magnética que promove o alinhamento e orientação dos prótons de hidrogênio de um determinado corpo. Os prótons são átomos positivos que se alinham de modo aleatório em diferentes corpos. A abundância de íons hidrogênio na água e nos tecidos adiposos oferece uma excelente fonte de prótons de hidrogênio, que podem ser usados na geração de imagens de uma RM ${ }^{73}$. Sob condições normais, o momento magnético de um indivíduo é gerado por bilhões de prótons no interior do corpo humano, que são aleatoriamente distribuídos (Figura 11). Esta aleatoriedade gera microscópicos campos magnéticos, onde um se anula perante a presença do outro, tendo como resultado um corpo magnético neutro. Quando os prótons de um paciente se encontram em um campo magnético muito forte, estes átomos tendem a agir como pequenos magnetos, alinhando e girando numa determinada frequiência, alterando o núcleo dos átomos de hidrogênio, fazendo com que os prótons se disponham longitudinalmente e em direção ao campo magnético externo como se fossem vetores matemáticos. Ressonância, então, é a transferência da energia vibrante de um sistema para o outro ${ }^{63,73,83}$.

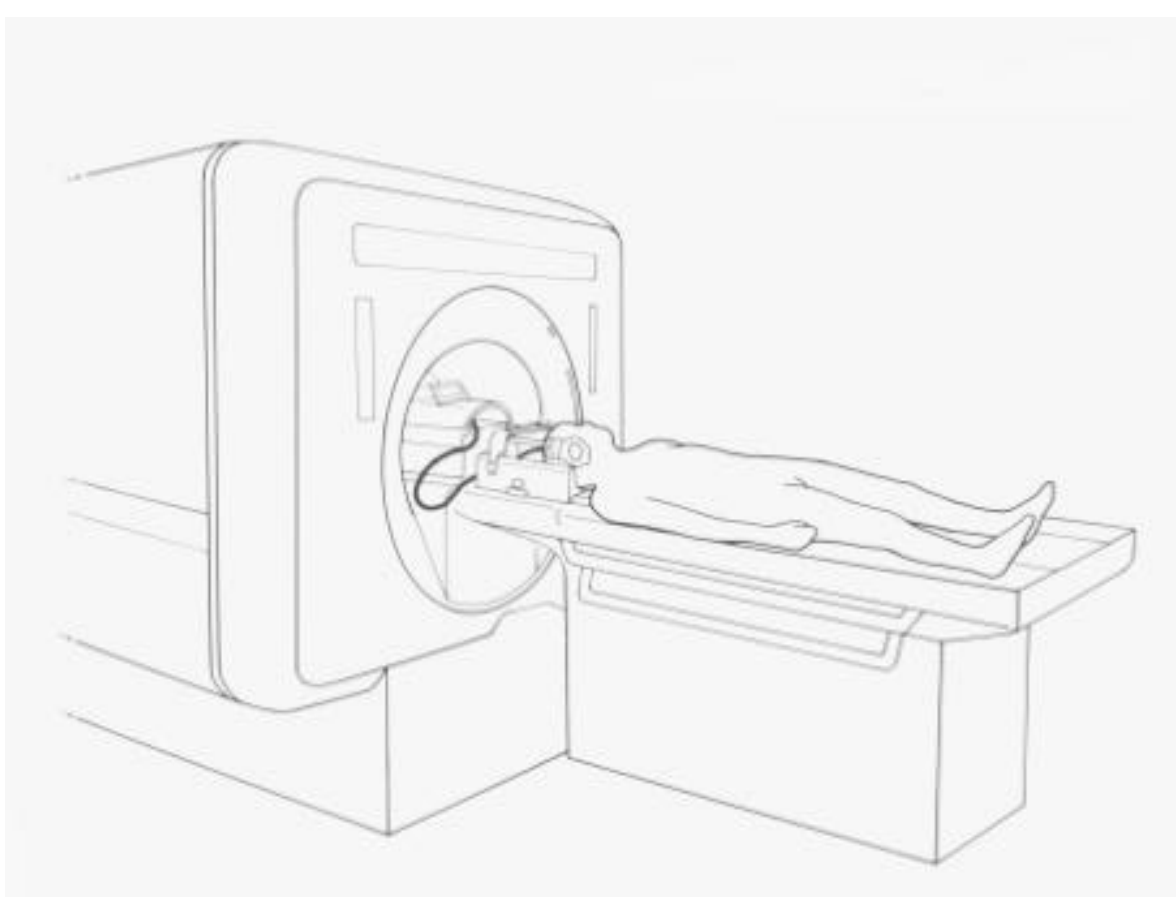


Para se obter as imagens, estes vetores magnéticos precisam ser excitados. O vetor é excitado por meio de ondas de radiofrequiência, que são passadas na freqüência exata para a estimulação das moléculas de hidrogênio.

A excitação dos prótons de hidrogênio manifesta-se diretamente sobre a extremidade do vetor magnético. A duração da radiofreqüiência determina o ângulo que essa extremidade tomará. A extremidade do vetor diminui e um novo vetor desta feita transversal aparece. Esta nova inclinação assume uma angulação por volta de $90^{\circ} \mathrm{em}$ relação ao eixo vertical (Figura 12). O resultado imediato é a absorção de energia destes vetores devido aos pulsos de radiofreqüência ${ }^{73}$.

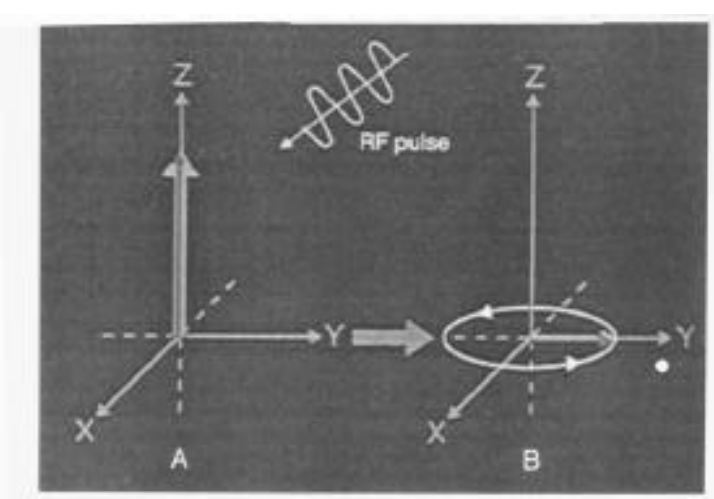

FIGURA 12 - Emissão de puls os de radiofreaüência (LANGLAIS et al $^{73}$ )

Após o término dos pulsos da radiofreqüência, os prótons de hidrogênio relaxam-se e lentamente retornam a posição do vetor magnético original. Com o retorno à posição original, ocorre uma indução de corrente elétrica detectada por antenas justapostas às áreas de interesse e transferida a um computador, cujas imagens serão reconhecidas por sinais 
em vários tons de cinza ${ }^{63,83}$. Após o exame, os prótons do corpo humano retornam a sua disposição original de neutralidade ${ }^{83}$ (Figura 13).

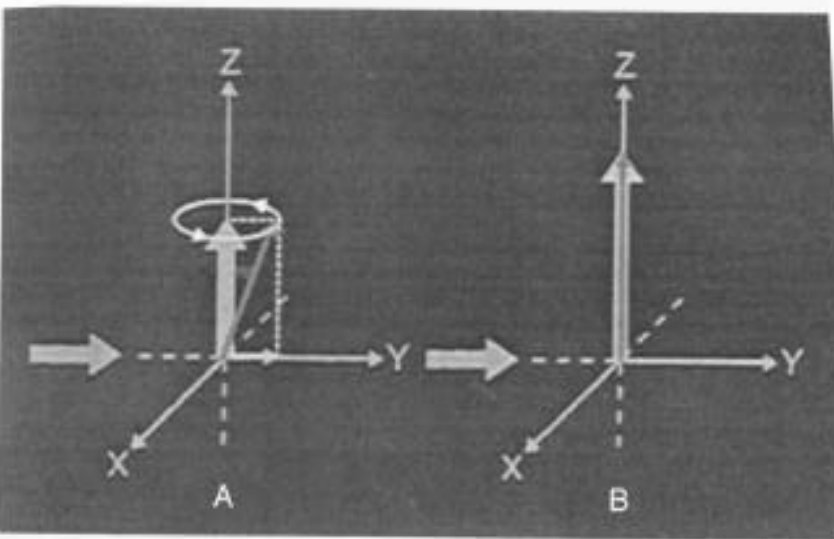

FIGURA 13 - Relaxamento e volta a posição original. (LANGLAIS et al $^{73}$ )

A unidade da magnitude do campo magnético é o tesla, no caso específico da energia do campo magnético. Na prática, campos magnéticos variam entre 0,1 a 2,0 Teslas. Acredita-se que para uso clínicos uma ótima imagem é obtida entre 0,3 a 1,5 Teslas ${ }^{32}$.

A imagem por RM permite diferenciar o disco articular das demais estruturas articulares. Numa ATM normal, o disco emite baixos sinais de freqüência e o osso cortical não emite sinais. A parte medular do osso cortical, o processo zigomático e a eminência articular transmitem altos sinais que aparecem em cores brancas ao computador. Em comparação às imagens normais, o sinal de intensidade decresce nos casos de disco deslocado ${ }^{63}$. Com emissão intermediária de sinais estão o músculo pterigoídeo lateral e os tecido retrodiscais. Alterações ósseas, tais como osteófitos, produzem altos sinais, com contraste significante quando adjacentes a tecidos que emitem sinais intermediários ${ }^{16,52,55}$. 


\section{3- Estudos comparativos de diagnóstico}

Achados clínicos foram comparados a partir de imagens por RMs pseudodinâmicas em 200 ATMs de 100 indivíduos ${ }^{22}$. Em 66,5\% das ATMs, houve uma correlação positiva entre ambos os métodos, enquanto que em mais da metade das ATMs, as RMs possibilitaram corrigir os diagnósticos clínicos. A dificuldade residiu na interpretação de RMs com DD para anterior com redução prematura e uma posição normal, havendo discordância em $15 \%$ entre os dois métodos. As imagens pseudodinâmicas foram bastante úteis no diagnóstico de DDSR e devem ser meios auxiliares no planejamento de uma cirurgia de disco.

Com resultados semelhantes, HANS et al (1992) ${ }^{30}$, avaliando uma população de 51 pacientes sob tratamento ortodôntico, constataram que dos 6 pacientes com DI diagnosticados por meio de RMs, apenas 3 possuíam estalido ou história de sons articulares. Em 8 ATMs, não se pôde determinar o diagnóstico, devido a movimentação dos pacientes ao exame das RMs. Dos 5 pacientes com estalido ou crepitação constatados clinicamente, 2 tinham confirmado os desarranjos através das RMs. Dos 10 pacientes com história de estalido, em 3 houve a confirmação pelas RMs. Portanto, exame clínico e história do paciente podem ser meios diagnósticos de escolha no tratamento ortodôntico, pois juntos auxiliam no diagnóstico das DTMs.

MARGUELLES-BONNET et al (1995) ${ }^{79}$ compararam os resultados clinicamente obtidos em 242 pacientes com suas respectivas RMs (imagens sagitais e coronais). Para análise dos resultados, foi utilizado o método cego de avaliação entre os especialistas em interpretação de RM. Houve uma perfeita concordância entre os dois métodos diagnósticos 
em 287 das 484 ATMs, enquanto nas 197 restantes este índice de concordância foi apenas parcialmente visto (distribuídos entre falsos positivo e negativo). Apesar da melhor correlação ter sido observada na categoria de doenças degenerativas da ATM, o exame clínico sozinho não consegue identificar os defeitos estruturais.

Em contrapartida, YATANI et al (1998) ${ }^{153}$ examinaram, através de um método cego para análise, 273 pacientes com diagnóstico clínico de DTMs. Os critérios clínicos utilizados foram: 1) história de estalido; 2) limitação de abertura; 3) deflexão para o lado afetado; 4) limitação de translação; 5) dor articular e 6) crepitação. RMs bilaterais foram obtidas de todos os pacientes e comparadas aos exame clínicos. A sensibilidade do exame clínico foi relativamente baixa, embora tenha atingido uma alta especificidade. A precisão do exame clínico variou entre 71 a $81 \%$.

Um outro estudo ressaltando a importância do exame clínico foi descrito por KERSTENS et al (1989) ${ }^{57}$, que avaliaram 55 pacientes unilateralmente com RMs de ATMs sintomáticas. Todos os pacientes não haviam respondido a mais de 6 meses de tratamento conservador. Utilizando 6 imagens do plano sagital de cada ATM, obtidas com boca aberta e fechada, percebeu-se uma grande correlação entre achados clínicos e imagens por ressonância. Em 33 casos, após a ressecção da eminência articular, houve correlação importante entre achados clínicos e cirúrgicos. A RM mostrou papel importante na diferenciação entre deslocamento parcial e completo do disco e, portanto, na possibilidade de indicar qual paciente se beneficia com um tratamento mais conservador.

A partir do diagnóstico realizado através de 30 artrografias utilizando videofluoroscopia, PANMEKIATE et al (1995) ${ }^{98}$ selecionaram 3 grupos de 10 pacientes: 
com posição normal do disco, com DDR e DDSR. Metade desses pacientes foram examinados por meio de radiografias transcranianas (RTrs) e o restante por tomografias sagitais, ambas na posição de boca aberta e fechada. A concordância entre os 7 examinadores foi unânime em 11 ATMs, quando apenas fluoroscopia foi empregada, e em 14 ATMs quando as artrografias foram suplementadas por RTrs e tomografias. Em 7 ATMs, 3 diferentes diagnósticos foram fornecidos com o emprego único da fluoroscopia e 5 com a utilização RTrs ou tomografias. A concordância foi mais acentuada para o DDSR do que nos outros dois grupos, independentemente do método radiográfico.

Em trabalhos comparativos das RMs com outras técnicas de determinação da posição do disco tais como artrografias ${ }^{50,132}$ ou TCs $64,65,146$, confirmou-se uma alta precisão no diagnóstico das imagens por RM. Desde que as tomadas das RMs sejam registradas no mesmo aparelho e se utilizem dispositivos padronizados no posicionamento do paciente ${ }^{134}$, a reprodutibilidade e confiabilidade dos resultados têm sido ressaltadas caso haja necessidade de avaliações em série ${ }^{75,145}$.

A partir do exame em 12 pacientes, DONLON; MOON (1987) ${ }^{24}$,verificaram que 19 ATMs tinham sinais clínicos de deslocamento do disco com e sem redução. Utilizando o exame clínico e a remoção cirúrgica do disco de 13 ATMs como referências, as RMs foram tão precisas quanto às artrotomografias na constatação de disco deslocado, enquanto que as artrotomografias revelaram com precisão as perfurações. Entretanto, a melhor correlação com os achados cirúrgicos foi demonstrada através do exame clínico. Em outro estudo comparando os dois meios de diagnóstico, as RMs demonstraram uma superioridade na avaliação de doenças reumáticas moderadas a severas em atividade na ATM, enquanto que as artrotomografias mostraram-se mais adequadas na dentificação de 
sinais indiretos de proliferação sinovial, o que poderia auxiliar um diagnóstico inicial de doença reumática da ATM ${ }^{74}$. Segundo KAPLAN et al. (1987) ${ }^{50}$, a utilização das imagens obtidas nas RMs serviu para uma correlação altamente positiva em relação às artrografias, no diagnóstico diferencial de concavidades anteriores (variações anatômicas da banda anterior do disco) descritas nos exames artrográficos como possíveis áreas de DD. No estudo de 28 ATMs, verificou-se que as concavidades anteriores necessariamente não se tratam de uma condição patológica do disco.

KATZBERG et al (1985) ${ }^{54}$ submeteram a exames com RMs 3 pacientes sem sinais e sintomas de DTM e 1 paciente com deslocamento do disco com redução em um das ATMs (assintomático do outro lado), diagnosticados por meio de artrografias. Imagens sagitais foram registradas na posição de boca aberta e fechada. A posição do disco articular nos pacientes assintomáticos foi a posição de 12 horas, entre a banda posterior do disco e a cabeça do côndilo, tendo essa sido mantida em boca aberta. Diferentemente no paciente assintomático, o disco mostrou-se anterior à cabeça do côndilo (boca fechada) e recapturado na posição de boca aberta. Houve uma perfeita correlação entre artrografias e RMs.

KIRK; CHARLOTTE (1989) ${ }^{65}$ compararam 35 ATMs examinadas com tomografias axiais com suas respectivas RMs. A média de espaço articular no exame tomográfico diminuiu a medida que se constatavam deslocamentos de disco por meio das RMs. Das 25 ATMs diagnosticadas com DD nas RMs, apenas 14 articulações mostravam, nas tomografias, uma tendência de deslocamento condilar fora da normal concentricidade em MIH. Os pacientes que apresentavam DDSR foram os únicos a mostrar evidências de degenerações ósseas. 
Em outro estudo comparativo entre tomografias e ressonâncias magnéticas, KAMELCHUK et al. (1997) ${ }^{47}$ avaliaram 82 ATMs de 41 indivíduos assintomáticos, nas posições MIH e máxima abertura bucal, com a cabeça fixada a suportes. Verificaram que, a partir das RMs como referência (Gold Standard), o diagnóstico por meio de tomografias dos DDs obteve uma sensibilidade de 0,43, uma especificidade de 0,80, um valor prognóstico positivo de 0,64 e um valor prognóstico negativo de 0,63. Portanto, as tomografias foram inapropriadas para o diagnóstico dos DIs da ATM. As conclusões em relação à indicação das tomografias computadorizadas (visualização de anormalidades ósseas) confirmam-se mesmo em espécimes necropsiadas quando comparadas às RMs, já que estas demonstraram maiores detalhes dos tecidos moles da ATM, assim como dos limites do disco e seus ligamentos ${ }^{146}$.

Avaliando a confiabilidade das tomografias computadorizadas helicoidais em relação às RMs, HAYASHI et al. (1999) ${ }^{34}$ examinaram 188 ATMs de 94 pacientes. Apenas deslocamentos anterior, ântero-medial e ântero-lateral foram incluídos na avaliação, já que deslocamentos látero-lateral e látero-medial não são possíveis, devido aos pólos lateral e medial do côndilo não serem visíveis nas TCs. Utilizando as RMs como Gold Standard para a verificação da posição do disco articular, as tomografias obtiveram uma sensibilidade, especificidade e precisão de 91\%, $100 \%$ e 97\%, respectivamente para boca fechada e 96\%, 99\% e 98\%, respectivamente para boca aberta. A detecção de discos deslocados para anterior com boca aberta foi quase igual às imagens obtidas por RMs, o que viabilizaria a utilização destas tomografias na avaliação de DTMs. 
Numa comparação entre artrografias $(n=13)$, tomografias computadorizadas $(n=11)$ e achados cirúrgicos $(n=5)$, imagens obtidas por RMs ofereceram uma descrição precisa tanto de ATMs normais quanto com Disfunção. As ressonâncias ainda ofereceram informações sobre a posição, a morfologia e a histologia do disco articular que não eram possíveis de se visualizar em artrografias e TC's. Nos achados cirúrgicos, as alterações histológicas envolveram calcificações ocorridas no próprio disco e nos ligamentos posteriores. Caso uma calcificação ocorra, o disco perde a sua elasticidade e torna-se rígido. A capacidade de se determinar altos sinais advindos destas calcificações nas RMs pode ser útil em condições pré-operatórias ${ }^{52}$.

Numa revisão de 400 artigos publicados entre 1978 e 1994 sobre diagnóstico de imagens da posição do disco das ATMs, LIEDBERG et al. (1996) ${ }^{76}$ coletaram dados referentes a sensibilidade, especificidade, valores de prognóstico e razões de probabilidade. Este estudo consistiu de busca pelo Medline, averiguação de teses não indexadas no Medline e por verificações de citações dos artigos das duas etapas anteriores. Na década de 80, grande parte das publicações exploravam as artrografias e TCs, enquanto a década seguinte representou o marco das RMs. Baseado nos estudos encontrados, as RMs mostraram ser o método de escolha para diagnóstico da posição do disco articular.

\section{4- Correlação entre observações clínicas e ressonâncias magnéticas}

Diante das imagens obtidas, há a necessidade de correlacioná-las com as observações clínicas. KIRCOS et al. ${ }^{62}$ (1987), WESTESSON; BROOKS (1992) ${ }^{143}$, WESTESSON; ERIKSSON; KURITA (1989) ${ }^{145}$ verificaram que todo paciente com sintomatologia mostra anormalidades de imagens e, em alguns pacientes assintomáticos, há 
imagens de alterações morfológicas. A porcentagem de assintomáticos mostrando anormalidades articulares, nestes trabalhos, variou de 0 a $36 \%$ do total de indivíduos investigados. Em contrapartida, em uma avaliação de 115 pacientes sintomáticos através de RMs, PAESANI et al (1992) ${ }^{97}$ encontraram, em $78 \%$ dos casos, algum grau de DI, enquanto que, nos $22 \%$ restantes, as ATMs apresentavam-se morfologicamente normais. Segundo SUTTON et al. (1992) ${ }^{124}$, é provável que todas as ATMs produzam sons articulares durante os movimentos funcionais, podendo muitas vezes representar uma variação anatômica ao invés de um processo degenerativo ${ }^{61,62}$. WESTESSON (1993) ${ }^{141}$ afirmou que existem anormalidades tanto em pacientes sintomáticos quanto nos assintomáticos, mas concluiu que a frequiência das alterações é significativamente menor e menos severa nos últimos. Um similar achado foi descrito por CHOLITGUL et al. (1997) ${ }^{10}$ que constataram, a partir de exame clínico e RMs de 88 ATMs em 51 pacientes com sinais e sintomas de DD uni ou bilateral, que as alterações teciduais mais extensas e severas eram encontradas em pacientes com deslocamentos de disco para anterior.

De acordo com MORROW et al. (1996) ${ }^{86}$, a prevalência de deslocamentos de disco para anterior, examinados por RMs, foi maior em indivíduos sintomáticos. Tanto no grupo dos sintomáticos quanto nos assintomáticos com deslocamentos de disco para anterior, houve uma maior freqüência de outros problemas articulares - como por exemplo o joelho - quando comparados com os grupos assintomáticos com ATMs normais. Parentes dos indivíduos sintomáticos com DD para anterior possuíam duas vezes mais DTMs.

Com enfoque semelhante, RIBEIRO et al. (1997) ${ }^{103 \mathrm{~b}}$ acompanharam 56 pacientes assintomáticos e 181 indivíduos com DTMs, por meio de RMs em cortes sagitais (boca aberta e fechada) e coronais (boca fechada). Observaram que, no grupo assintomático, 28 
ATMs tinham discos deslocados (10 unilaterais e 9 bilaterais). Dos pacientes com DTMs, 25 apresentavam sintomas bilaterais, mas sem deslocamentos, 51 tinham DDs unilaterais e 105 possuíam deslocamentos bilaterais. A presença de DDs é relativamente comum em indivíduos assintomáticos (34\%) e está altamente associada a pacientes com DTMs (86\%)

Também mostrando uma maior prevalência de DD em indivíduos sintomáticos, KATZBERG et al. (1996) ${ }^{56}$, em avaliações com RMs, encontraram DDs em 25 das 76 (33\%) e em 79 das 102 (77\%) articulações estudadas, respectivamente em pacientes assintomáticos e sintomáticos. A forma anatômica dos discos entre os grupos não foi estatisticamente significante, embora tenha havido uma relação entre o bruxismo e ATMs com DDs, o que poderia explicar uma possível variação anatômica. Dados semelhantes foram encontrados por DAVANT et al (1993) ${ }^{17}$ que, através de RMs em plano sagital em 40 pacientes e 10 assintomáticos, observaram 75\% e 35\% de DDs respectivamente. DE LEEUW et al. (1995) ${ }^{21}$ estudaram 46 pacientes, 30 anos após terem sido inicialmente diagnosticadas com DIs, em planos sagitais (boca fechada e aberta) de 55 ATMs. O grupo controle consistiu de 15 ATMs em 10 voluntários, sem qualquer sinal e sintoma de DTMs. A posição do disco articular mantinha-se $90 \%$ deslocada para anterior, associada a uma configuração convexa ou contorcida do disco articular; enquanto que, no grupo controle, os discos apresentavam-se numa posição normal e forma bicôncava. HARMS et al. (1985) ${ }^{33}$ realizaram exames em 115 ATMs de 67 pacientes sintomáticos, constatando que 23 destas ATMs se encontravam normais. Por outro lado, alguns pacientes possuíam 1 ou mais diagnósticos. MILANO et al. (2000) ${ }^{81}$ verificaram que em $80 \%$ das articulações sintomáticas examinadas, o DD ocorreu bilateralmente, enquanto que em $15 \%$ unilateral e em apenas $5 \%$ os discos encontravam-se numa posição normal. O DD para anterior e a deformação biplanar foram os fenômenos mais freqüentemente encontrados, diferente dos 
deslocamentos puramente laterais ou mediais e deformação com alargamento da porção posterior do disco. As alterações da posição e morfologia do disco podem ser interpretadas como fatores predisponentes para o aumento de sinais e sintomas de DTMs ou como fatores que evoluam para a formação de degenerações articulares.

Avaliando 243 pacientes com sinais e sintomas de DTMs e 57 voluntários livres de sintomas, TASAKI et al (1996) ${ }^{135}$ constataram 10 categorias de classificação da posição do disco. Todos os pacientes foram submetidos a exames por RMs (boca aberta e fechada) das ATMs, baseado nos achados do exame clínico. Dois examinadores interpretaram as imagens separadamente e, em casos de diferenças quanto ao resultado, um diagnóstico consensual era estabelecido. Em 18\% dos indivíduos sintomáticos, o disco encontrava-se numa posição normal, enquanto que o mesmo achado havia sido diagnosticado em $70 \%$ do grupo controle.

O DD para anterior em indivíduos assintomáticos pode ser um fator predisponente para o estabelecimento de Disfunção na ATM ou simplesmente ser uma variação anatômica. Em estudo realizado com indivíduos assintomáticos, 32\% das articulações estavam com DD para anterior, sugerindo que fatores independentes de DOD ou agindo em combinação com este desarranjo podem causar DTM, tais como o recrutamento anormal dos músculos, variações da morfologia devido a idade, artrites ou outras condições degenerativas e variações morfológicas do disco devido a uma sobrecarga ${ }^{62}$.

Segundo MURAKAMI et al. (1993) ${ }^{85}$, apenas $13 \%$ dos DDs completamente para anterior foram reduzidos na posição de boca aberta, concluindo que quanto menor for o 
grau de DD, maior a freqüência de redução. Neste mesmo grupo, a maioria dos discos estava distorcida, deduzindo assim que este fenômeno ocorra após o deslocamento.

RAMMELSBERG; JÄGER; DUC (2000) ${ }^{101}$ mostraram, através de RMs, que pacientes com DDR tinham uma posição do côndilo mais posterior quando comparados com os grupos controle e de pacientes com DDSR. Os indivíduos com DDSR apresentaram uma redução significante dos espaços articulares anterior e posterior, levando o côndilo a assumir uma posição de concentricidade. Pacientes com DDR ou DDSR unilaterais demostraram uma maior variabilidade dos espaços articulares anterior e posterior, quando comparados com aqueles que possuíam deslocamentos bilaterais. Os diferentes estágios de DDs estão associados com variações significantes da posição condilar.

A prevalência de deslocamentos de disco em crianças e jovens tem sido estudada. Por meio de cortes sagitais em RMs, PAESANI et al. (1999) ${ }^{96}$ constataram, em 30 indivíduos com idade variando entre 2 meses a 5 anos e sedados com hidrato de cloro, que a posição do disco articular estava normal em todas as ATMs, portanto sugerindo que a posição do disco não representa uma variação anatômica congênita. Já em pacientes adolescentes pré-ortodônticos, a posição normal do disco tanto unilateral quanto bilateral foi mais prevalente no gênero masculino do que no feminino, assim como anterior e rotacional (preferencialmente ântero-medial), medial ou lateral e variações na morfologia foram mais freqüentes no gênero feminino ${ }^{90}$. Nas mulheres, observou-se a lassidão das articulações decorrente de alterações metabólicas e sugestiva do maior DD. 
O registro de DD para posterior é pouco documentado na literatura. WESTESSON; LARHEIN; TANAKA (1998) ${ }^{147}$ examinaram 35 ATMs com deslocamento posterior do disco e um grupo controle de 62 indivíduos assintomáticos, por meio de artrografias e RMs em cortes sagitais (boca aberta e fechada) e coronais (boca fechada). Em cortes sagitais da RM, imagens com baixos sinais na posição posterior à proeminência superior do côndilo devem ser interpretadas como deslocamento posterior do disco. Em compensação, nas artrografias, o deslocamento posterior do disco só pôde ser detectado quando o material de contraste foi injetado no interior dos espaços articulares superior e inferior. Não houve a presença de DD em quaisquer pacientes do grupo controle.

Muitos estudos abordaram a eficácia da técnica de movimentação mandibular na redução de discos deslocados na ATM 66, 67, 68. KURITA; KURASHIMA; OHTSUKA (1999) ${ }^{67}$, avaliando 79 ATMs em 74 pacientes com DDSR, verificaram que apenas $18 \%$ dos discos foram reduzidos através da técnica de manipulação. Isto provavelmente ocorreu devido aos pacientes se encontrarem em estágios avançados de DIs, onde o disco dificilmente é reduzido por causa da formação de fibrose capsular e adesão intracapsular. Estudando 30 ATMs com história de estalido recíproco, variando de 4 meses a mais de 5 anos, numa amostra de 18 pacientes, KIRK (1991) ${ }^{64}$ verificou que o reposicionamento do disco, com uso de placas protrusivas, foi visto em apenas 3 articulações, determinando que o conceito de recaptura do disco é um termo empregado somente clinicamente. Ainda com uso de placas protrusivas na tentativa de recaptura do disco, KURITA et al. (1998) 66 verificaram que, de acordo com avaliações clínicas, 75,6\% das 82 articulações obtiveram sucesso com o tratamento. Quando estes dados clínicos foram comparados com os resultados mostrados pelas RMs, a avaliação clínica alcançou uma precisão de 91,5\%, embora a incidência de falsos negativos tenha sido alta (40\%) e de falsos positivos no valor 
de 4,8\%. Em outro estudo posterior, KURITA et al. (1998) ${ }^{68}$ estudaram por RMs (cortes sagitais) 41 ATMs que tiveram o disco recapturado com o uso de placas protrusivas. Em 25 delas, os discos deslizaram na direção posterior, apesar da quantidade de movimento ter sido insignificante. Não só a utilização de placas de reposicionamento do disco articular, como também a promoção da estabilidade do disco recapturado, dependerão do restabelecimento da oclusão e da capacidade adaptativa da ATM. Acredita-se que uma oclusão estável deve ser oferecida ao paciente, após a utilização da terapia com placas, por meio de aparelhos ortodônticos, protéticos ou cirurgias. Utilizando aberturas incisais de 3 e $5 \mathrm{~mm}$ para placas oclusais, resultados foram variáveis quanto à movimentação intraarticular. De um total de 12 casos com placas de $3 \mathrm{~m}$ de abertura, o disco foi deslocado para posterior e superior em 3 casos, em 2 o complexo côndilo-disco moveu-se anterior e inferiormente e em 4 pacientes o disco não se moveu. Entretanto, o côndilo deslocou-se anterior, inferior ou posteriormente. Os 3 casos restantes, bem como aqueles nos quais utilizaram-se de placas de $5 \mathrm{~mm}$ de abertura, houve bastante variação no relacionamento côndilo-disco, sem tendência de deslocamento ${ }^{12}$.

De acordo com o trabalho de CHOI; YOO; LEE. (1994) ${ }^{9}$, após 3 a 4 meses de tratamento com placas protrusivas e fisioterapia em 10 ATMs (10 pacientes) com DDSR, periodicamente acompanhados com RMs, todos os pacientes obtiveram uma abertura bucal maior do que $47 \mathrm{~mm}$. Contudo, as imagens das RMs mostravam os discos deformados e ainda deslocados para anterior, sugerindo que o restabelecimento da abertura bucal não ocorre pela recaptura do disco, mas sim pela melhoria da mobilidade condilar e adaptação dos ligamentos posteriores. 
SATO et al (1999) ${ }^{113}$ estudaram, por meio de RM, ATMs de 21 pacientes com DDSR por meio de artrografias, sem receber qualquer tratamento durante 12 meses. Identificaram num intervalo de 12 a 80 meses, por meio de RMs, que os discos não foram recapturados sem algum tipo de intervenção, mas continuaram com o seu processo natural de deformação, embora os sinais e sintomas clínicos estivessem sido aliviados. Em outro estudo ${ }^{112}$, o mesmo grupo de autores avaliou novamente pacientes com DDSR por um período superior a 12 meses, após injeção de hialuronato de sódio no espaço articular superior. Os sinais e sintomas clínicos melhoraram durante o acompanhamento. Através de RMs, em todos os pacientes sintomáticos, o disco mostrava-se deslocado para anterior com boca fechada e não reduzido com boca aberta, além de apresentar diversas formas; enquanto que, em todos os indivíduos do grupo controle, os discos encontravam-se numa posição normal.

Vários estudos compararam a imagem por RM com a correspondente morfologia em espécimes necropsiadas 32, 54, 116, 137 .Um consenso nestes trabalhos tem mostrado a correlação entre imagens por RM e a morfologia dos cadáveres igual ou superior a $85 \%$.

A eficácia na identificação das estruturas anatômicas da ATM em espécimes necropsiadas, por meio de RM, tem sido investigada 16, 32, 54, 116, 146 . O emprego de cadáveres oferece a possibilidade de se fazer uma correlação com as patologias presentes de uma forma mais precisa, além de não haver movimentações da cabeça do paciente durante o processamento das imagens. Por outro lado, o processo de resfriamento ao qual é submetido o cadáver não está isento de deslocamentos de estruturas importantes no diagnóstico. 
Outra desvantagem é que geralmente não se consegue obter informações pertinentes sobre idade, sexo, ou possíveis condições clínicas sugestivas para o diagnóstico. A utilização de planos sagitais e angulados ou coronais e coronais angulados foi empregado por STEENKS; BLEYS; WITKAMP (1994) ${ }^{120,121}$, aplicando-se a mesma metodologia em ATMs necropsiadas de um indivíduo portador de dentaduras completas. A visualização de detalhes anatômicos e deslocamentos anterior, lateral e medial foi confirmada por fotografias e cortes seccionais, comprovando a precisão das imagens por ressonância magnética. É importante o registro de imagens tanto em plano sagital quanto coronal para que se obtenha uma correta avaliação das anormalidades ósseas e posição dos discos articulares. As imagens coronais, quando utilizadas sozinhas, proporcionavam diagnósticos corretos em torno de $77 \%$, enquanto que a adição de imagens sagitais aumentou para $86 \%$ o índice de acertos ${ }^{116}$.

Deslocamentos do disco lateral e medialmente são comuns e a utilização de mais de um plano para avaliação das imagens de RMs faz-se necessária para a identificação de alterações na ATM; os planos sagitais e coronais completam-se para a obtenção de um correto diagnóstico. Este conjunto de estudos, salientando os deslocamentos do disco também no sentido látero-medial, minimiza o número de falsos negativos e falsos positivos não percebidos em exames só com tomadas sagitais. Deslocamentos laterais e/ou mediais podem ocorrer sem necessariamente ter ocorrido um deslocamento anterior. Entretanto, deslocamentos ântero-mediais do disco parecem ser mais comuns do que os ântero-laterais, tanto em espécimes quanto em pacientes ${ }^{55}$. Resultados ainda mais expressivos, utilizando os planos sagital e coronal, foram encontrados por TASAKI; WESTESSON (1993) ${ }^{133}$ que obtiveram uma precisão de $95 \%$ na avaliação da posição e morfologia do disco e $93 \%$ para as alterações ósseas. As imagens no plano coronal evitaram falsos negativos em $13 \%$ das 
ATMs. A presença desses falsos negativos ocorreu devido a incapacidade das RMs em descrever os aspectos mais mediais e laterais da ATM. Dificuldades de interpretação em espécimes necropsiadas podem ocorrer tendo em vista que, estruturas teciduais diferentes produzem semelhantes sinais nas imagens das RMs. O tendão central do músculo pterigoídeo lateral pode parecer como uma extensão do disco, assim como a remodelação fibrocartilaginosa da superfície articular iniciada dentro de um disco perfurado apresenta a mesma imagem do tecido de um disco normal.

Ainda questionando a relação do côndilo-disco na ATM, pesquisadores sugerem que a posição do côndilo para posterior freqüentemente está associada com pacientes com DD. Outros autores afirmam não haver nenhum tipo de correlação. KURITA et al (2001) ${ }^{69}$ mostraram, a partir de imagens examinadas em RM de 231 ATMs, que quando o disco está levemente deslocado, o côndilo está deslocado mais para posterior. Entretanto, quando o DD está mais anterior, o côndilo tende a se posicionar mais concentricamente.

Alguns estudos abordam a importância das RMs na verificação dos achados patológicos de ATMs, incluindo os DDs ${ }^{114,} 127$. TAKAKU et al (1998) ${ }^{127}$, avaliando a utilidade de RMs na verificação da presença de DDs e da intensidade de sinais, antes da remoção cirúrgica, em 11 ATMs, confirmaram todos os casos de DDs, durante cirurgia. Também foram encontrados altos sinais de intensidade na banda posterior do disco e tecidos retrodiscais, respectivamente compatíveis com degenerações mixomatosas e alterações edematosas. SCHACH; SADOWSKY (1988) ${ }^{115}$ verificaram que o relacionamento côndilo-disco de indivíduos sintomáticos, sem história prévia de cirurgias na ATM, estava favorável em 90\% das ATMs examinadas, enquanto que as articulações que haviam sido submetidas a procedimentos cirúrgicos prévios ao exame mostraram 
maior número de artefatos de imagens e dificuldade de se diagnosticar os tecidos moles e sua relação com os outros tecidos ósseos. Contudo, tais artefatos podem ser deslocados, promover infecções ou gerar adesão entre as superfície articulares ${ }^{155}$. Poucos estudos têm sido acompanhados por RMs e conseqüentemente o efeito da reposição do disco. Após a remoção não tem tido uma comprovação efetiva. A maioria destes trabalhos tem registrado a presença da formação de um novo tecido entre a fossa e o côndilo, agindo como um pseudodisco com emissão de sinais de média a alta intensidade ${ }^{31,126,144}$.

Avaliação microscópica do tecido retrodiscal, removido de pacientes com DD em articulações dolorosas, mostrou a presença de fibrose, remodelação e hialinização das fibras de colágeno e uma alta densidade de fibroblastos, comparadas com ATMs normais 114. Nos deslocamentos de disco, tem sido observada uma diminuição de intensidade de sinais na região do tecido retrodiscal. WESTESSON; PAESANI (1993) ${ }^{149}$ compararam 69 pacientes com DD e 28 assintomáticos, por meio de RMs. As imagem foram obtidas nos planos coronal e sagital na posição de boca fechada e sagital de boca aberta. A diminuição de sinais no tecido retrodiscal foi observada em 16 indivíduos do grupo sintomático. Em contrapartida, nenhum paciente do grupo assintomático exibiu tais aspectos. Havendo uma relação entre estágios posteriores de deslocamentos de disco e diminuição de intensidade de sinais, não se pôde fazer qualquer associação com níveis de dor.

SANO E WESTESSON (1995) ${ }^{109}$ concluíram que a média de sinais $\mathrm{T}_{2}$ nas RMs de ATMs, advindos do tecido retrodiscal, é maior em pacientes com sintomatologia dolorosa do que em indivíduos assintomáticos, o que pode ser explicado pelo aumento da vascularização na região. 
WESTESSON; BROOKS (1992) ${ }^{143}$ avaliaram 379 pacientes com sintomas de DTMs e 11 voluntários assintomáticos, através de imagens T1 e T2, em cortes sagitais e coronais. Os resultados mostraram que efusão articular primariamente ocorreu em ATMs com discos deslocados (40\% em DDR e 50\% em DDSR) e sua ocorrência foi fortemente associada com a presença de dores nas articulações.

ADAME et al. (1998) ${ }^{1}$ examinaram 111 pacientes, num total de 123 ATMs, com diagnóstico de efusão articular oferecido por RMs. O grupo controle constituiu de 31 pacientes (46 ATMs) com patologias articulares, mas sem efusão. Uma imagem de efusão foi definida como sinais de alta intensidade em pelo menos dois consecutivos cortes sagitais em T2. Os resultados sugeriram que efusão articular está vinculada a degenerações articulares da ATM (osteófitos, necroses vasculares e osteocondrites) e pouco relacionada a dores na ATM.

Um dos grandes desafios de qualquer recurso diagnóstico é a concordância entre os examinadores em especial para a verificação da posição do disco articular. O que constitui um leve deslocamento, para um examinador, pode representar uma posição normal, para um segundo observador. A calibração dos observadores, através de discussões coletivas de como interpretar as imagens de acordo com os critérios estabelecidos, pode influenciar significativamente a avaliação de uma doença. É sabido que a concordância interexaminador diminui a medida que aumenta o número de observadores ${ }^{98}$. A utilização de pares de observadores (A-B/A-C/B-C) para testar a variabilidade inter-examinador pode produzir resultados bastante satisfatórios $93,94,95$. 
Observadores que nunca haviam trabalhado juntos anteriormente avaliaram 70 ATMs de adolescentes, por meio de RMs em cortes sagitais e coronais. Um total de 10 RMs foram utilizadas para calibração inicial dos examinadores. Após padronização da classificação do disco e baseado no teste estatístico Kappa, observou-se, nas 60 RMs, moderada concordância entre os examinadores na visualização de discos deslocados medial e lateralmente (respectivamente 0,486-0,622 e 0,450-0,566), enquanto que para DDSR foi verificada uma concordância significativa $(K=0,914){ }^{88}$. Em outro estudo subseqüente ${ }^{89}$, foram utilizados quatro examinadores para a avaliação de 57 RMs de ATMs de adolescentes. Após análise quantitativa, o coeficiente de correlação foi de 0,681 para extensão do disco e 0,830 para deslocamento.

TASAKI; WESTESSON; RAUBERTAS (1993) ${ }^{137}$ obtiveram imagens de 149 ATMs por meio de RMs. As imagens foram analisadas em intervalos de 2 a 4 semanas, posteriormente a uma calibração prévia. A concordância intra-examinador para posição do disco, configuração e variações ósseas foi de 95\%, 90\% e $89 \%$ respectivamente, enquanto que a concordância inter-examinador para os mesmos critérios foi de $90 \%, 89 \%$ e $94 \%$ respectivamente. Alta qualidade de imagens, calibração e critérios de interpretação bem definidos foram os principais aspectos para que haja uma boa correlação entre os examinadores.

Combinando análises intra e inter-examinadores, ORSINI et al (1997) 95 constataram, após uma interpretação inicial intra-examinadora de RMs em 20 pacientes (boca aberta - imagem sagital, e boca fechada - imagens sagital e coronal), um aumento da frequiência de concordância inter-examinador (3 examinadores) em relação à posição do 
disco articular. Contudo, mesmo após reunião para consenso das dúvidas de diagnóstico, foram observadas variações sensíveis quanto à configuração do disco.

A posição do disco vem sendo bastante estudada e, por isso, uma avaliação criteriosa em pacientes desdentados totais torna-se imperiosa, objetivando o conhecimento mais aprofundado desses achados. 
3- PROPOSIÇÕES

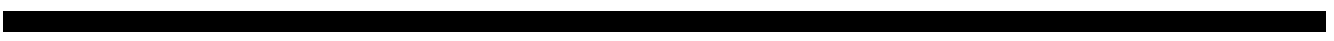




\section{PROPOSIÇÕES}

Baseado nos questionamentos quanto aos componentes da ATM, os objetivos deste trabalho, utilizando RMs, em pacientes portadores de sons articulares (experimental) e pacientes sem sons articulares (controle), usuários de Próteses Totais (PTs) duplas foram:

(1) Avaliar a posição do disco nos pacientes desdentados totais;

(2) Verificar se houve ou não recaptura do disco na posição de boca aberta;

(3) Correlacionar as posições dos discos encontradas com os sinais obtidos por exame clínico e,

(4) Descrever a intensidade de sinais, as alterações ósseas, a morfologia dos discos articulares e o nível de translação condilar 
4- MATERIAL E MÉTODOS

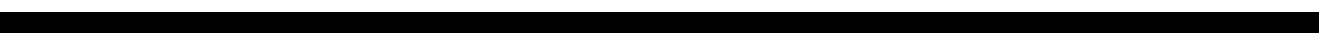




\section{MATERIAL E MÉTODOS}

- Seleção da amostra

Para a realização deste trabalho, um total de 25 pacientes foram selecionados na clínica de Prótese Total, do Departamento de Prótese Dentária, da Faculdade de Odontologia de Bauru, Universidade de São Paulo. Dois grupos constituíram a amostra: o primeiro com 15 pacientes apresentando clinicamente sinais de sons articulares detectados por meio de inspeção manual da ATM e, num segundo grupo, 10 pacientes livres de quaisquer sons articulares (grupo controle). Ambos grupos eram assintomáticos para a presença de dor. A seleção da amostra foi feita no período de agosto de 2000 a junho de 2001.

Para a seleção dos grupos de trabalho, os seguintes critérios foram estabelecidos:

a) Nenhum paciente deveria ter história prévia de tratamento com disfunção;

b) Os pacientes selecionados deviam fazer uso dos pares de dentadura, sem levar em consideração o seu tempo de uso;

c) Todos os pacientes deveriam ter uma abertura bucal mínima de $35 \mathrm{~mm}$ conforme estabelecido por TAKAKU; SANO; YOSHIDA (2000) ${ }^{126}$ e YOSHIDA et al. $(2000)^{156 ;}$

d) O grupo controle não apresentava sinais de ruídos articulares à palpação;

e) Nenhum paciente que tinha indicação para prótese imediata foi selecionado. 
- Anamnese e avaliação clínica dos pacientes

Houve a realização de um exame clínico, dividido em exame físico e anamnese. Os pacientes foram submetidos por um examinador, previamente calibrado, (examinador 1) a um questionário sobre abordagens anamnésicas, a um exame físico dividido em avaliação da ATM e exame muscular (anexo 1), e a um exame de Ressonância Magnética. Tais exames foram realizados por um examinador que não teve participação na interpretação das imagens por RM. Houve a preocupação de não induzir nenhum tipo de resposta pelos pacientes. Todos os pacientes ficaram cientes de que foram avaliados não só para o tratamento protético, como também com finalidade de pesquisa. O trabalho foi submetido à Comissão de Ética e aprovado sem restrições (Anexo 3).

A verificação do rangimento entre dentes foi avaliada, pelo examinador 1 , por meio de questionamento direto ao paciente sobre o hábito ou subjetivamente por meio da observação da condição dos dentes artificiais da dentadura em relação ao tempo de uso.

Para a determinação da máxima abertura bucal e dos movimentos laterais protrusivos, o examinador 1 utilizou-se de uma régua plástica graduada em milímetros, mensurando a distância entre as bordas incisais dos incisivos superiores e inferiores.

- Análise dos ruídos articulares da ATM

Foi pedido a todos pacientes que realizassem o movimento de máxima abertura bucal por 3 vezes consecutivas enquanto o examinador 1 registrava os sons articulares. Se o som estava presente em dois dos movimentos de abertura e fechamento, registrou-se como um achado positivo, de acordo com o que foi preconizado por ORSINI et al 
$(1998,1999){ }^{93,94}$. Se este som possuísse características semelhantes a pedras de cascalho atritando-se, considerou-se como som de crepitação. Considerou-se estalido simples na presença de um único som em abertura ou fechamento e havia estalido recíproco quando detectava-se o som em abertura e fechamento.

A percepção clínica de hipermobilidade foi baseada nos conceitos de PERTES; GROSS (1995) ${ }^{100}$ que descreveram a presença de uma depressão pré-auricular, associada a um salto lateral dos côndilos em abertura máxima, independente do grau de abertura bucal.

- Palpação da ATM

Para esta avaliação da ATM, foi utilizada a palpação digital bilateral pelo examinador 1 com uma carga de aproximadamente 450 a 900 gramas, com os dedos indicadores colocados 10 a 20mm à frente do conduto auditivo externo, solicitando-se aos pacientes que realizassem movimentos de abertura e fechamento ${ }^{100}$. Inicialmente, os pacientes foram instruídos quanto à diferença entre pressão e desconforto, para que se eliminassem as dúvidas quanto às respostas. Realizou-se a palpação da ATM com boca fechada (aspecto lateral) e boca aberta (aspecto posterior), sendo determinados os seguintes valores de avaliação: 0 - ausência de sensibilidade à palpação, 1 - sensibilidade leve, 2 sensibilidade moderada e 3 - sensibilidade severa. 
- Palpação muscular

Os pacientes foram também submetidos, pelo examinador 1, à palpação muscular bilateral, exercendo pressão firme com os dedos, porém de forma suave. Manteve-se uma pressão constante de aproximadamente 1500 gramas ${ }^{14}$. A sensação dolorosa, por meio do reflexo palpebral, após informar ao paciente a diferença entre dor e pressão, foi classificada em 0 - ausente, 1 - leve, 2 moderada e 3 - forte ${ }^{100}$. Os músculos avaliados foram os masséteres superficial e profundo, os temporais, os digástricos, os trapézios e os esternocleidomastoídeos.

- Ressonância Magnética

Todas as imagens foram realizadas no serviço de RM do Centro de Diagnóstico de Imagem, em Bauru-SP, através do aparelho Flexart da Toshiba com potência regulada para 0,5 Tesla. A seqüência empregada foi a parassagital oblíqua, ponderada em T1 com cortes de espessura de 3mm e "gap" de $0,3 \mathrm{~mm}$.

O equipamento possui bobinas próprias para ATM e o filme utilizado foi o Ektascan 100 IK da Kodak com dimensões de 35 x 43cm (as imagens foram gravadas em fita magnética). A sequiência foi registrada em T1 com valores de 490 para TR, 15 para TE, 90/180 para F4, 2,2 para NAQ e 12,0 x 12,0cm para FOV, enquanto que para T2* o TR foi de 400, um TE igual a 20, 25 para F4, NAQ de 4 e FOV de 12,0 x 12,0cm. Foram registradas tomadas de boca fechada em cortes sagitais (T1 e $\mathrm{T} 2 *$ ) e cortes coronais (T1), bem como tomadas de boca aberta em cortes sagitais (T1 e T2*). O tempo para captação das imagens sagitais $\mathrm{T} 1$ e $\mathrm{T} 2 *$ foi de 6 ' 30".e 5'08', respectivamente, enquanto para as 
imagens coronais foi de 6'20". Inicialmente, localizadores axiais foram usados para estabelecer um plano sagital de orientação em relação ao longo eixo do côndilo. Posteriormente, para a captação das imagens sagitais e coronais, planos perpendiculares e paralelos ao longo eixo dos côndilos foram incididos respectivamente, mostrando uma orientação oblíqua para a obtenção das imagens. Não houve a impressão dos planos de cortes axiais na avaliação dos resultados, o que facilitaria a checagem do paralelismo.

A manutenção da boca aberta foi determinada pela interposição, entre as dentaduras, de silicona por condensação da marca Optosil. A RM permitiu a visualização precisa dos discos articulares. Todas as tomadas de imagem foram realizadas no mesmo equipamento, por uma única profissional da área médica devidamente instruída quanto à necessidade de visualização da cavidade articular, e foram diretamente acompanhadas pelo examinador 1. Após os exames terminados, foram selecionados os 3 melhores cortes de cada tomada, uma central, uma medial e outra lateral, tanto para boca aberta quanto para boca fechada.

- Análise das imagens obtidas por RM

As imagens foram avaliadas por um único examinador Cirurgião-Dentista (examinador 2) previamente calibrado, com treinamento avançado em DTM. Os parâmetros avaliados pelo examinador foram: posição e redução do disco articular; morfologia do disco, alteração de sinais, alterações ósseas e mobilidade condilar.

A presença de concavidades, erosão e/ou osteófitos no côndilo, na fossa mandibular e/ou na eminência articular de cada articulação foi considerada doença ósseo-degenerativa 
(DOD). A aparência achatada ou aplainada (sem irregularidades no córtex) dos componentes ósseos da articulação ou alterações morfológicas simétricas foram classificadas como remodelação óssea ${ }^{103 b}$.

As alterações de sinais nas RMs são perceptíveis devido a alterações vasculares por inflamação, edema intra-articular, degenerações do disco, podendo resultar em diagnósticos diferenciados do normal. A presença de sinais nos espaços articulares foi descrita quando pelo menos um dos espaços estava envolvido. Foram consideradas como alterações de sinais, a redução destes em T1 (R1) e em T2* (R2), bem como a sua intensificação em T1 (I1) e em T2* (I2).

A posição condilar em boca aberta foi dividida em estágios: ausência da translação condilar (valor 0); translação aquém da eminência ou hipomobilidade (valor 1); translação ao nível da eminência (valor 2) e translação além do ápice da eminência articular denominada hipermobilidade (valor 3).

A partir desta metodologia empregada, a relação côndilo-disco, assim como o contorno ósseo, foram utilizados para classificar os pacientes como: normal $(\mathrm{N})$, com deslocamento do disco com redução (DDR), com deslocamento do disco sem redução (DDSR), e/ou com doença ósseo degenerativa (DOD). A posição anatômica será classificada como superior (Normal), DD total anterior, DD parcial anterior no $1 / 3$ lateral da articulação e DD parcial anterior no 1/3 medial da articulação, DD ântero-lateral, DD ântero-medial, DD lateral, DD medial e DD posterior ${ }^{132}$. De acordo com o preconizado por TASAKI (1993) ${ }^{132}$, quando o disco estava deslocado na posição de boca fechada e retornou à posição normal (superior) sobre o côndilo, em boca aberta, os pacientes foram 
classificados como portadores de DDR. Quando o disco permaneceu deslocado em relação à cabeça do côndilo na posição de boca aberta, os pacientes foram classificados como portadores de DDSR. Portanto, no caso de DD, deu-se o diagnóstico de recaptura do disco ou não (Figura 14).

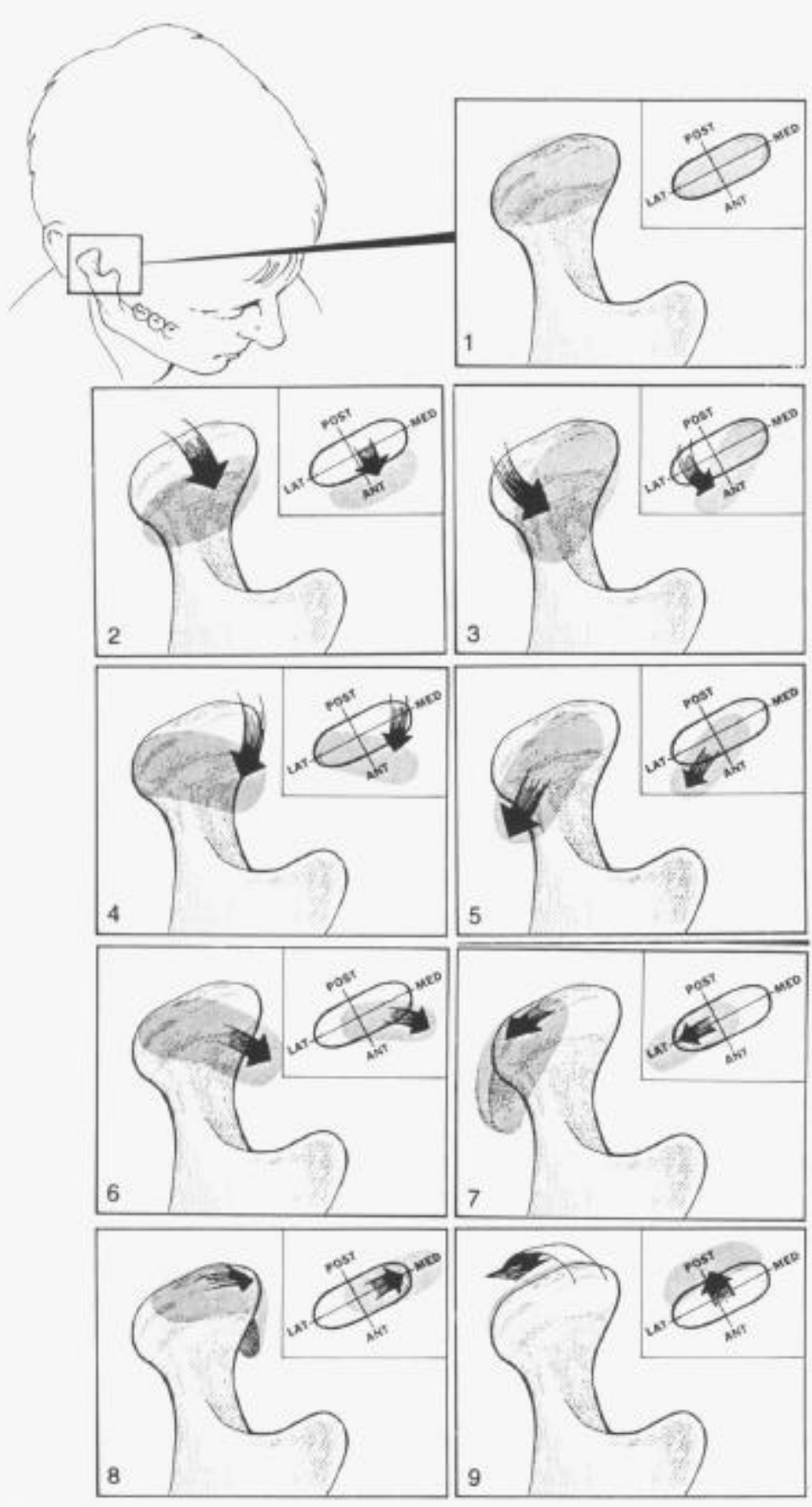

FIGURA 14 - Posições do disco articular segundo TASAKI et al ${ }^{132}$. 1- Posição superior; 2- DD anterior; 3- DD parcial anterior no terço lateral da ATM; 4- DD parcial anterior no terço medial da ATM; 5- DD ântero-lateral; 6- DD ântero-medial; 7- DD lateral; 8- DD medial; 9- DD posterior 
As imagens coronais foram empregadas objetivando-se complementar a posição do disco articular. Neste plano, o disco foi classificado como superior, medial ou lateral (Figura 15).

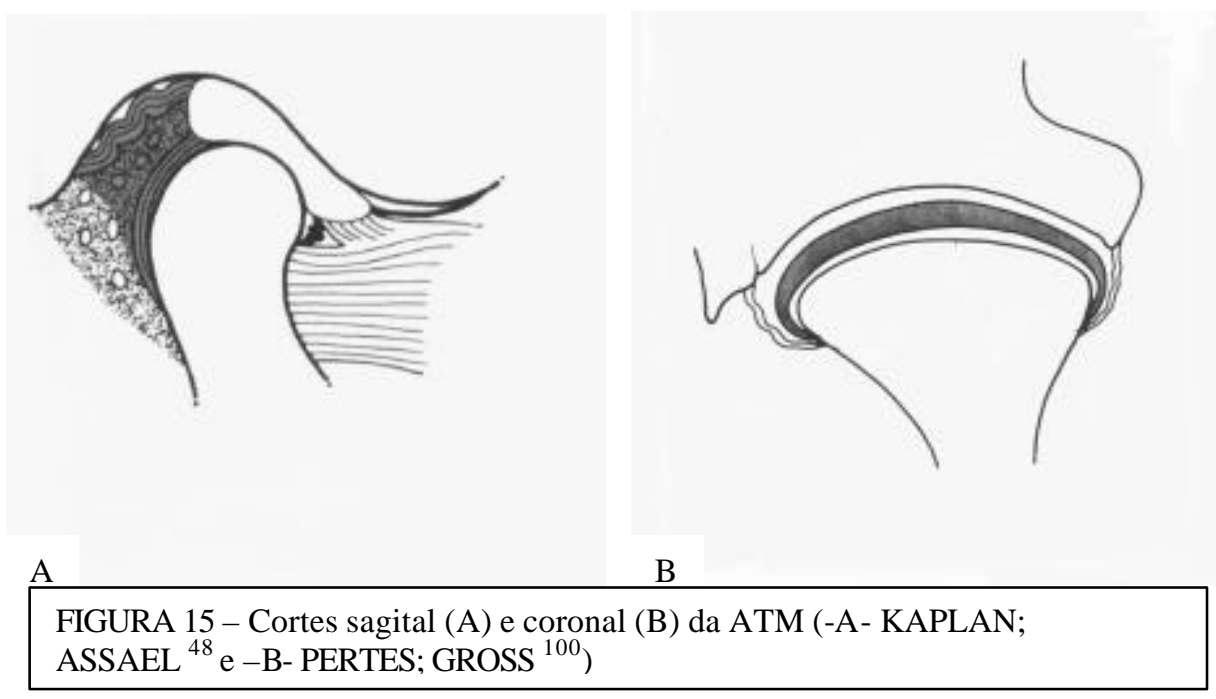

A morfologia do disco foi avaliada nas articulações com ou sem DD e/ou DOD, na posição de boca aberta e boca fechada. O disco bicôncavo foi considerado como forma normal. O aumento ou deformação das bandas do disco (biconvexo ou biplanar) também foi avaliado. Uma classificação indeterminada foi usada para classificar todos os discos que não poderiam ser classificados como nenhum dos acima citados. O protocolo de avaliação dos exames das RMs está demonstrado no Anexo 2.

- Análise estatística

A análise estatística foi baseada em métodos descritivos com valores absolutos e relativos. Para a comparação entre os grupos controle e experimental, foram utilizados os testes de Fisher e Qui-quadrado, adotando-se nível de significância de 5\%. 


\section{RESULTADOS}

A idade dos pacientes selecionados variou de 41 a 81 anos, com média de 62,08 anos. Não houve valores estatisticamente significantes ( $\mathrm{p}=0,8842$; Spearman $=0,030)$ de porcentagem de ocorrência de DD em um determinado grupo etário ou gênero $(\mathrm{p}=0,4382$; $\chi^{2}=1,649$ ), apesar de ter havido uma maior porcentagem de DD em pelo menos uma das ATMs nas mulheres $(86,66 \%)$ do que nos homens (70\%) (Tabela 1).

\begin{tabular}{|c|c|c|c|c|c|c|c|c|c|c|c|c|c|c|c|c|c|c|c|c|c|c|c|c|c|c|}
\hline & Idade & 78 & 46 & 42 & 79 & 41 & 55 & 65 & 76 & 74 & 53 & 72 & 81 & 52 & 45 & 62 & 57 & 62 & 71 & 68 & 46 & 49 & 65 & 73 & 80 & 60 \\
\hline \multirow[t]{2}{*}{ Homem } & DD & & & & & & & 1 & 1 & & & & 2 & & 1 & & 2 & & & & & 2 & & & 1 & \\
\hline & Normal & & & & & 2 & 2 & 1 & 1 & & & & & & 1 & & & & 2 & & & & & & 1 & \\
\hline \multirow[t]{2}{*}{ Mulher } & DD & 1 & 2 & 2 & 2 & & & & & 2 & 2 & 1 & & 2 & & 1 & & 1 & & & 1 & & 2 & 2 & & \\
\hline & Normal & 1 & & & & & & & & & & 1 & & & & 1 & & 1 & & 2 & 1 & & & & & 2 \\
\hline
\end{tabular}

Tabela 1- Número de articulações com DD nas RMs em relação ao gênero e a idade

A ocorrência de intensidade de sinais em $\mathrm{T} 2 *$ advindos dos espaços articulares superior e inferior era semelhante tanto em articulações com sons articulares quanto no grupo controle. Não foi possível fazer uma correlação estatística significativa ( $p=0,743$; $\chi^{2}=0,743$ ) entre o aumento de sinais dos espaços articulares e o diagnóstico da posição do disco (Tabela 2). Observou-se uma intensificação de sinais em 26 (86,66\%) das 30 articulações com DD (DDR e DDSR), enquanto que em 16 (80\%) das 20 articulações sem deslocamento do disco também foram encontrados valores significativos de aumento de sinais. As articulações diagnosticadas com aumento de sinais não tinham escores altos à palpação, tanto no aspecto posterior, quanto lateral da ATM.

Não houve também uma diferença estatisticamente significante quanto à intensidade ou redução de sinais do disco articular $\left(p=0,236, \chi^{2}=1,40\right.$ para $I 1 ; p=0,133$, $\chi^{2}=2,26$ para $\mathrm{I} 2 ; \mathrm{p}=0,400$ para $\left.\mathrm{R} 2\right)$, espaços articulares $(\mathrm{p}=1,000$ para $\mathrm{I} 2)$ e região medular 
do côndilo ( $\mathrm{p}=$ 0,289 para $\mathrm{R} 1 ; \mathrm{p}=0,265$ para $\mathrm{R} 2 ; \mathrm{p}=0,130$ para $\mathrm{I} 2$ ), ao se comparar pacientes com sons articulares com o grupo controle (Tabela 3).

\begin{tabular}{|l|l|l|}
\hline Deslocamento do disco & No $^{\text {o de articulações }}$ & No de ATMs c/ aumento de sinais \\
\hline Superior & 20 & 16 \\
\hline DDR & 25 & 22 \\
\hline DDSR & 5 & 4 \\
\hline
\end{tabular}

Tabela 2- Número de articulações, com posição superior do disco ou com deslocamentos do disco, que apresentavam intensificação de sinais

\begin{tabular}{|l|l|l|l|l|l|l|l|l|l|l|l|l|}
\hline \multirow{2}{*}{ Grupos } & \multicolumn{4}{|c|}{ Disco } & \multicolumn{4}{c|}{ Côndilo } & \multicolumn{3}{c|}{ Espaços Articulares } \\
\cline { 2 - 12 } & R1 & I1 & R2 & I2 & R1 & I1 & R2 & I2 & R1 & I1 & R2 & I2 \\
\hline Experimental & 0 & 24 & 0 & 13 & 1 & 0 & 3 & 3 & 0 & 0 & 0 & 25 \\
\hline Controle & 0 & 13 & 1 & 13 & 3 & 0 & 0 & 6 & 0 & 0 & 0 & 17 \\
\hline
\end{tabular}

Tabela 3- Número de articulações que apresentavam intensidade

e redução de sinais nas diferentes estruturas anatômicas, nos grupos experimental e controle

Verificou-se uma translação condilar ao nível da eminência articular em 21 ATMs (42\%); nas demais articulações, foi observada uma translação além da eminência em 7 (14\%) ATMs e aquém da eminência em 19 (38\%) articulações. Em 3 ATMs (6\%), não houve translação condilar. Não se observou uma tendência para um determinado DD, quando havia uma translação condilar, verificando-se uma relação estatisticamente insignificante entre a ocorrência de translação condilar e de DD $\left(p=0,511 ; \chi^{2}=5,26\right)$ (Tabela 4). 


\begin{tabular}{|c|c|c|c|}
\hline \multirow[t]{2}{*}{ Translação condilar } & \multicolumn{3}{|c|}{ Deslocamento do disco } \\
\hline & Superior & DDR & DDSR \\
\hline Ausência & 2 & 1 & 0 \\
\hline Aquém da eminência & 9 & 9 & 1 \\
\hline Ao nível da eminência & 7 & 10 & 4 \\
\hline Além da eminência & 2 & 5 & 0 \\
\hline
\end{tabular}

Tabela 4- Número de articulações, com posição superior do disco ou com deslocamentos do disco, que apresentavam ou não diferentes translações condilares

A morfologia do disco foi diagnosticada nas imagens de boca aberta. Nos pacientes do grupo controle, foram consideradas normais ou bicôncavas 11 (55\%) articulações, sendo que nas outras 9 (45\%) houve uma forma biconvexa ou indeterminada. Já no grupo experimental, a configuração do disco teve a seguinte distribuição: 17 (56,66\%) normais, $12(40 \%)$ biconvexos ou biplanares e 1 (3,33\%) indeterminado (Figura 16). Não se verificou uma relação estatisticamente significante entre as morfologias do disco e o grupo no qual o paciente se encontrava $\left(p=0,615 ; \chi^{2}=0,97\right)$.

$\mathrm{Na}$ análise das diferentes morfologias do disco separadamente e sua relação com o DD, apenas foi possível observar valor significativamente diferente quando os discos eram biconvexos ou biplanares, ou seja, a grande maioria deles (13) apresentava DDR ( $\mathrm{p}=0,022$; $\left.\chi^{2}=11,43\right)$. Entretanto, observaram-se também ATMs com DDR sem alterações da sua configuração (12) (Tabela 5). Não houve associação da deformidade do disco com degeneração condilar ou com a emissão de altos sinais. 


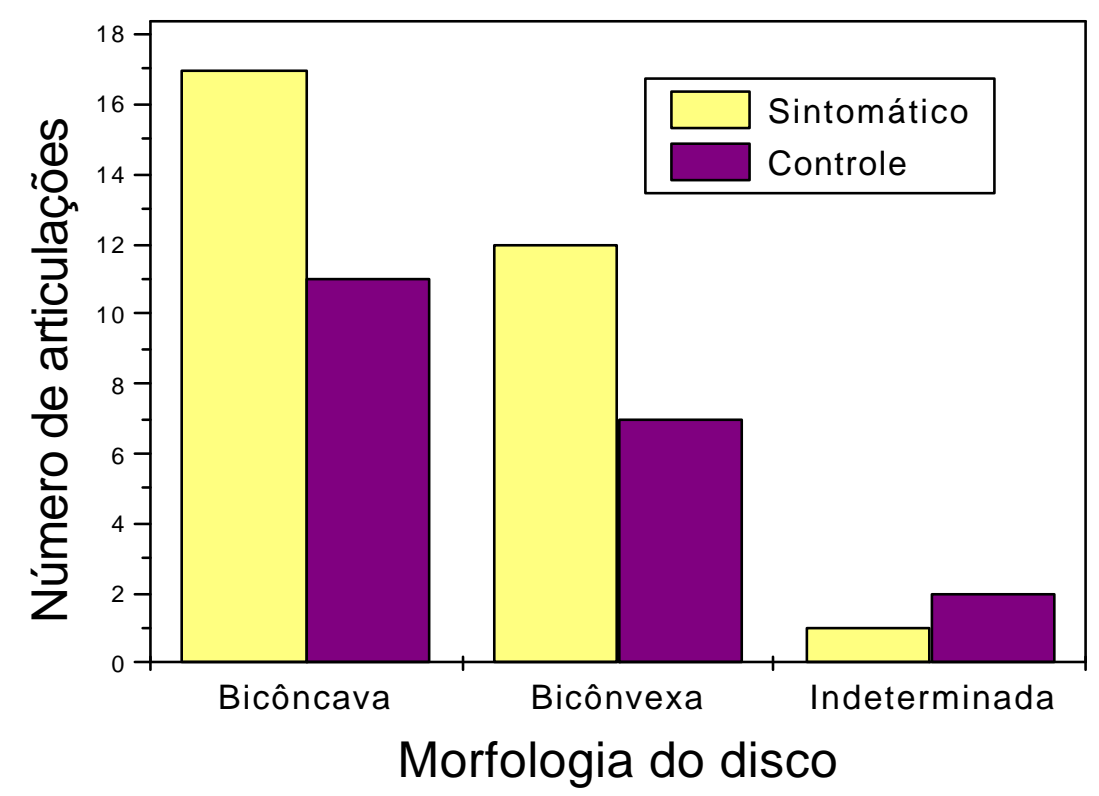

Figura 16- Número de articulações apresentando diferentes morfologias do disco, nos grupos controle e experimental

\begin{tabular}{|c|c|c|c|}
\hline \multirow[t]{2}{*}{ Morfologia do disco } & \multicolumn{3}{|c|}{ Deslocamento do disco } \\
\hline & Superior & DDR & DDSR \\
\hline Normal & 15 & 12 & 1 \\
\hline Biconvexa & 3 & 13 & 3 \\
\hline Indeterminada & 2 & 0 & 1 \\
\hline
\end{tabular}

Tabela 5- Número de articulações, com posição superior do disco ou com deslocamentos do disco, que apresentavam as diferentes morfologias do disco

Através dos cortes sagitais, foi possível identificar 16 (32\%) articulações com algum grau de DOD, sendo a maioria localizada nos côndilos dos pacientes experimentals (8). Os números de ATMs normais e com remodelação óssea foram proporcionais em ambos os grupos. Não houve uma maior prevalência de algum tipo de alteração óssea 
analisada entre os 2 grupos $\left(p=0,234, \chi^{2}=2,91\right.$ para a eminência; $p=0,396, \chi^{2}=1,85$ para a fossa; $\mathrm{p}=0,370 ; \chi^{2}=1,99$ para a região medular do côndilo) (Tabela 6).

\begin{tabular}{|l|l|l|l|l|l|l|}
\hline \multirow{3}{*}{ Estruturas } & \multicolumn{5}{|c|}{ Alterações ósseas } \\
\cline { 2 - 8 } & \multicolumn{5}{|c|}{ Controle } & \multicolumn{3}{c|}{ Experimental } \\
\cline { 2 - 8 } & Normal & Remodelado & DOD & Normal & Remodelado & DOD \\
\hline Eminência & 15 & 5 & 0 & 17 & 10 & 3 \\
\hline Fossa & 16 & 4 & 0 & 20 & 8 & 2 \\
\hline Côndilo & 3 & 14 & 3 & 7 & 15 & 8 \\
\hline
\end{tabular}

Tabela 6- Número de articulações normais, remodeladas e com degenerações ósseo-articulares presentes em diferentes estruturas anatômicas, nos grupos controle e experimental

O resultado da análise de 50 ATMs mostrou que o critério de classificação utilizado foi capaz de determinar a correta posição do disco. A frequiência de pacientes com DD, unilateral, foi semelhante entre os grupos controle e experimental, não havendo diferenças estatísticas relevantes $\left(\mathrm{p}=0,231 ; \chi^{2}=2,93\right)$. Observou-se uma tendência de DD bilaterais em articulações sintomáticas (9) (Figura 17). 


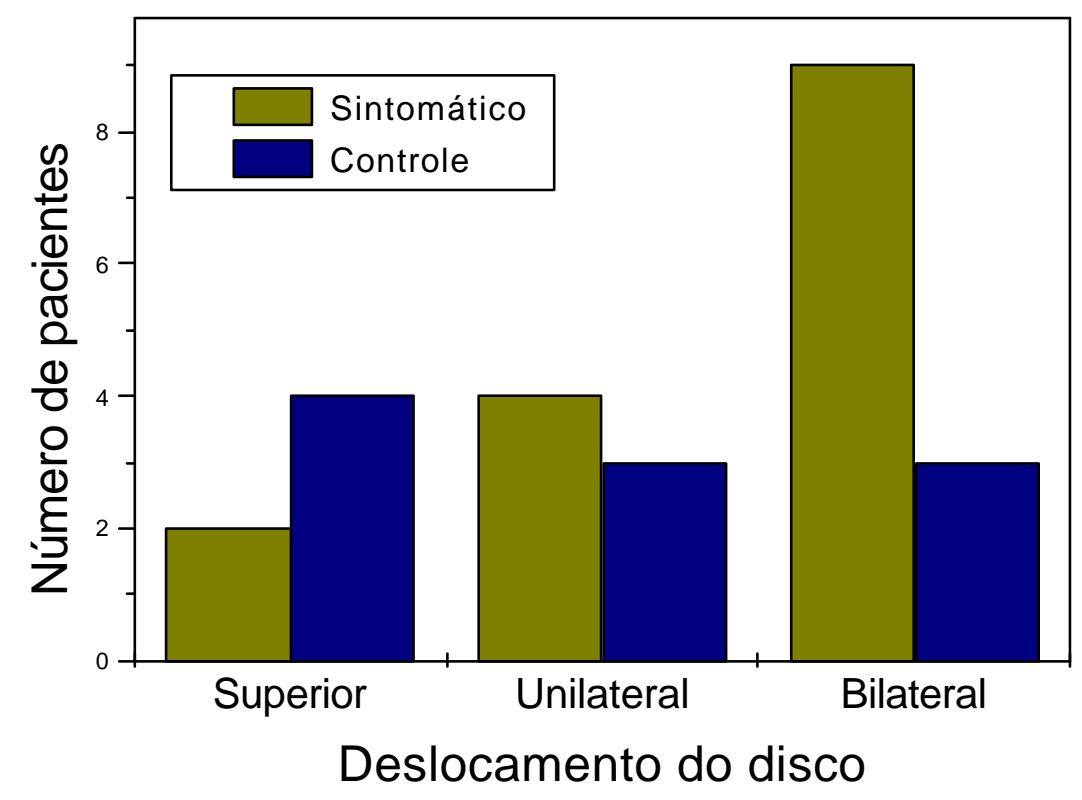

Figura 17- Número de pacientes com diferentes posições do disco, nos grupos controle e experimental

A distribuição dos diversos tipos de DD e achados clínicos estão apresentados na tabela 7. O estalido articular foi o achado clínico mais comum (18 ATMs), comparado com a crepitação e a hipermobilidade (6 ATMs cada). Um total de 9 pacientes apresentavam leve grau de sensibilidade à palpação da ATM, sendo que 3 destes bilateralmente. Apenas em 3 indivíduos, foi registrada uma maior sensibilidade da ATM à palpação. Esta sensibilidade não foi relacionada ao tipo de DD e à intensificação de sinais. Os pacientes possuíam uma máxima abertura bucal com média de 47,8mm, variando de 37 a 66mm, enquanto a média dos movimentos excursivos mandibulares (protrusão, lateralidade direita e esquerda) oscilou entre 4 e $11 \mathrm{~mm}$, com média de $6,05 \mathrm{~mm}$. Houve uma perda média da máxima abertura bucal de 2,8mm após a inserção da silicona de condensação. Não foi avaliado o momento do estalido articular. Apenas 4 pacientes apresentavam rangimento. A maioria dos pacientes (18) não retirava as próteses para dormir. Nove pacientes relataram tempo de uso, do último par de PTs, de 10 a 20 anos. 
Observou-se que, das 18 ATMs que apresentavam estalidos articulares, 4 (22,2\%) possuíam o disco em uma posição normal. Por outro lado, em 9 (45\%) ATMs assintomáticas, foi detectada a presença de sinais de DD (Figura 18). A relação dos pacientes diagnosticados clinicamente com hipermobilidade mostrou que 3 (50\%) articulações estavam com DDR e outras 3 (50\%) possuíam o disco em uma posição normal. O exame clínico não obteve uma correlação estatisticamente significante com as imagens obtidas por RM ( $\left.\mathrm{p}=0,248 ; \chi^{2}=7,86\right)$. De um total de 30 ATMs estudadas no grupo experimental, $19(63,33 \%)$ apresentavam DDR após a abertura bucal. Diferentemente, em outras $2(6,66 \%)$ ATMs, o disco permaneceu deslocado para anterior na máxima abertura bucal. O disco permaneceu estável, tanto em fechamento quanto em abertura bucal, em 9 (30\%) ATMs sintomáticas. No grupo controle, os valores foram os seguintes: em 11 (55\%) ATMs havia um relacionamento superior do disco, em 6 (30\%) ocorreu um DDR e nas outras $3(15 \%)$ houve um DDSR (Tabela 7).

\begin{tabular}{|l|l|l|l|l|}
\hline \multirow{2}{*}{ disco } & \multicolumn{4}{|l|}{} \\
\cline { 2 - 6 } & Sem som & Estalido & Crepitação & Hipermobilidade \\
\hline Normal & 11 & 4 & 2 & 3 \\
\hline DDR & 6 & 13 & 3 & 3 \\
\hline DDSR & 3 & 1 & 1 & 0 \\
\hline
\end{tabular}

Tabela 7 - Número de articulações com achados clínicos positivos e negativos em relação ao deslocamento do disco. 


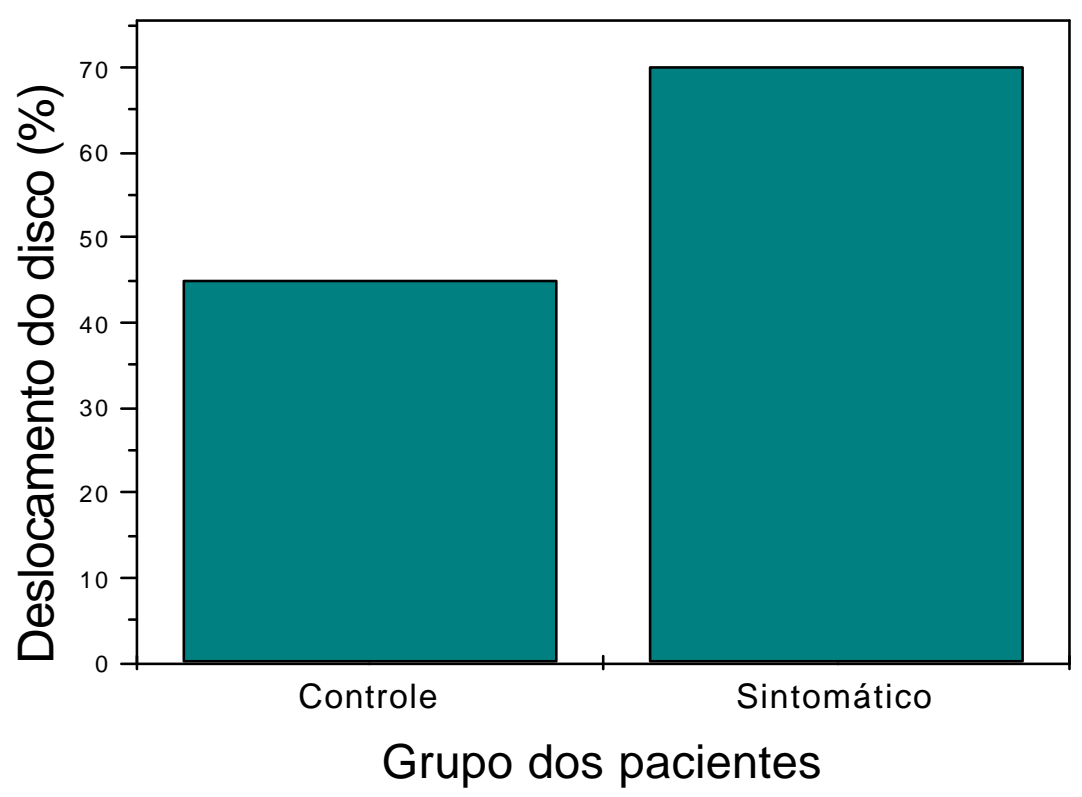

Figura 18- Prevalência de deslocamento do disco nos grupos experimentais e controle

Do total de articulações com posição superior do disco, 11 (55\%) eram do grupo controle e 9 (30\%) do grupo experimental. O DD para anterior foi diagnosticado em 4 (20\%) articulações do grupo controle e em 5 (16,66\%) do grupo experimental. Foram diagnosticadas 8 ATMs com deslocamento rotacional, sendo 7 com DD ântero-lateral e 1 com DD ântero-medial. O deslocamento puramente lateral ocorreu em 11 articulações (10 no grupo experimental e 1 no controle) e o deslocamento puramente medial ocorreu em apenas 1 ATM (experimental). Tais diagnósticos não seriam detectáveis sem os cortes coronais. Foi encontrado 1 DD parcial no 1/3 lateral da ATM (experimental). Não foram vistos DD para posterior e DD parcial no 1/3 medial da ATM em nenhum dos dois grupos (Figura 19). 


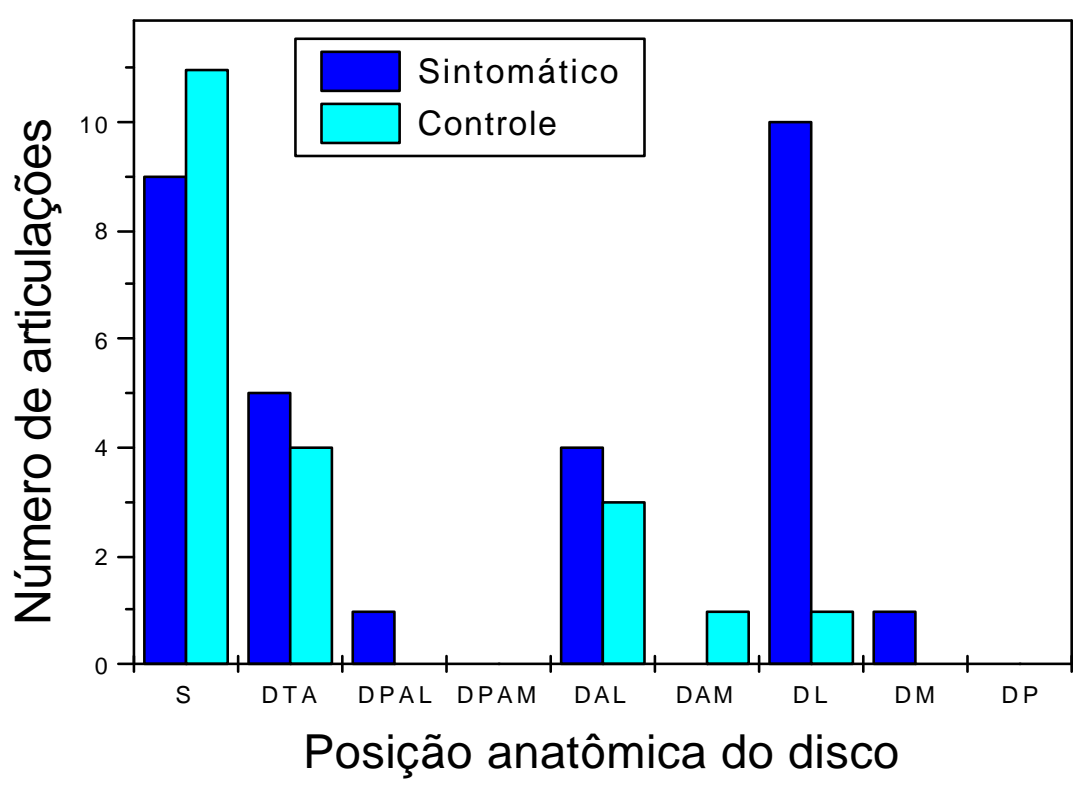

Figura 19- Número de articulações dos grupos controle e experimental com diferentes posições anatômicas do disco articular onde: S- Superior; DTADeslocamento total anterior do disco; DPAL- Deslocamento parcial no 1/3 lateral; DPAM- Deslocamento parcial no 1/3 medial; DL- Deslocamento lateral; DMDeslocamento Medial; DP- Deslocamento Posterior

Seguem abaixo algumas imagens de RM com os seus respectivos diagnósticos. 

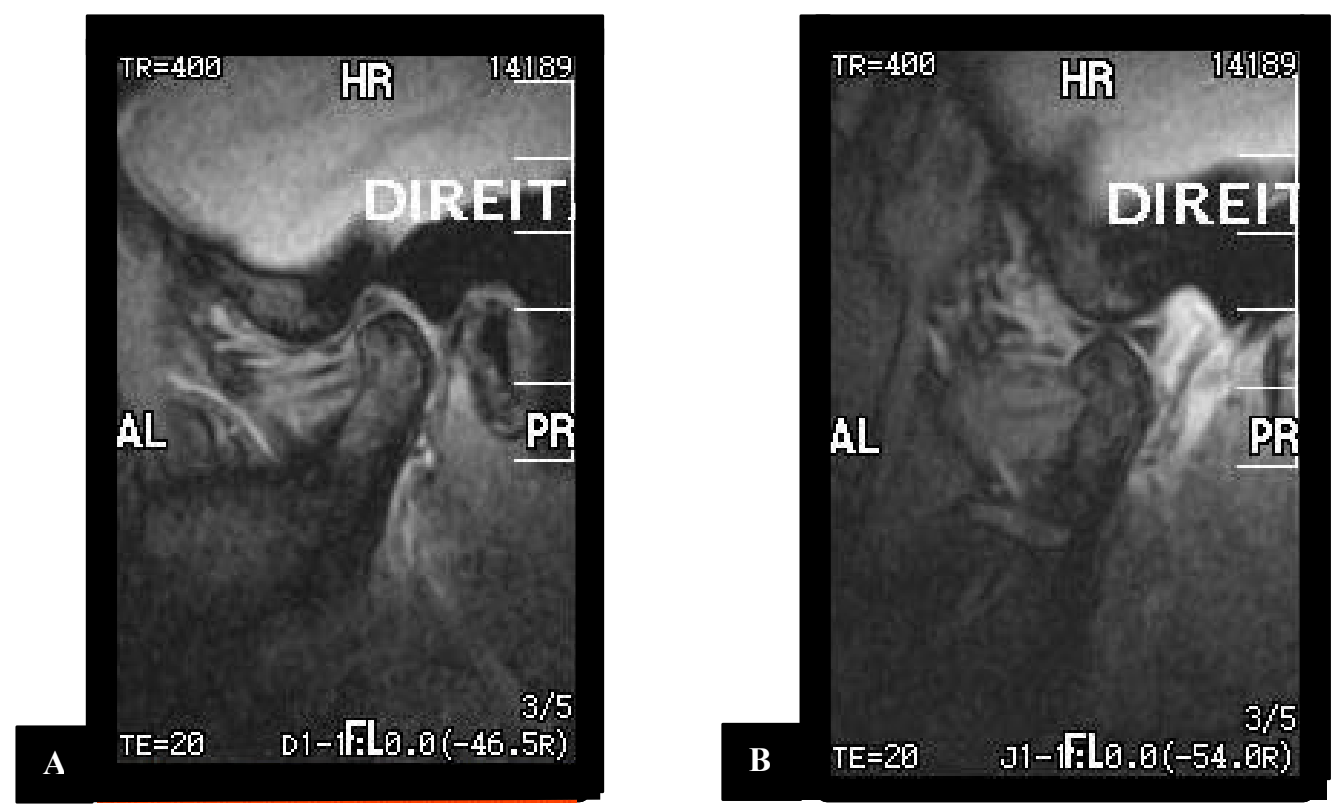

Figura 20 - Posição superior do disco em cortes parassagital de boca fechada (A) e parassagital de boca aberta (B). Morfologia do disco bicôncava.
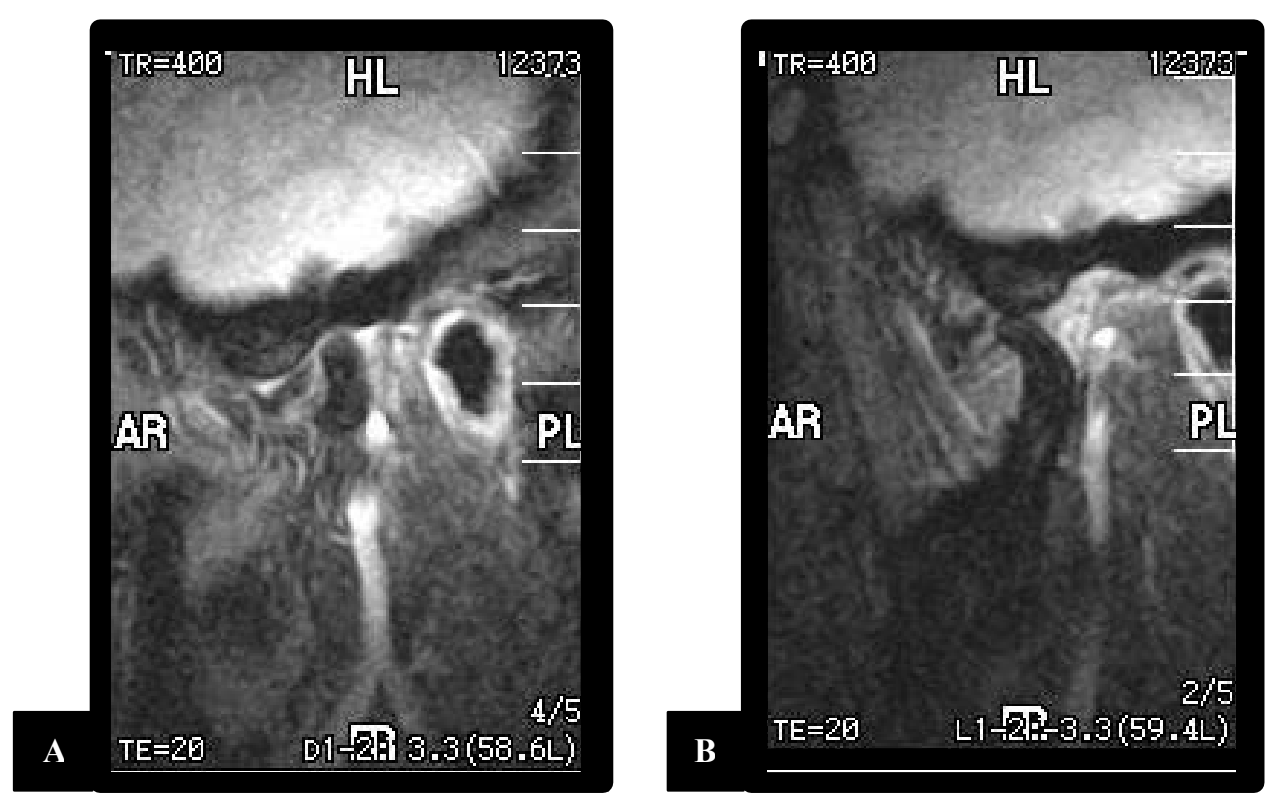

Figura 21- DDSR. DD total anterior em corte parassagital de boca fechada (A) e permanência do disco deslocado em corte parassagital de boca aberta (B). 

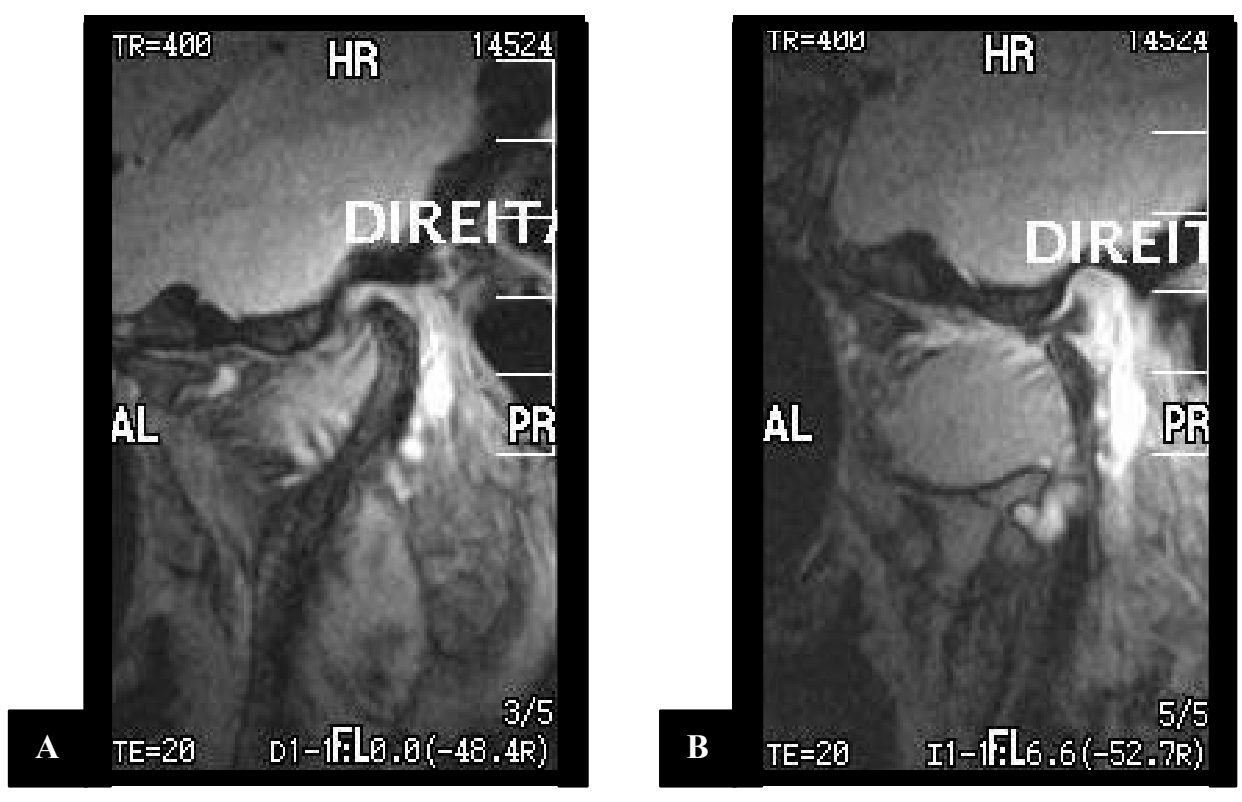

Figura 22- DDR. DD total anterior em corte parassagital de boca fechada (A) e redução do disco deslocado em corte parassagital de boca aberta (B).
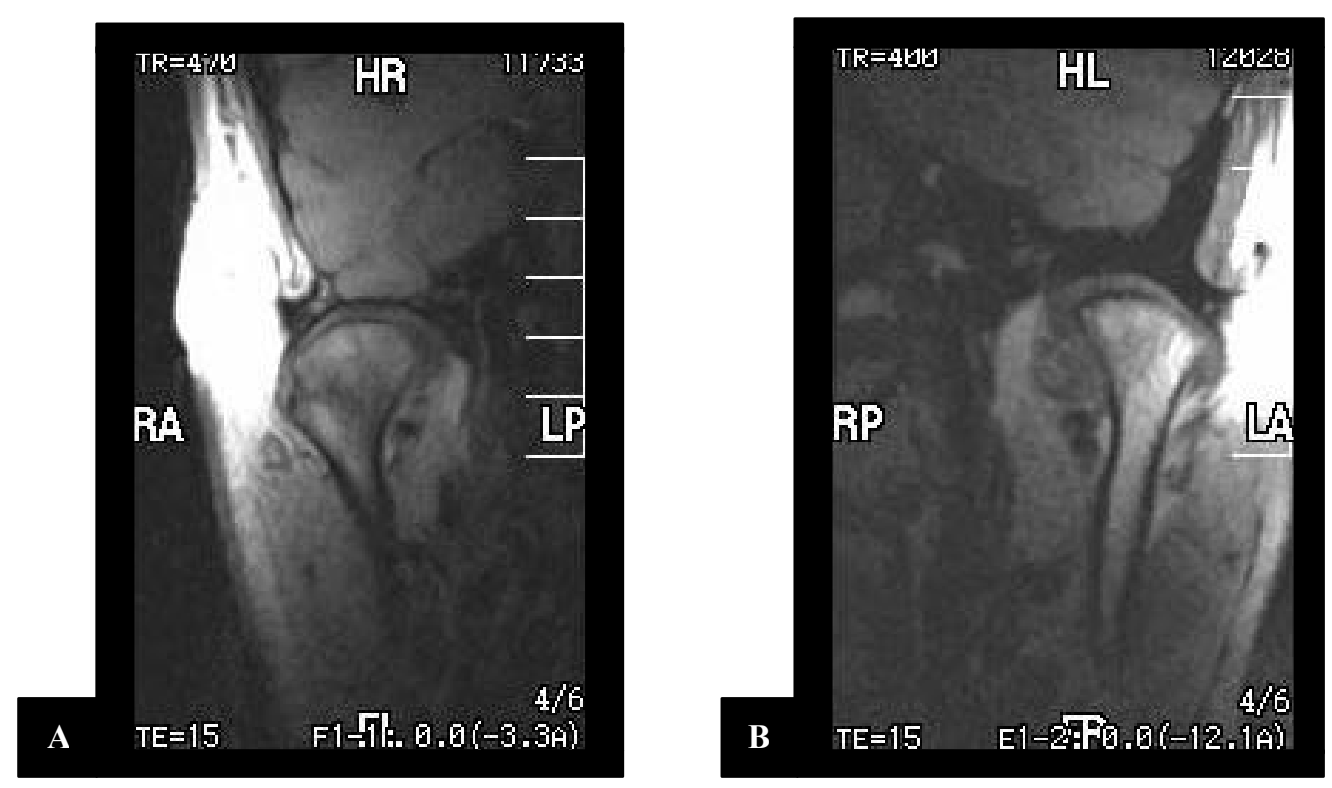

Figura 23 - Deslocamento medial (A) e lateral (B) do disco em corte coronal de boca fechada. 

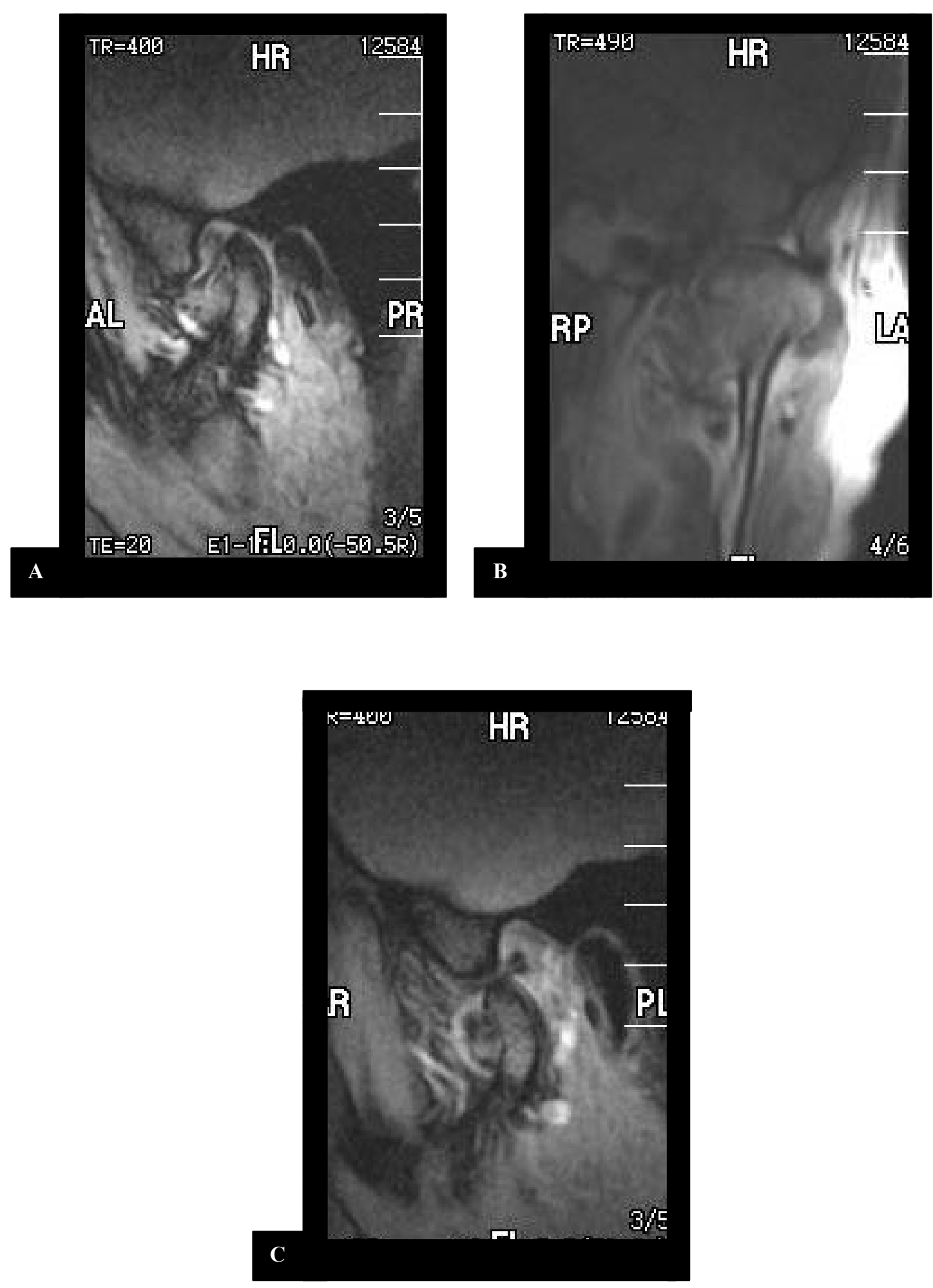

Figura 24 - DDR rotacional. Deslocamento ântero-lateral do disco com redução. (A) parassagital em boca fechada, (B) coronal em boca fechada, (C) parassagital em boca aberta. 
6- DISCUSSÃO 


\section{DISCUSSÃO}

Há alguns aspectos deste presente estudo que serão discutidos seja por motivos de comparação com a literatura, seja como justificativa da metodologia empregada.

- Meio de obtenção dos sons articulares e material para registro da máxima abertura bucal

Há uma grande variedade de meios para auscultação dos sons articulares, desde meios tradicionais, como a palpação digital, a aparelhos que registram estes sons tais como os sonógrafos. Muitos trabalhos utilizam estetoscópio 29,79,82, 156 ou uma associação deste instrumento com a palpação $77,148,149$. Há autores que ainda empregam a palpação digital bilateral como único meio de se determinar os sons articulares ${ }^{10,30,93,153}$.

A presença de estalido é considerada como uma condição de DI da ATM ${ }^{107,142}$. O ouvido humano é capaz de detectar sons numa frequiência que oscila entre 16 e 16.000Hertz, sendo mais sensível a freqüências entre 500 e $5000 \mathrm{Hertz}^{129}$. TALLENTS et al. (1993) ${ }^{129}$ observaram que a maioria das articulações com sons articulares próximos a 100Hertz tornavam difícil a detecção pelo ouvido humano. SUTTON et al. (1992) ${ }^{124}$ constataram que todas as articulações provavelmente emitem sons, variando de acordo com os instrumentos utilizados para registros e a instabilidade de uma articulação quanto à produção de determinados sons por repetidas vezes. 
Nosso trabalho utilizou a inspeção digital visto que a captação da vibração dos sons articulares não detectados por este método não seriam representativos de alguma imagem significativa por meio das RMs. O que mudaria com o uso do estetoscópio não é propriamente a sua faixa de frequiência, mas sim a sua intensidade. A unidade de medida da intensidade é o decibel e provavelmente, com o uso deste instrumento, ocorra uma amplificação dos sons (acima de 60 decibeis). Foi pedido a todos os pacientes que executassem a máxima abertura bucal por 3 vezes consecutivas enquanto o examinador registrava os sons articulares. Se o som estava presente em dois dos movimentos de abertura e fechamento, registrou-se como um achado positivo. Este método de avaliação dos sons articulares foi preconizado por ORSINI et al. (1998) ${ }^{94}$ e ORSINI et al. (1999) ${ }^{93}$.

A abertura bucal é determinada, comumente, através de dispositivos que mantenham a boca numa posição desejada tais como o compasso de Burnett ${ }^{89}$. Entretanto, tais dispositivos, caso fossem utilizados em pacientes desdentados totais, não conseguiriam produzir o efeito necessário, tendo em vista que o deslocamento das dentaduras promoveria um certo grau de desconforto, impedindo a execução da RM.

Baseados nos trabalhos preconizando polivinil siloxano para assegurar a máxima intercuspidação habitual 47, 60, 88, 89, utilizamos siliconas por condensação (Polisiloxano) para manter o paciente de boca aberta, embora sejam desconfortáveis.

- Distribuição quanto ao gênero e idade

A influência do gênero na prevalência de DDs e DTMs tem sido pesquisada desde o início dos anos 70. Segundo os trabalhos iniciais, não há uma maior predileção de sinais de 
DTM em homens ou mulheres assintomáticos ${ }^{2,28}$. Entretanto, estudos mais recentes têm mostrado uma maior prevalência de sinais e sintomas, bem como de DDs, em mulheres tanto na idade juvenil quanto adulta $30,56,103 \mathrm{a}, 103 \mathrm{~b}, 119$.

Assim também parece ocorrer nos pacientes sintomáticos, nos quais se observa maior frequiência de sintomatologia nas mulheres em comparação aos homens, apresentando proporções de $2: 1^{41}, 3: 1^{81}$ e até mesmo 4:1 ${ }^{135}$. KIRCOS et al. (1987) ${ }^{62}$ verificaram uma porcentagem maior de DD em homens, entretanto, isto pode ter sido em decorrência do pequeno tamanho da amostra. Em nosso trabalho, verificou-se uma leve tendência de DD em pacientes do gênero feminino (86,66\%), em relação aos do gênero masculino (70\%); entretanto, sem diferenças estatisticamente significativas.

A razão para uma maior ocorrência de DD em mulheres permanece ainda obscura. Uma hipótese pode ser o fato das mulheres procurarem mais prontamente o tratamento quando estão doentes do que os homens. Outra explicação, talvez mais plausível, é a ocorrência mais freqüente de lassidão ou frouxamento de ligamentos articulares de forma sistêmica em pacientes com DD do que em pacientes assintomáticos ou com outros tipos de Disfunção, associada ao fato deste frouxamento ligamentar ocorrer mais comumente em indivíduos do gênero feminino ${ }^{151}$. Este frouxamento pode ser oriundo da alteração do metabolismo do colágeno, visto que altas proporções de colágeno tipo III e tipo I têm sido encontradas em pacientes com DD ${ }^{151}$. As DTMs têm sido correlacionadas com o aumento de prolapsos da válvula mitral entre os indivíduos, indicando a alteração do metabolismo do colágeno como um possível fator etiológico para o frouxamento ligamentar ${ }^{59,151}$. 
Existe um pico de incidência de DD em ATMs com sinais e sintomas de DTM durante a puberdade ${ }^{43}$. PAESANI et al. (1999) ${ }^{96}$ mostraram que é mínima a probabilidade de ocorrer DD no período dos 2 meses até os 5 anos de idade. Entre 8 e 15 anos, a prevalência tanto em indivíduos assintomáticos quanto sintomáticos foi de $6 \%{ }^{30}$. A prevalência de DD, deformação do disco e DOD em populações mais idosas é maior do que em jovens 22, 99, 152. Provavelmente, processos degenerativos nas ATMs estão fortemente ligados com o avanço da idade, com variações estruturais devido à osteoartrose, enquanto que os sinais e sintomas freqüentemente diminuem 104, 105. A prevalência e severidade de alterações degenerativas aumentam com o envelhecimento também em outras áreas do sistema músculo-esquelético ${ }^{43}$. Em nosso trabalho, utilizando pacientes com idade entre 41 a 81 anos, não se observou predileção de DD em nenhuma faixa etária específica. Uma população heterogênea quanto a idade e gênero pode comprometer a eficácia de um meio de diagnóstico, visto a existência de condições patológicas inerentes a determinadas faixas etárias, gerando dúvidas em relação à precisão do meio diagnóstico utilizado $^{125,133}$.

- Avaliação intra-examinador e inter-examinadores

A ressonância magnética tem sido utilizada para a avaliação de DIs e alterações da ATM, desde aproximadamente $1985^{33}$. Muitos estudos mostraram uma concordância acentuada entre análises intra-observador e inter-observadores, ao se utilizar imagens de RMs $47,88,89,91,94,95,134,137,146$. Esta concordância é maior do que aquela observada a partir da utilização de outras técnicas radiográficas de avaliação da ATM ${ }^{5}$. 
Existem algumas justificativas para uma boa perfomance do examinador num determinado estudo, tais como um treinamento prévio do examinador, a qualidade da imagem e critérios de interpretação bem definidos ${ }^{137}$. Hoje, quase todos os trabalhos que abordam a avaliação com examinadores inserem, no planejamento, um período de treinamento prévio e ressaltam a importância de uma calibração. ORSINI et al. (1997) ${ }^{95}$ obtiveram melhores resultados após a execução de calibração na segunda sessão de análise das imagens, posterior a uma primeira sem calibração. Adicionalmente, a combinação de imagens sagitais e coronais tem feito com que haja um aumento na concordância entre os observadores de uma $\mathrm{RM}^{133}$.

Uma avaliação da imagem só é confiável se um observador interpreta a mesma imagem em diferentes ocasiões ou se diferentes observadores interpretam a imagem de uma maneira única ${ }^{137}$. Quando se aumenta o número de observadores para a interpretação de imagens, a concordância inter-observadores tende a diminuir ${ }^{89}$. A maioria dos estudos utilizando RMs na interpretação de imagens da ATM preconiza a utilização de apenas dois observadores 133, 137. Assim, a não concordância entre examinadores pode ser reduzida quando poucos examinadores estão envolvidos num programa de calibração ${ }^{18}$. Uma avaliação diferente foi utilizada por NEBBE et al. (2000) ${ }^{89}$ que empregaram 4 observadores para imagens sagitais e coronais da ATM por meio de RMs. De todas as comparações inter-examinadores, apenas a determinação da posição do disco no aspecto lateral da ATM obteve uma concordância moderada, devido à dificuldade de identificação do disco nesta região.

A concordância intra-observador tem sido ligeiramente superior à interobservadores em relação a posição e forma do disco, embora diferenças não sejam 
estatisticamente significantes 95,137 . Em uma revisão de 400 artigos publicados sobre diagnóstico a partir da imagem da posição do disco articular na ATM, LIEDBERG et al. (1996) ${ }^{76}$ mostraram que, em comparação aos exames artrográficos e tomográficos, a RM obteve quase que uma perfeita concordância intra-examinador na identificação de DD para anterior.

No presente estudo, um único observador interpretou as ATMs, por meio de RM, em uma única ocasião. Uma vez que critérios de classificação padronizados e calibração prévia foram aplicados, acreditamos na obtenção de uma avaliação precisa.

- Efusão articular nos espaços articulares superior e inferior

A presença de sinais na região mais anterior da ATM, especificamente nos espaços articulares superior e inferior ao disco, tem sido discutida na literatura $107,117,143$. O termo efusão articular tem sido aplicado à presença de altos sinais nestes espaços em pelo menos dois cortes consecutivos em RM ${ }^{1}$. A efusão articular é mais visível em imagens T2 ${ }^{117}$. WESTESSON; BROOKS (1992) ${ }^{143}$ encontraram uma forte associação entre efusão articular e pacientes com sintomatologia dolorosa. A porcentagem de pacientes com efusão foi maior nos estágios mais avançados de DD do que nos estágios iniciais ${ }^{1}$.

Nossa pesquisa revelou que não houve diferenças estatisticamente significantes em relação à emissão de sinais dos espaços articulares, tanto em pacientes experimentals quanto no grupo controle. Este aumento de sinais pode ser proveniente tanto de processos inflamatórios que fazem aumentar a concentração de prótons de hidrogênio, quanto do aumento da quantidade de proteoglicanas e água. 
Não houve uma relação entre a sensibilidade à palpação nos aspectos lateral e posterior da ATM e a intensificação de sinais nas RMs, em nosso trabalho. O significado real do aumento de sinais no disco articular ainda é desconhecido. As áreas de hipersinal do disco (banda posterior) podem ser sugestivas de um aumento de proteoglicanas ${ }^{103 a}, 114$.

Outro achado com diagnóstico subjetivo foi a intensificação ou redução de sinais na região medular do côndilo. $\mathrm{O}$ aumento de sinais em $\mathrm{T} 1$ sugere a presença de edema articular, assim como a redução, em T1 e T2, seria compatível com necrose avascular ${ }^{103 a}$.

- Deslocamento de disco e tratamento

A necessidade de tratamento de DD tem sido bastante discutida na literatura, devido a diferentes filosofias de trabalho. Pacientes com DDSR obtiveram sensível melhora de sinais e sintomas clínicos sem qualquer tipo de tratamento, mesmo permanecendo com os discos deslocados e deformados através de imagens de RM 77, 110, 112, 113. SATO et al. (1997) ${ }^{111}$ observaram que aproximadamente $2 / 3$ dos pacientes não tratados e com DDSR mostraram redução espontânea dos sinais e sintomas clínicos após o diagnóstico. Entretanto, pacientes tiveram uma sensível melhora quando submetidos a uma injeção de hialuronato de sódio no espaço articular superior, embora as condições de deslocamento e deformidade do disco permanecessem inalteradas, levando a crer que o hialuronato de sódio contribui na amenização dos sintomas e no aumento da máxima abertura bucal ${ }^{111,112}$. Já KERSTEN et al. (1989) ${ }^{57,58}$ afirmaram que, para DD parcial anterior, seria indicativo um tratamento mais conservador e, quando não houvesse uma 
resposta positiva, a cirurgia deveria ser realizada. As situações mais extremas como DDSR dificilmente, segundo o autor, obteriam sucesso com condutas mais conservadoras.

O DD pode ser na verdade uma variação anatômica de uma articulação normal do que preferencialmente um DI da ATM ${ }^{62}$. O deslocamento para posterior do disco trata-se de uma condição rara e, quando presente, está mais freqüentemente associado a pacientes sintomáticos ${ }^{147}$. A situação mais comum é a DD para anterior, a qual tem gerado discussões na literatura quanto a melhor forma de terapia. DTM é uma desordem que pode ser manifestada de diversas maneiras, algumas vezes aparentemente não correlacionada com a $\operatorname{ATM}^{7,12}$.

Não houve qualquer tipo de tratamento para os pacientes diagnosticados com DD, no presente trabalho, já que todos os indivíduos deste trabalho não possuíam sintomatologia dolorosa. Não consideramos que o DD seja uma condição essencial para que os profissionais tratem os seus pacientes, ainda mais que índices elevados de DD são comumente observados em pacientes assintomáticos. Portanto, embora várias soluções tenham sido sugeridas para tratamento de DTMs $4,57,66,68,77,78,111,144$, torna-se importante obter o alívio dos sintomas mesmo sem conseguir a real correção da posição anterior do $\operatorname{disco}^{98}$.

- Deslocamentos medial, lateral e rotacional do disco

Deslocamentos medial e lateral do disco (sideways) podem ocorrer sem um deslocamento do seu componente anterior, o que é denominado de um deslocamento 
puramente lateral ou medial ${ }^{55}$, embora DDs ântero-mediais ou ântero-laterais, denominados de DDs rotacionais, sejam relatados na literatura como mais freqüentes.

Tanto em pacientes quanto em espécimes necropsiadas, os DDs ântero-laterais ou mediais e puramente mediais ou laterais não são achados incomuns ${ }^{10,55,116}$. CHOLITGUL et al. (1997) ${ }^{10}$ mostraram que 1/5 das ATMs tinham tanto deslocamentos mediais quanto laterais, uma prevalência comparável aos registrados por KATZEBERG et al. (1988) ${ }^{55}$, mas muito menores do que os $50 \%$ verificados por TASAKI et al. (1996) ${ }^{135}$. Isto sugere que os planos de imagens coronal e sagital são complementares e podem ser importantes numa completa avaliação das anormalidades articulares ${ }^{55,}{ }^{116}$. Além da melhor visualização do disco, anormalidades ósseas são bem descritas nos planos coronais e sagitais, permitindo a descrição de erosões e remodelamentos do côndilo ${ }^{116}$.

O deslocamento ântero-medial 55, 90, 133, assim como o deslocamento puramente medial (sideway) ${ }^{55}$ do disco, têm sido mais prevalentes do que os deslocamentos ânterolaterais (rotacionais) e puramente laterais (sideway). TASAKI et al. (1996) ${ }^{133}$ obtiveram, em contraposição a maioria dos trabalhos, uma maior prevalência de deslocamentos do disco ântero-laterais tanto em pacientes sintomáticos quanto assintomáticos. Além disso, o emprego de técnicas cirúrgicas não permite a visualização precisa de tais deslocamentos, visto que não oferece uma vista seccional transversal da ATM ${ }^{133}$. NEBBE; MAJOR (2000) ${ }^{90}$, entretanto, encontraram valores percentuais mais elevados de DDs laterais numa amostra constituída de adolescentes, havendo uma supremacia destes achados em pacientes do gênero feminino. 
Nosso trabalho está de acordo com os achados de TASAKI et al. (1996) ${ }^{135}$. Nós pudemos observar que DDs ântero-laterais foram mais evidentes do que DDs ânteromediais. Houve também um número expressivo de DDs laterais (10) em pacientes do grupo experimental. O correto significado desses deslocamentos ainda não é totalmente compreendido. O que parece é que, para aqueles profissionais que se utilizam de terapias para DDs, os pacientes com DD medial são mais refratários ao tratamento, quando comparados com os pacientes com DD anterior ${ }^{55}$.

- Deslocamento e morfologia do disco

A alteração da morfologia do disco pode resultar em DIs da ATM e agir como causa do impedimento funcional articular $35,36,85$. A deformação do disco pode estar relacionada com pacientes DDSR e, ao mesmo tempo, a configuração normal do disco (forma de gravata borboleta) pareceu variar como resultado dos diferentes deslocamentos articulares ${ }^{142}$. Segundo YILMAZ (2001) ${ }^{154}$, quanto mais avançado for o DI, mais deteriorada estará a configuração do disco.

WESTESSON; BRONSTEIN; LIEDBERG (1985) ${ }^{142}$ também afirmaram que raramente a deformação dos discos é encontrada quando este se apresenta numa posição normal e que o tratamento mais correto, em indivíduos sintomáticos com DI, seria a tentativa de diminuir a possibilidade de estabelecimento da deformação do disco. YOSHIDA et al. (2000) ${ }^{156}$ classificaram a deformação do disco com concavidades voltadas para o aspecto superior e inferior da ATM, por meio de RMs pseudodinâmicas, e constataram, através dos resultados obtidos, que a deformação voltada para cima do disco pode representar um estágio mais avançado do DI da ATM. Em estudo realizado em 
espécimes necropsiadas, constatou-se que uma posição anterior do disco é uma condição que geralmente precede a sua deformação ${ }^{150}$. Segundo WESTESSON; BRONSTEIN; LIEDBERG (1985) ${ }^{142}$, a deformação do disco, assim como a sua posição, são dependentes do plano de tratamento instituído. Revelaram, ainda, que informações sobre a deformação do disco facilitarão o planejamento do tratamento cirúrgico, tanto numa eventual reposição quanto na possível remoção.

Houve, em nossas observações, uma relação estatisticamente significante entre morfologia do disco biconvexa e o DDR com boca aberta $\left(p=0,022 ; \chi^{2}=11,43\right)$. Portanto, nós podemos afirmar que deformação do disco tem uma tendência para ocorrer em articulações com DD. Dos 19 discos com morfologia biconvexa, 16 (84\%) apresentaram DDR ou DDSR.

- Deslocamento do disco em pacientes experimentals e assintomáticos

Por muitos anos, acreditava-se que o DD fosse a causa principal para $o$ estabelecimento das DTMs, com trabalhos tentando reposicionar o disco para uma posição considerada mais adequada dentro da ATM ${ }^{23,}{ }^{80}$. A maior discussão dos trabalhos, avaliando a ATM por meio de RM, recai sobre a proporção de discos deslocados em indivíduos sintomáticos e assintomáticos. Estudos em pacientes sintomáticos encontraram uma alta prevalência de DD ${ }^{86}, 96,103 a, 103 b$. MORROW et al. (1996) ${ }^{86}$ mostraram que pacientes com DTM e DD para anterior tinham duas vezes mais chances de apresentar outros membros familiares com os mesmos deslocamentos. Além disso, estes autores revelaram que indivíduos com DD para anterior tinham 3 vezes mais a possibilidade de ter problemas em outras articulações do corpo. KATZEBERG et al. (1996) ${ }^{56}$ mostraram que 
também há uma prevalência significativa em indivíduos assintomáticos ${ }^{62,129}$. Os valores percentuais de DD oscilam em números elevados de prevalência, tais como $78 \%{ }^{96}, 82 \%$ ${ }^{129}, 76 \%{ }^{103 a}$, $103 \mathrm{~b}$ e $95 \%{ }^{81}$ em indivíduos sintomáticos, e $33 \%{ }^{81}, 32 \%{ }^{62}, 30 \%{ }^{129}, 15 \%{ }^{145}$, $34 \%{ }^{103 a, 103 b}$ em indivíduos assintomáticos.

Os valores de DD encontrados neste presente trabalho foram maiores em pacientes experimentals (70\%) quando comparados com o grupo controle (45\%). Confirmou-se, porém, que DD em indivíduos assintomáticos é um achado comum. Considerando a amostra total (50 ATMs) como um único grupo assintomático em relação à dor, a porcentagem de DD foi significante, ou seja, de 60\% (30 ATMs).

A descrição de deslocamentos parciais do disco não é facilmente encontrada, tendo em vista que nem todos os autores se utilizam de uma mesma classificação da posição do disco. KERSTEN et al. (1989) ${ }^{57}$ revelaram uma prevalência de $46 \%$ de DD parcial anterior num total de 55 ATMs. Esta classificação, baseada nos trabalhos do TASAKI et al. (1993) ${ }^{132}$, funcionaria como um instrumento de comunicação entre clínicos e pesquisadores da área científica, visto que permite detalhes mínimos do posicionamento do disco articular ${ }^{129}$. Mesmo utilizando os critérios acima propostos, a identificação de DDs parciais em nossa pesquisa continuou sendo um achado de pouca prevalência (1 ATM do grupo experimental).

Em populações assintomáticas, o estalido articular tem ocorrido em aproximadamente 30 a $50 \%$ e, mesmo assim, a maioria dos pacientes estão isentos de sintomas. O DD não necessariamente causa dor ${ }^{23}$. A presença de DD para anterior não 
pode ser suficiente para se determinar uma DTM, mas pode aumentar o risco de seu estabelecimento $^{86}$.

As possíveis explicações para as diferenças entre nossos resultados e os outros estudos estão nos critérios de seleção que foram utilizados e nos meios de diagnósticos empregados para a interpretação das imagens. Nós empregamos RMs, ao invés de artrografias ou TC's. A injeção de contraste no espaço articular inferior é geralmente insensível na identificação de DDs puramente mediais ou laterais (sideways) ${ }^{72}$, o que é facilitado por tomadas coronais das RMs. Adicionalmente, as imagens obtidas por TC's não conferem a resolução necessária para a descrição de tecidos moles.

- Exame clínico x Ressonância Magnética

A precisão e correlação do exame clínico tem sido questionada quanto à real capacidade de reprodução de detalhes da ATM que propicie ao profissional a possibilidade de um correto diagnóstico. CHOLITGUL et al. (1997) ${ }^{10}$ descreveram que aqueles pacientes que possuíam sinais e sintomas de DTMs, tais como dores e sons articulares, tinham imagens compatíveis com DD. ERICKSSON; WESTESSON (1983) ${ }^{26}$, por meio de artrografias, também encontraram valores significativos em relação aos achados de estalidos simples com DD com redução e limitação de abertura de boca com DDSR. O exame clínico mostrou-se bastante eficiente na identificação de DTMs, numa comparação com exames obtidos por RMs em pacientes que iriam se submeter a tratamento ortodôntico 30. 
Por outro lado, YATANI et al. (1998) ${ }^{153}$, utilizando RMs, mostraram que a capacidade de diferenciação de DDSR, por meio de exame clínico e histórico do paciente, não foi tão significativa em relação a outras possibilidades de diagnóstico. A precisão do diagnóstico clínico variou entre 71 a $81 \%$. Articulações com DDSR produziram expressivos valores de falsos negativos, o que colocou em dúvida a validade do diagnóstico clínico. Os mesmos autores registraram que a precisão do exame clínico para diagnóstico de DDR também foi baixa, com valores de 43 e $75 \%$.

Apesar de não termos encontrado uma associação significativa entre achados clínicos e imagens das RMs, seguimos a opinião de TENENBAUM et al. (1999) ${ }^{138}$. Dada a associação existente entre exame clínico e o diagnóstico final, parece apropriado que, ao menos por situações específicas tais como planejamento cirúrgico ou uma correlação de sintomatologia dolorosa, pacientes com suspeita de DD não necessariamente têm que estar sujeitos a imagens sofisticadas, procedimentos invasivos ou dispositivos de trajetórias mandibulares.

- Alterações ósseas

As estruturas ósseas da ATM podem sofrer alterações, tais como a adaptação a cargas funcionais, processo denominado de remodelação, ou modificação, passando a ser reconhecida como portadora de doenças ósseo degenerativas.

Trabalhos mais antigos afirmaram que DDs com ou sem redução evoluiriam certamente para DODs ${ }^{6}, 27$. É sabido que nem todos os pacientes com DDR necessariamente avançam para DDSR e que nem todos os pacientes com DDSR evoluem 
para DOD, bem como tanto pacientes com DDR e DDSR podem apresentar sinais de DOD 26, 46. Já CHOLITGUL et al. (1997) ${ }^{10}$ mostraram que osteófitos foram mais comumente encontrados em articulações com DDSR; porém isto não implica que todas as articulações com DDSR irão desenvolver DOD ${ }^{22}$. DE MOT; CASSELMAN; DEBOEBER ${ }^{22}$ encontraram DOD não somente em pacientes idosos, mas também em pacientes jovens com idades variando entre 10 e 20 anos. RIBEIRO et al. (1997) ${ }^{103 b}$ encontraram altos índices tanto de DD quanto de DOD, em crianças. De acordo com nossa pesquisa, não podemos afirmar que há uma prevalência de DOD em pacientes idosos. Das 150 avaliações das estruturas anatômicas da ATM, observou-se que em 16 (10,6\%) delas houve o diagnóstico de DOD.

Há uma correlação na literatura entre DOD e DD, sugerindo que a DOD pode ser o resultado do DD 53,150. Por outro lado, estudos microscópicos demonstraram que variações osteodegenerativas foram encontradas em articulações com relação normal côndilo-disco ${ }^{20}$. Tais resultados favorecem a idéia de que o DD pode ser um sinal de DOD e não a sua causa. Acreditamos que o DOD pode preceder o DD ou mesmo podem ocorrer juntos, mas não relacionados entre si ${ }^{23}$.

A morfologia da eminência pode ser alterada devido a DI ${ }^{60,70,123}$. Em estudo realizado sobre a curvatura da eminência articular, foi constatado que houve uma redução da convexidade da porção posterior da eminência nas ATMs com DD para anterior. Isto poderia ser justificado pela resposta adaptativa à posição alterada do disco, aumentando a mobilidade do côndilo na presença desse deslocamento crônico, e pelo padrão de cargas não funcionais sobre a ATM ${ }^{58}$. KURITA et al. (2000) ${ }^{70}$ hipotetizaram que a forma de eminência está relacionada com o desenvolvimento do DD, sendo que as eminências mais 
profundas são predisponentes para um DDR e que, caso esta situação evolua para um progressivo aplainamento, poderá ocorrer um DDSR ${ }^{123}$. Em geral, o DD é menos provável de ocorrer em articulações com eminência rasa. Por outro lado, variações das superfícies articulares do côndilo e da eminência, resultantes de degenerações e remodelações, não parecem ser causadas pelo DD ${ }^{70}$.

Em nosso trabalho, não houve uma correlação entre o índice de remodelações da eminência articular e prevalência de DD, visto que também ocorreu DD em articulações compatíveis com a normalidade. Das 10 ATMs do grupo experimental que apresentavam remodelação da eminência, em 7 articulações verificou-se um DDR e em 3 o disco estava na posição superior. Por outro lado, das 17 ATMs com aspectos normais na eminência, 11 $(64,7 \%)$ apresentavam DDR e, nas $6(35,2 \%)$ restantes, o disco estava na posição superior. Valores semelhantes foram encontrados quando se analisou a fossa e o côndilo. A carga funcional (compressão/pressão) talvez possa justificar a remodelação das estruturas anatômicas da ATM encontrada em ambos os grupos.

SCWAIGHOFER et al. (1990) ${ }^{116}$ e CROWLEY et al. (1996) ${ }^{16}$ afirmaram que as imagens coronais descrevem claramente erosões e achatamentos condilares, enquanto os cortes sagitais mostram melhor a presença de osteófitos. Variações sutis do contorno da cortical óssea foram mais precisas nas imagens de corte central das imagens coronais 116, 133. No estudo realizado por CROWLEY et al. (1996) ${ }^{16}$, as imagens sagitais falharam na identificação de remodelações da superfície articular. Outros trabalhos mostraram que TC's permanecem superior na descrição das alterações ósseas $48,49,60$. As alterações ósseas observadas no nosso trabalho mostraram uma maior prevalência de DOD em côndilos de pacientes experimental do que degenerações na eminência e na fossa. Avaliando a 
eminência, a fossa e o côndilo das ATMs do grupo controle, DOD foi observado apenas no côndilo de 3 articulações; enquanto que, no grupo experimental, esta degeneração foi detectada em todas as estruturas anatômicas, perfazendo um total de 13 registros (3 na eminência; 2 na fossa e 8 no côndilo). 
7- CONCLUSÕES

ancmeng 


\section{CONCLUSÕES}

De acordo com o exposto, pode-se concluir que:

1- Em pacientes desdentados totais, o DD foi de $45 \%$ e $70 \%$ nos grupos controle e experimental respectivamente;

2- No grupo experimental (total de 30 articulações), 19 articulações apresentaram DDR após a abertura bucal. Diferentemente, em 2 ATMs, o disco permaneceu deslocado para anterior na máxima abertura bucal. O disco permaneceu estável, tanto em fechamento quanto em abertura bucal, em 9 ATMs. No grupo controle (total de 20 articulações), 11 ATMs apresentaram um relacionamento superior do disco, 6 demonstraram DDR e 3 mostraram DDSR;

3- Não houve uma correlação significativa entre as posições dos discos encontradas com os sinais obtidos por exame clínico, tendo em vista ter havido DD em articulações do grupo controle e posições superiores do disco em ATMs sintomáticas;

4- Dos aspectos ainda descritos pelas RMs, tais como a intensidade de sinais, as alterações ósseas, a morfologia dos discos articulares e o nível de translação condilar, houve apenas uma correlação estatisticamente significante entre a morfologia biconvexa do disco e a presença de DDR. 


\section{REFER ÊNCIAS BIBLIOGRÁFICAS *}

1-ADAME, C.G. et al. Effusion in magnetic resonance imaging of the temporomandibular joint: A study of 123 joints. J Oral Maxillofac. Surg., v.56, n.3, p.314-8, Mar. 1998.

2-AGERBERG, G.; CARLSSON, G.E. Functional disorders of the mastication system: distribution of symptom according to age and Sex as judged from investigation by questionnaire. Acta Odont. Scand. v.30, n.6, p.597-613, Dec. 1972

3-AKERMAN, S.; KOPP, S.; BOHLIN, M. Histological changes in temporomandibular joints from elderly individuals. Acta Odontol. Scand., v.44, n.4, p.231-9, 1986.

4-ARAT, Z.M. et al. Changes in the TMJ disc-condyle-fossa relationship following functional treatment of skeletal class II division 1 malocclusion: A magnetic resonance imaging study. Amer. J. Orthod. Dentofac. Orthop., v.119, n.3, p.316-9, Mar. 2001.

5-BLAIR, G.S. et al. Circular tomography of the temporomandibular joint. Oral. Surg., v.35, n.3, p.416-27, Mar.1973.

\footnotetext{
* Normas recomendadas para uso no âmbito da Universidadede São Paulo, com base no documento "Referências Bibliográficas: exemplos" emanado do Conselho Supervisor do Sistema Integrado de Bibliotecas da USP, em reunião de 20 de setembro de 1990.
} 
6-BRONSTEIN, S.L.; TOMASETTI, B.J.; RYAN, D.E. Internal derangement of the temporomandibular joint correlation of arthrography with surgical findings. J. Oral Surg., v.39, n.8, p.572-84, Aug. 1981.

7-CHEN, C.W.; BOULTON, J.L.; GAGE, J.P. Effects of splint therapy in TMJ dysfunction: a study using magnetic resonance imaging. Aust dent. J., v.40, n.2, p.71-8, Apr. 1995.

8-CHEN, Y.J.; GALLO, L.M.; MEIER, D.; PALLA, S. Dynamic magnetic resonance imaging technique for the study of the temporomandibular joint. J. Orofac. Pain., v.14, n.1, p.65-73, Winter 2000.

9-CHOI, B.H.; YOO, J.H.; LEE, W.Y. Comparison of magnetic resonance imaging before and after nonsurgical treatment of closed lock. Oral. Surg., v. 78, n.3, p.301-5, Sept. 1994.

10-CHOLITGUL, W. et al. Clinical and magnetic resonance imaging findings in temporomandibular joint disc displacement. Dentomaxillofac. Radiol., v.26, n.3, p.183-8, May 1997

11-CHRISTENSEN, E.L. et al. Computed tomography of condylar and articular disk positions within the temporomandibular joint. Oral. Surg., v.64, n.6, p.757-67, Dec. 1987. 
12-CHU, S. et al. The effect of interocclusal appliances on temporomandibular joints as assessed by 3D reconstruction of MRI scans. Aus. dent. J., v.46, n.1, p.18-23, Mar. 2001.

13-COHEN, H.; ROSS, S.; GORDON, R. Computerized tomography as a guide in the diagnosis of temporomandibular joint disease. J. Amer. dent. Assoc., v.110, n.1, p.57-60, Jan. 1985.

14-CONTI, P.C.R. A cross-sectional study of prevalence and etiology of signs and symptoms of temporomandibular disorders in high school and university students. J. Orofac. Pain., v.10, n.3, p. 254-62, Summer 1996.

15-CONWAY, W.F. et al. Temporomandibular joint motion: Efficacy of fast lowangle shot MR imaging. Radiology., v.172, n.3, p.821-6, Sept. 1989.

16-CROWLEY, C. et al. Correlations between anatomic and MRI sections of human cadaver temporomandibular joints in the coronal and sagittal planes. J. Orofac. Pain., v.10, n.3, p.199-216, Summer 1996.

17-DAVANT, T.S. et al. A quantitative computer-assisted analysis of disc displacement using sagittal view magnetic resonance imaging. J. Oral Maxillofac. Surg., v.51, n.9, p.974-9, Sept. 1993. 
18-DAVIES, G.N.; CADELL, P.B. Four investigations to determine the reliability of caries recording-methods. Arch. Oral Biol., v.8, n.5, p.331-48, May/June 1963.

19-DAWSON, P.E. New definition for relating occlusion to varying conditions of the temporomandibular joint. J. prosth. Dent., v.74, n.6, p.619-27, 1995.

20-DE BONT, L.G.B.; BOERING, G.; LIEM, R.S.B. Osteoarthrosis and internal derangement of the temporomandibular joint: a light microscopic study. J. Oral Maxillofac. Surg., v.44, n.2, p.634-43, July/ Dec. 1986.

21-DE LEEUW, R.; et al. TMJ articular disc position and configuration 30 years after initial diagnosis of internal derangement. J. Oral Maxillofac Surg., v.53, n.3, p.234-42, Mar. 1995.

22-DE MOT, B.; CASSELMAN, J.; DEBOEBER, J. Pseudodynamic magnetic resonance imaging in the diagnosis of temporomandibular joint dysfunction. J. prosth. Dent., v. 72, .n.3, p.309-13, Sept. 1994.

23-DOLWICK, M.F.; DIMITROULIS, G. A re-evaluation of the importance of disc position in temporomandibular disorders. Aust. dent J., v.41, n.3, p.184-7, 1996 
24-DONLON, W.; MOON, K.L. Comparison of magnetic resonance magnetic, arthrotomography and clinical and surgical findings in temporomandibular joint internal derangements. Oral Surg., v.64, n.1, p.2-5, July 1987

25-EMSHOFF, R. et al. The diagnostic value of ultrasonography to determine the temporomandibular joint disk position. Oral Surg. v.84, n.6, p.688-96, Dec. 1997.

26-ERIKSSON, L.; WESTESSON, P.L. Clinical and radiological study of patients with anterior disc displacement of the temporomandibular joint. Swed. Dent., v.7, p.55-64, 1983.

27-FARRAR, W.B.; McCARTY, W.L. Inferior joint space arthrography and characteristics of condylar paths in internal derangements of TMJ. J. prosth. Dent., v.41, n.5, p.548-55, May 1979.

28-GAZIT, E. et al. Prevalence of mandibular dysfunction in 10-18 year old Israeli schoolchildren. J. Oral Rehabil., v.11, p.307-17, 1984

29-GÖKALP, H.; TÜRKKAHRAMAN, H. Changes in position of the temporomandibular joint disc and condyle after disc repositioning appliance therapy: A functional examination and magnetic resonance imaging study. Angle Orthod., v.70, n.5, p.400-8, Oct. 2000. 
30-HANS, M.G.; LIEBERMAN, J.; GOLDBERG, J.; ROZENCWEIG, G.; BELLON, E. A comparison of clinical examination, history, and magnetic resonance imaging for identifying orthodontic patients with temporomandibular joint disorders. Amer J. Orthod. Dentofac. Orthop., v.101, n.1, p.54-9, Jan. 1992

31-HANSSON, L.G.; ERIKSSON, L.;WESTESSON, P.L. Magnetic resonance evaluation after temporomandibular joint disketomy. Oral Surg. ,v.74, n.6, p.801-10, Dec. 1992.

32-HANSSON, L.G. et al. MR imaging of the temporomandibular joint: comparison of images of autopsy specimens made at $0,3 \mathrm{~T}$ and $1,5 \mathrm{~T}$ with anatomic cryosections. Amer. J. Roentgenol., v.152, p.1241-4, June 1989.

33-HARMS, S.E. et al. The temporomandibular joint: Magnetic resonance imaging using surface coils. Radiology., v.157, n.1, p.133-6, Oct. 1985.

34-HAYASHI, T. et al. Detectability of anterior displacement in the temporomandibular joint on helical computed tomography: The value of open mouth position. Oral Surg. v. 88, n.1, p.106-11, July 1999.

35-HEFFEZ, L.; JORDAN, S. A classification of temporomandibular joint disk morphology. Oral. Surg., v.67, n.1, p.11-9, Jan. 1989. 
36-HEFFEZ, L.; JORDAN, S.; GOING, R. Determination of the radiographic position of temporomandibular joint disc. Oral Surg., v.65, n.3, p.272-80, Mar. 1988.

37-HELMS, C.A. et al. Temporomandibular joint: Morphology and signal intensity characteristics of the disk at MR imaging. Radiology., v.172, n.3, p.817-20, Sept. 1989.

38-HELMS, C.A.; VOGLER, J.B.; MORRISH, R.B. Diagnosis by computed tomography of temporomandibular joint meniscus displacement. J. prosth. Dent., v.51, n.4, p.544-7, Apr. 1984.

39-HELMS, C.A. et al. Temporomandibular joint internal derangements: TC diagnosis. Radiology., v.152, n.2, p.459-62, Aug. 1984.

40-HOLLENDER, L. et al. A new coronal imaging plane for magnetic resonance imaging of the temporomandibular joint disc. Dentomaxillofac. Radiol., v.27, n.1, p.48-50, Jan. 1998.

41-ISACSSON, G.; LINDE, C.; ISBERG, A. Subjective symptoms in patients with temporomandibular disk displacement versus patients with myogenic craniomandibular disorders. J. prosth. Dent., v.61, n.1, p.70-7, Jan. 1989. 
42-ISACSSON, G. et al. Internal derangements of the temporomandibular joint: radiographic and histologic changes associated with severe pain. J. Oral Maxillofac Surg., v.44, n.2, p.771-8, July/Dec. 1986

43-ISBERG, A.; HÄGGLUND, M.; PAESANI, D. The effect of age and gender on the onset of symptomatic temporomandibular joint disk displacement. Oral Surg., v. 85, n.3, p.252-7, Mar. 1998

44-ISBERG, A. et al. Hyperplastic soft tissue formation in the temporomandibular joint associated with internal derangement. Oral Surg., v.61, n.1, p.32-8, Jan. 1986.

45-ISBERG, A.; STENSTRÖM, B.; ISACSSON, G. Frequency of bilateral temporomandibular joint disc displacement in patients with unilateral symptoms: a 5-year follow-up of the asymptomatic joint. A clinical and arthrotomographic study. Dentomaxillofac. Radiol., v.20, p.73-6, May 1991.

46-ISBERG, A.; WESTESSON, P.L. Movement of the disc and condyle in the temporomandibular joints with clicking. An arthrographic and cineradiographic study on autopsy specimens. Acta Odont. Scand., v.40, n.3, p.151-64, 1982 
47-KAMELCHUK, L. et al. Adolescent TMJ tomography and magnetic resonance imaging: A comparative analysis. J. Orofac. Pain., v.11, n.4, p.321-7, Fall 1997.

48-KAPLAN, A.; ASSAEL, L. Temporomandibular disorders: Diagnosis and treatment. Philadelphia: W.B. Saunders Company., 1991.

49-KAPLAN, P.A.; HELMS, C.A. Current status of temporomandibular joint imaging for the diagnosis of internal derangement. Amer. J. Roentgenol., v.152, n.4, p.697-705, Apr., 1989.

50-KAPLAN, P.A. et al. The normal temporomandibular joint: MR and arthrographic correlation. Radiology., v.165, p.177-8, Oct. 1987.

51-KAPLAN, P.A. et al. Inferior joint space arthrography of normal temporomandibular joints: Reassessment of diagnostic criteria. Radiology., v.159, n.3, p.585-9, June 1986.

52-KATZBERG, R.W. et al. Normal and abnormal temporomandibular joint: MR imaging with surface coil. Radiology., v.158, n.1, p.183-9, Jan. 1986

53-KATZBERG, R.W.; KEITH, D.A.; GURALNICK, W.C. Internal derangement and osteoarthritis of the temporomandibular joint. Radiology., v.146, p.10712, 1983. 
54-KATZBERG, R.W. et al. Magnetic resonance imaging of the temporomandibular joint meniscus. Oral. Surg., v.59, n.4, p.332-5, Apr. 1985.

55-KATZBERG, R.W. et al. Temporomandibular joint: MR assessment of rotational and sideway disk displacements. Radiology, v.169, n.3, p.741-8, Dec. 1988.

56-KATZBERG, R.W. et al. Anatomic disorders of the temporomandibular joint disc in asymptomatic subjects. J. Oral Maxillofac. Surg. v. 54, n.2, p.14753, Feb. 1996.

57-KERSTENS, H.C.J. et al. Magnetic resonance imaging of partial temporomandibular joint disc displacement. J. Oral Maxillofac. Surg. v.47, n.1, p.25-9, Jan. 1989.

58-KERSTENS, H.C.J. et al. Inclination of the temporomandibular joint eminence and anterior disc displacement. Int. J. Oral Maxillofac. Surg., v.18, n.4, p.229-32, Aug. 1989.

59-KIM, S.M.; COHEN, S.G.; DOUGLAS, P. Relationship between internal derangement of TMJ and mitral valve prolapse. J. dent Res., v.68, p.416, 1989. /abstract $1877 /$ 
60-KINNIBURGH, R.D. et al. Osseous morphology and spatial relationships of the temporomandibular joint: Comparisons of normal and anterior disc positions. Angle Orthod., v.70, n.1, p.70-80, Feb. 2000.

61-KIRCOS, L.T. et al. Magnetic resonance imaging of the temporomandibular joint. J. dent. Res., v.65, p.286, 1986. /abstract 1055/

62-KIRCOS, L.T. et al. Magnetic resonance imaging of the TMJ disc in asymptomatic volunteers. J. Oral. Maxillofac. Surg., v.45, n.2, p.852-4, July/Dec. 1987.

63-KIRK, W.S. Diagnosing disk dysfunction and tissue changes in the temporomandibular joint with magnetic resonance imaging. J. Amer. dent. Assoc., v.119, n.4, p.527-30, Oct. 1989.

64-KIRK, W.S. Magnetic resonance imaging and tomographic evaluation of occlusal appliance treatment for advanced internal derangement of the temporomandibular joint. J. Oral. Maxillofac. Surg., v.49, n.1, p.9-12, Jan. 1991.

65-KIRK, W.S.; CHARLOTTE, N.C. A comparative study of axial corrected tomography with magnetic resonance imagery in 35 joints. Oral. Surg., v.68, n.5, p.646-52, Nov. 1989 
66-KURITA, H. et al. Evaluation of disk capture with a splint repositioning appliance - Clinical and critical assessment with MR imaging. Oral. Surg., v.85, n.4, p.377-80, Apr. 1998.

67-KURITA, H.; KURASHINA, K.; OHTSUKA, A. Efficacy of a mandibular manipulation technique in reducing the permanently displaced temporomandibular joint disc. J. Oral Maxillofac. Surg., v. 57, n.7, p.7848, July 1999.

68-KURITA, H. et al. Change of position of the temporomandibular joint disk with insertion of a disk-repositioning appliance. Oral. Surg., v.85, n.2, p.142-5, Feb.1998.

69-KURITA, H. et al. A study of the relationship between the position of the condylar head and displacement of the temporomandibular joint disk. Dentomaxillofac. Radiol. v.30, n.3, p.162-5, May 2001

70-KURITA, H. et al. Is the morphology of the articular eminence of the temporomandibular joint a predisposing factor for disc displacement? Dentomaxillofac. Radiol., v.29, n.3, p.159-62, May 2000.

71-KURITA, K. et al. Histologic features of the temporomandibular joint disk and posterior disk attachment: Comparison of symptom-free persons with normally positioned disks and patients with internal derangement. Oral. Surg., v.67, n.6, p.635-43, June 1989. 
72-KURITA, K. et al. Temporomandibular joint: diagnosis of medial and lateral disk displacement with anteroposterior arthrography - correlation with cryosections. Oral Surg., v.73, n.3, p.364-8, Mar. 1992.

73-LANGLAIS, R.P. et al. Magnetic resonance imaging in dentistry. dent. Clin. Nort. Amer., v.44, n.2, Apr. 2000.

74-LAHREIN, T.A.; SMITH, H.J.; ASPETRAND, F. Temporomandibular joint abnormalities associated with rheumatic disease: Comparison between MR imaging and arthrotomography. Radiology., v.183, n.1, p.221-6, Apr. 1992

75-LAURELL, K.A.; TOOTLE, R. Use of a cephalostat for magnetic resonance imaging of the TMJ. J. dent. Res., v.65, n.1, p.286, 1986. /abstract 1056/

76-LIEDBERG, J. et al. Evidence-based evaluation of three imaging methods for the temporomandibular disc. Dentomaxillofac. Radiol., v.25, n.5, p.234-41, Nov. 1996

77-LUNDH, HAKAN; WESTESSON, P.L. Disk-repositioning onlays in the treatment of the temporomandibular joint disk displacement: Comparison with a flat occlusal splint and with no treatment. Oral Surg., v.53, n.6, p.836-8, June 1985. 
78-MANZIONE, J.V. et al. Artrographically guided splint therapy for recapturing the temporomandibular joint meniscus. Oral Surg., v.57, n.3, p.235-40, Mar. 1984.

79-MARGUELLES-BONNET, R.E. et al. Clinical diagnosis compared with findings of magnetic resonance imaging in 242 patients with internal derangements of the TMJ. J. Orofac Pain, v.9, n.3, p.244-53, Summer 1995

80-McCARTY, W.L.; FARRAR, W.B. Surgery for internal derangement of the temporomandibular joint. J. prosth. Dent., v.42, n.2, p.191-6, Aug. 1979.

81-MILANO, V. et al. Magnetic resonance imaging of temporomandibular disorders: classification, prevalence and interpretation of disc displacement and deformation. Dentomaxillofac. Radiol., v.29, n.6, p.352-61, Nov. 2000.

82-MILLER, T.L. et al. Temporomandibular joint clicking with nonreducing anterior displacement of the meniscus. Radiology., v.154, n.1, p.121-4, Jan. 1985.

83-MOHANAN, R.; ALDER, M.; NUMMIKOSKI, P. Magnetic resonance imaging: Pratical theory and clinical relevance. J. Amer. dent. Ass., v.125, n.7, p.998-1002, July 1994 
84-MUHL, Z.F.; SADOWSKY, C.; SAKOLS, E.I. Timing of temporomandibular joint sounds in orthodontic patients. J. dent. Res., v.66, p.1389-92, 1987.

85-MURAKAMI, S. et al. Magnetic resonance evaluation of the temporomandibular joint disc position and configuration. Dentomaxillofac. Radiol., v.22, n.4, p.205-7, Nov. 1993.

86-MORROW, D. et al. Relationship of other joint problems and anterior disc position in symptomatic TMD patients and in asymptomatic volunteers. J. Orofac. Pain., v.10, n.1, Winter 1996.

87-MUSGRAVE, M.T. et al. Improved magnetic resonance imaging of the temporomandibular joint oblique scanning planes. Oral. Surg., v.71, n.5, p.525-8, May 1991.

88-NEBBE, B. et al. Interobserver reliability in quantitative MRI assessment of temporomandibular joint disk status. Oral. Surg., v.86, n.6, p.746-50, Dec. 1998

89-NEBBE, B. et al. Magnetic resonance imaging of the temporomandibular joint: Interobserver agreement in subjective classification of disk status. Oral. Surg., v. 90, n.1, p.102-7, July 2000. 
90-NEBBE, B.; MAJOR, P.W. Prevalence of TMJ disc displacement in a preorthodontic adolescent sample. Angle Orthod., v.70, n.6, p.454-63, Dec. 2000

91-NEBBE, B. et al. Quantitative assessment of temporomandibular joint disk status. Oral. Surg., v.85, n.5, p.598-607, May 1998.

92-OKESON, J.P. Long-term treatment of disc-interference disorders of the temporomandibular joint with anterior repositioning occlusal splints. J. prosth Dent., v.60, n.5, p.611-6, Nov. 1988.

93-ORSINI, M.G. et al. Clinical predictability of temporomandibular joint disc displacement. J. dent. Res., v.78, n.2, p.650-60, Feb. 1999.

94-ORSINI, M.G. et al. Diagnostic value of 4 criteria to interpret temporomandibular joint normal disk position on magnetic resonance images. Oral Surg., v.86, n.4, p.489-97, Oct. 1998.

95-ORSINI, M.G. et al. The influence of observer calibration in temporomandibular joint magnetic resonance imaging diagnosis. Oral. Surg., v.84, n.1, p.82-7, July 1997

96-PAESANI, D. et al. Prevalence of temporomandibular joint disk displacement in infants and young children. Oral. Surg., v. 87, n.1, p.15-9, Jan. 1999 
97-PAESANI, D. et al. Prevalence of temporomandibular joint internal derangement in patients with craniomandibular disorders. Amer. J. Ortho. Dentofac. Orthop., v.101, p.41-7, 1992.

98-PANMEKIATE, S. et al. Temporomandibular joint disc position in arthrography. A descriptive analysis of the observer perfomance. Dentomaxillofac Radiol., v. 24, n.4, p.243-9, Nov. 1995

99-PEREIRA, F.J.; LUNDTH, H.; WESTESSON, P.L; Morphologic changes in the temporomandibular joint in diferent age groups: an autopsy investigation. Oral. Surg., v.78, n.3, p.279-87, Sept. 1994.

100-PERTES, R.A. GROSS, S.G. Clinical management of temporomandibular disorders and orofacial pain., Chicago, Quintessence, 1995. 368p.

101-RAMMELSBERG, P.; JÄGER, L.; DUC, J.M.P. Magnetic resonance imagingbased joint space measurements in temporomandibular joints with disk displacements and in controls. Oral. Surg., v. 90, n.2, p.240-8, Aug. 2000.

102-RAMMELSBERG, P. et al. Variability of disk position in asymptomatic volunteers and patients with internal derangements of the TMJ. Oral. Surg., v. 83, n.3, p.393-9, Mar. 1997. 
103a-RIBEIRO, R. Avaliação estrutural da articulação temporomandibular em crianças e adultos jovens assintomáticos através de imagens por ressonância magnética. Bauru, 1996/ Tese

103b-RIBEIRO, R.F. et al. The prevalence of disc displacement in symptomatic and asymptomatic volunteers aged 6 to 25 years. J. Orofac. Pain., v.11, n.1, p.37-47, Winter 1997

104-RIEDER, C.E.; MARTINOFF, J.T. The prevalence of mandibular dysfunction. Part II: a multiphasic dysfunction profile. J. prosth. Dent. v.50, n.2, p.23744, Aug. 1983

105-RIEDER, C.E.; MARTINOFF, J.T.; WILCOX, S.A. The prevalence of mandibular dysfunction. Part I: Sex and age distribution of related signs and symptoms. J. prosth. Dent., v.50, n.1, p.81-8, July 1983.

106-ROBERTS, C.A.; TALLENTS, R.H.; KATZBERG, R.W. Clinical and arthrographic evaluation of temporomandibular joint sounds. Oral Surg., v.62, n.4, p.373-7, Oct.1986.

107-RUDISH, A. et al. Magnetic resonance imaging findings of internal derangement and effusion in patients with unilateral temporomandibular joint pain. Oral Surg.,. v.92, n.5, p.566-71, 2001. 
108-SANO, T. Recent developments in understanding temporomandibular joint disorders. Part 2: changes in the retrodiscal tissue. Dentomaxillofac. Radiol., v.29, n.5, p.260-3, Sept. 2000.

109-SANO, T.; WESTESSON, P.L. Magnetic resonance imaging of the temporomandibular joint. Increased $\mathrm{T} 2$ signal in the retrodiskal tissue of painful joints Oral Surg., v.79, n.4, p.511-6, Apr. 1995.

110-SATO, S. et al. The natural course of anterior disc displacement without reduction in temporomandibular joint: follow-up at 6,12 and 18 months. J Oral Maxillofac Surg., v.55, n.3, p.234-8, Mar. 1997.

111-SATO, S. et al. Effect of lavage with injection of sodium hyaluronate for patients with nonreducing disk displacement of the temporomandibular joint. Oral Surg., v.84, n.3, p.241-4, Sept. 1997.

112-SATO, S. et al. Disc position and morphology in patients with nonreducing disc displacement treated by injection of sodium hyaluronate. Int J. Oral Maxillofac. Surg., v.28, n.4, p.253-7, Aug. 1999.

113-SATO, S. et al. Long-term changes in clinical signs and symptoms and disc position and morphology in patients with nonreducing disc displacement in the temporomandibular joint. J Oral Maxillofac., v.57, n.1, p.23-30, Jan. 1999. 
114-SCAPINO, R.P. Histopathology associated with malposition of the temporomandibular joint disk. Oral Surg., v.55, n.4, p.382-97, Apr. 1983.

115-SCHACH, R.T.; SADOWSKY, P.L. Clinical experience with magnetic resonance imaging in internal derangements of the TMJ. Angle Orthod., v.58, n.1, p.21-32, Jan. 1988.

116-SCHWAIGHOFER, B.W. et al. MR imaging of the temporomandibular joint: A cadaver study of the value of coronal images. Amer. J. Roentgenol., v.154, p.1245-9, June 1990.

117-SEGAMI, N. et al. Does joint effusion on T2 magnetic resonance images reflect synovitis? Comparison of arthroscopic findings in internal derangements of the temporomandibular joint. Oral Surg., v.92, n.3, p.3415,2001

118-SIRVERSTEIN, R. et al. MRI assessment of the normal temporomandibular joint with the use of projective geometry. Oral. Surg., v.77, n.5, p.523-30, May 1994.

119-SOLBERG, W.K.; WOO, M.E.; HOUSTON, J.B. Prevalence of mandibular dysfunction in young adults. J. Amer. Dent. Assoc., v.98, n.1, p.25-34, Jan. 1979 
120-STEENKS, M.H.; BLEYS, R.L.A.; WITKAMP, T.D. Temporomandibular joint structures: A comparison between anatomic and magnetic resonance findings in a sagittal and angulated plane. J. Orofac. Pain., v.8, n.2, p.12035, Spring 1994.

121-STEENKS, M.H.; BLEYS, R.L.A.; WITKAMP, T.D. Temporomandibular joint structures: A comparison between anatomic and magnetic resonance findings in a coronal and an angulated coronal plane. J. Orofac. Pain., v.8, n.4, p.335-49, Fall 1994.

122-SUENAGA, S. et al. Dynamic MR imaging of the temporomandibular joint in patients with arthrosis: relationship between contrast enhancement of the posterior disk attachment and joint pain. Amer. J. Roentgenol., v.166, n.6, p.1475-81, June 1966.

123-SÜLÜN, T. et al. Morphology of the mandibular fossa and inclination of the articular eminence in patients with internal derangement and in symptomfree volunteers. Oral Surg., v.92, n.1, p.98-107, July, 2001.

124-SUTTON, D.I. et al. Temporomandibular joint sounds and condyle/disk relations on magnetic resonance images. Amer. J. Orthod. Orthop., v.101, n.1, p.70-8, Jan. 1992.

125-SWET, J.A. Measuring the accuracy of diagnostic systems. Science., v,240, n.3, p.1285-93, June 1988 
126-TAKAKU, T.; SANO, T.; YOSHIDA, M. Long-term magnetic resonance imaging after temporomandibular joint discectomy without replacement. J. Oral Maxillofac. Surg., v.58, n.7, p. 739-45, July 2000.

127-TAKAKU, T. et al. A comparison between magnetic resonance imaging and pathologic findings in patients with displacement. J. Oral Maxillofac. Surg., v.56, n.2, p.171-6, Feb.1998.

128-TAKAKU, T. et al. Correlation of magnetic resonance imaging and surgical findings in patients with temporomandibular joint disorders. J. Oral Maxillofac. Surg., v.53, n.11, p.1283-8, Nov. 1995.

129-TALLENTS, R.H. et al. Temporomandibular joint sounds in asymptomatic volunteers. J. prosth. Dent., v.69, n.3, p.298-304, Mar. 1993.

130-TALLENTS, R.H. et al. Evaluation of arthrographically assisted splint therapy in treatment of TMJ disk displacement. J. prosth. Dent., v.53, n.6, p.836-8, June 1985 .

131-TANIMOTO, K. et al. Computed tomography versus single-contrast arthrotomography in evaluation of the temporomandibular joint disc. A study of autopsy specimens. Int J Oral Maxillofac. Surg., v.18, p.354-8, 1989. 
132-TASAKI, M. Magnetic resonance imaging and arthrographic assessment of temporomandibular joint disk displacements. Sweden, 1993 /Thesis/

133-TASAKI, M.; WESTESSON, P.L. Temporomandibular joint: Diagnostic accuracy with sagittal and coronal MR imaging. Radiology.,v.186, n.3, p.723-9, Mar. 1993

134-TASAKI, M.; WESTESSON, P.L. Observer performance in interpretation of MR images of the temporomandibular joint. Oral. Surg., v.75, p.528-31, 1993.

135-TASAKI, M. et al. Classification and prevalence of temporomandibular disk displacement in patients and symptoms-free volunteers. Amer. J. Orthod. Dento. Fac. Orthop., v.109, n.3, p.249-62, Mar. 1996.

136-TASAKI, M. et al. Magnetic resonance imaging of the temporomandibular joint: Value of axial images. Oral. Surg., v.75, n.4, p.528-31, Apr. 1993.

137-TASAKI, M.; WESTESSON, P.L.; RAUBERTAS, R.F. Observer variation in interpretation of magnetic resonance images of the temporomandibular joint. Oral. Surg., v. 76, n.2, p.231-4, Aug. 1993

138-TENENBAUM, H.C. et al. Temporomandibular disorders: Disc displacements. J. Orofac. Pain., v.13, n.4, p.285-90, Fall 1999. 
139-TOYAMA, M. et al. Magnetic resonance arthrography of the temporomandibular joint. J. Oral Maxillofac. Surg., v.58, n.9, p.978-83, Sept. 2000.

140-WESTESSON, P.L. Double-contrast arthrotomography of the temporomandibular joint: introduction of an arthrographic technique for visualization of the disk and articular surfaces. J.Oral Maxillofac Surg., v.41, n.3, p.163-72, Mar. 1983.

141-WESTESSON, P.L. Reliability and validity of imaging diagnosis of temporomandibular joint disorder. Adv. dent. Res., v.7, n.2, p.137-51, Aug. 1993.

142-WESTESSON, P.L; BRONSTEIN, S.L.; LIEDBERG, J. Internal derangement of the temporomandibular joint: Morphologic description with correlation to joint function. Oral. Med., v. 59, n.4, p.323-31, Apr. 1985.

143-WESTESSON, P.L.; BROOKS, S.L. Temporomandibular joint: Relation between MR evidence of effusion and the presence of pain and disk displacement. Amer. J. Roentgenol., v.159, p.559-63, Sept. 1992.

144-WESTESSON, P.L.; ERIKSSON, L. Diskectomy of the temporomandibular joint: A double-contrast arthrotomographic follow up study. Oral. Surg., v.71, p.407, 1991. 
145-WESTESSON, P.L.; ERIKSSON, L.; KURITA, K. Reability of a negative clinical temporomandibular joint examination: Prevalence of disk displacement in asymptomatic temporomandibular joints. Oral. Surg., v.68, n.5, p.551-4, Nov. 1989.

146-WESTESSON, P.L. et al. TC and MR of the temporomandibular joint. Amer. J. Roentgenol., v.148, p.1165-71, June 1987.

147-WESTESSON, P.L.; LARHEIN, T.A.; TANAKA, H. Posterior disc displacement in the temporomandibular joint. J. Oral Maxillofac. Surg., v.56, n.1, p.1266-73, Nov. 1998.

148-WESTESSON, P.L.; LUNDH, HAKAN. Temporomandibular joint disk displacement: Arthrographic and tomographic follow-up after 6 months treatment with disk-repositioning onlays. Oral. Surg., v.66, n.3, p.271-8, Sept. 1988.

149-WESTESSON, P.L.; PAESANI, D. MR imaging of the TMJ - Decreased signal from the retrodiskal tissue. Oral. Surg., v.76, n.5, p.631-5, Nov. 1993

150-WESTESSON, P.L; ROHLIN, M. Internal derangements related to osteoarthrosis in temporomandibular joint autopsy specimens., Oral. Surg., v.57, n.1, p.17-22, Jan.1984. 
151-WESTLING, L. Temporomandibular joint dysfunction and systemic joint laxity. Swed dent. J. Supply. v.81, p.1-79, 1992.

152-WILDMAN, S.E. et al. Temporomandibular joint pathosis related to Sex, age, and dentition in autopsy material. Oral. Surg., v.78, n.4, p.416-25, Oct. 1994.

153-YATANI, H. et al. The validity of clinical examination for diagnosing anterior disk displacement without reduction. Oral. Surg., v. 85, n.6, p. 654-60, June 1998

154-YILMAZ, N.T.; TOLLER, M.Ö. Magnetic resonance imaging evaluation of temporomandibular joint disc deformities in relation to type of disc displacement. J. Oral Maxillofac Surg., v.59, n.8, p.860-5, Aug. 2001.

155-YIR, W.Y.; ZYSSET, M.; MERRIL, R.G.; Histologic study of the fate of autogenous articular cartilage grafts in the human temporomandibular joint. J. Oral Maxillofac. Surg. v.50, n.9, p.964-7, Sept. 1992.

156-YOSHIDA, H. et al. Flexure deformation of the temporomandibular joint disk in pseudodynamic magnetic resonance images. Oral. Surg., v.89, n.1, p. 104-11, Jan. 2000. 


\section{ABSTRACT}

This study evaluated the condyle/disc relationships on magnetic resonance images in a group of subjects with silent temporomandibular joints when tested clinically with those in subjects with discernible temporomandibular sounds. Twenty five completely edentulous patients were selected to receive new complete dentures. A questionnaire was filled out and magnetic resonance imaging taken with new dentures. TMD was assessed by physical examination. Only one calibrated examiner evaluated the magnetic resonance imaging by a technique proposed by TASAKI for disc position. The study was based on bilateral MRIs of 15 patients (symptomatic) and 10 symptom-free volunteers (control). According to the methodology and statistical analysis, it was noted that disc displacement was found in $45 \%$ of the TMJs with no history of articular sounds. In 6 TMJs of control group, a reducing disc displacement was found and in 3 TMJs a permanent displacement was found. Disc displacements were identified in $70 \%$ of patients. Reducing disc displacement was found in 19 of these TMJs, whereas permanent displacement was found in 2 TMJs. In 9 of the joints of the symptomatic group, a superior disc position was found. These observations demonstrate that an audible click may not imply a displaced disc. 


\begin{abstract}
ANEXOS
Os anexos contém informações que auxiliarão para uma melhor compreensão do material e método utilizado nesta pesquisa:

ANEXO 1. Protocolo de avaliação clínico-anamnésico

ANEXO 2.Protocolo de avaliação das RMs

ANEXO 3. Aprovação da Comissão de Ética
\end{abstract}




\section{ANEXO 1 \\ UNIVERSIDADE DE SÃO PAULO}

FACULDADE DE ODONTOLOGIA DE BAURU

Nome: Data de nascimento:

Endereço: Bairro:

Cidade: Estado: CEP: Fone residencial:

\section{ANAMNESE}

SIM NÃO Às VEZES

1. Você sente dificuldade em abrir a boca?

2. Você sente dificuldade em movimentar sua mandíbula para os lados?

3. Você sente desconforto ou dor muscular ao mastigar?

4. Você sente dores de cabeça com freqüência?

5. Você sente dores no pescoço e/ou ombros?

6. Você sente dores de ouvido ou próximo a ele?

7. Você percebe algum ruído na ATM?

8. Você usa apenas um lado de sua boca para mastigar?

9. Você sente dores na face ao acordar?

10. Você se considera uma pessoa tensa?

11. Há dificuldade fonética após o uso da nova dentadura?

12. Você apresenta algum dos seguintes hábitos?

Ranger dentes

Apertar dentes

Morder unhas
Mascar chicletes

Uso contínuo de telefone

13. Quantas dentaduras já usou?

$\begin{array}{ll}\text { nenhuma } & \text { uma } \\ \text { duas } & \text { mais de duas }\end{array}$

14. Remove alguma das próteses antes de dormir?

$\begin{array}{ll}\text { inferior } & \text { superior } \\ \text { ambas } & \text { nenhuma }\end{array}$

16 Há quanto tempo usa as atuais dentaduras?

17 Sente desconforto em lugares fechados? 
18 Faz uso de marcapasso ou outro dispositivo metálico no corpo?

\section{EXAME CLÍNICO}

1. AVALIAÇÃO DA ATM:

a) Movimentação:

\section{DOR}

ABERTURA MÁXIMA $\mathrm{mm}$

(incluindo trespasse)

LATERALIDADE DIREITA $\mathrm{mm}$

LATERALIDADE ESQUERDA $\mathrm{mm}$

PROTRUSÃO $\mathrm{mm}$

ABERTURA: Simétrica

Desvio:

Direita

Esquerda

Deflexão:

Direita

Esquerda

b) Ruídos articulares:

ABERTURA

FECHAMENTO

ESTALIDO:

Direito

Esquerdo

Direito

Esquerdo

CREPITAÇÃO:

Direito

Esquerdo

HIPERMOBILIDADE:

Direito

Esquerdo

c) Palpação da ATM:

\section{EXAME MUSCULAR:}

\begin{tabular}{|l|l|l|}
\hline & Direita & Esquerda \\
\hline Aspecto lateral & & \\
\hline Aspecto posterior & & \\
\hline
\end{tabular}

DIREITO

ESQUERDO

\section{Temporal}

Anterior

Médio

Posterior 
DIREITO

\section{Masseter superficial}

Origem

Médio

Posterior

Masseter profundo

Digástrico posterior

Esternocleidomastoídeo

Trapézio (superior)
ESQUERDO

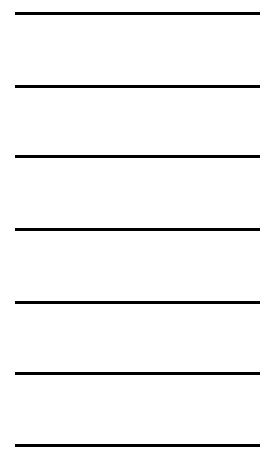




\section{ANEXO 2 \\ PROTOCOLO DE AVALIACÃO DOS EXAMES DAS \\ RESSONÂNCIAS MAGNÉTICAS}

NOME DO PACIENTE:

1- ALTERAÇÕES ÓSSEAS

\begin{tabular}{|c|c|c|}
\hline IA- ( & )NORMAL ( & )REMODELADO \\
\hline & )NORMAL ( & )REMODELADO \\
\hline ILO & )NORMAL ( & )REMODELADO \\
\hline
\end{tabular}

2- ALTERAÇÕES DE SINAIS NA RM R1( )
$\mathrm{R} 1(\quad)$
R1( )

DISCO I1 ( )

MEDULAR DO CÔNDILO I1( ）

ESPAÇOS ARTICULARESI1( ) $\mathrm{R} 2($ ) $\mathrm{R} 2($ )

R2( ) I2 ( )

3- TRANSLAÇÃO CONDILAR

( ) 0-AUSÊNCIA

( ) 2 AO NÍVEL DA EMINÊNCIA
( ) 1- AQUÉM DA EMINÊNCIA

( ) 3-ALÉM DA EMINÊNCIA

4- POSIÇÃO ANTÔMICA E RELAÇÃO CÔNDILO-DISCO

4.1- POSIÇÃO ANATÔMICA

( )SUPERIOR

( )DD TOTAL ANTERIOR

( )DD PARCIAL ANTERIOR NO 1/3 LATERAL ( )DD PARCIAL ANTERIOR NO 1/3 MEDIAL

( )DD ÂNTERO-MEDIAL （ )DD ÂNTERO LATERAL

( )DD LATERAL ( )DD MEDIAL

( )DD POSTERIOR

\section{2- RELAÇÃO CÔNDILO-DISCO}

( ) SUPERIOR ( )DDR ( )DDRS

( ) DOD

\section{5- MORFOLOGIA DO DISCO}

( )BICÔNCAVO OU NORMAL （ )BICONVEXO OU BIPLANAR

( )INDETERMINADO 